\title{
Urban Rats in Wellington: Estimating Home Ranges, Population Densities and Detection Probabilities
}

BY

Henry Robert Mackenzie

\author{
A thesis \\ submitted to Victoria University of Wellington \\ in fulfilment of the requirements for the degree of \\ Master of Science in Ecology and Biodiversity
}




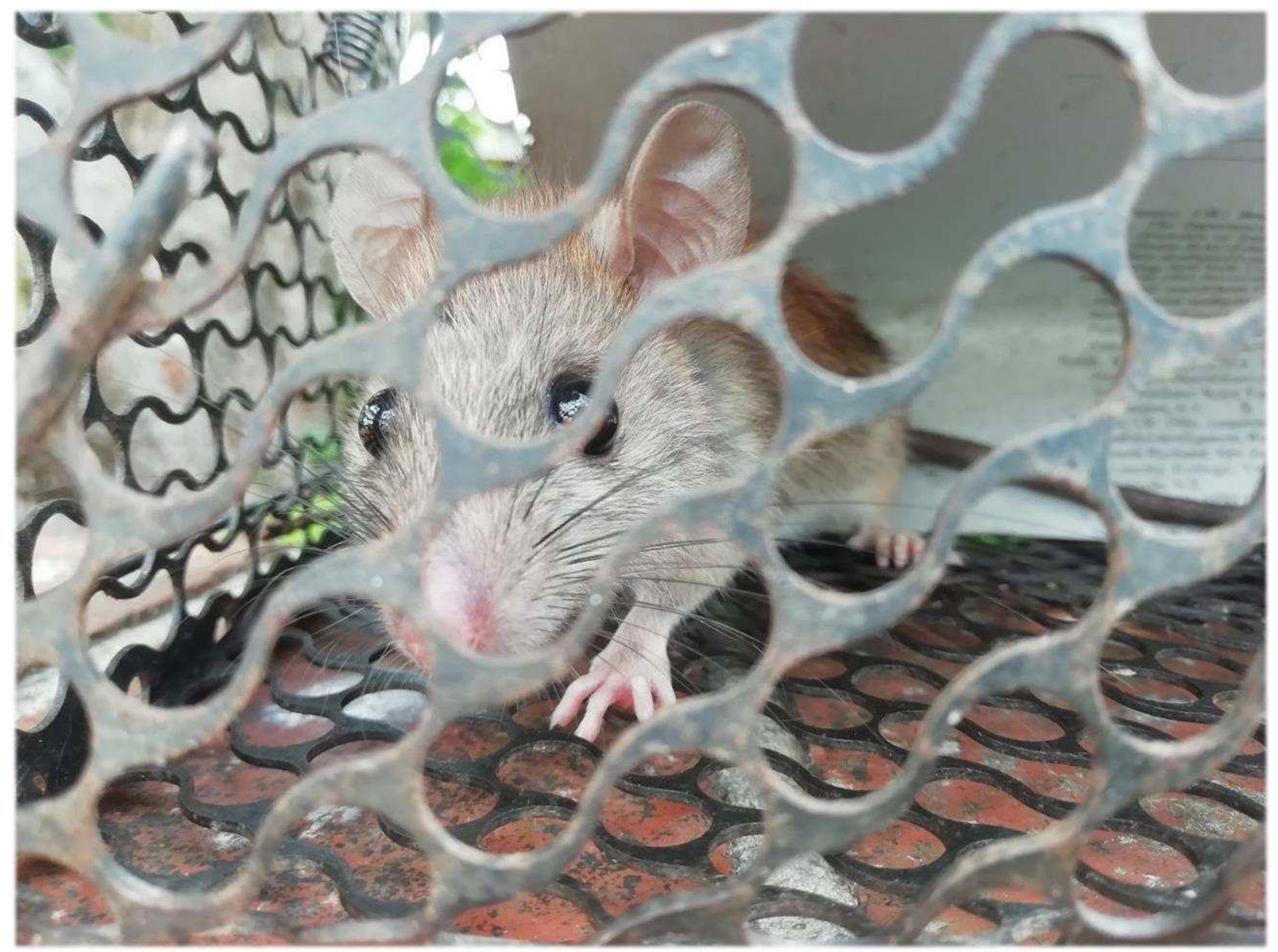

Supervisor:

Dr Stephen Hartley,

Director of the Centre of Biodiversity \& Restoration Ecology at the School of Biological Sciences, Victoria University of Wellington. 


\section{Acknowledgments}

This research was generously supported by Manaaki Whenua - Landcare Research, The Centre for Biodiversity and Ecological Restoration (CBRE), Predator Free New Zealand and Predator Free Wellington.

First and foremost a huge thank you to my supervisor Dr Stephen Hartley whose cool head always prevailed. Your guidance and support in this undertaking is and was hugely appreciated. I would also like to thank Craig Pritchard, whom without I do not see how this work would have been possible. You put far too much of your own time into this work and I cannot thank you enough. To Patricia Stein, a big thank you for your support and consideration.

On a personal note. To my Dad, thank you pushing me to go after this master's and to get that 'monkey off my back'. To my Mum, thank you for your constant support, the encouraging messages and wise inspirational quotes, my favorite and the most helpful 'It doesn't matter how slowly you go so long as you do not stop'. To my Aunt, thank you for your support and for taking the time to read through this work, your comments were incredibly helpful. To Grandad, thank you for always being so encouraging of whatever I have chosen to do, I know you would have been proud.

And lastly but definitely not least, thank you to my partner Rachel, if I were to list all the ways you have helped me through this, I would definitely run the word count. Suffice to say I could not have done this without you. 


\section{Table of Contents}

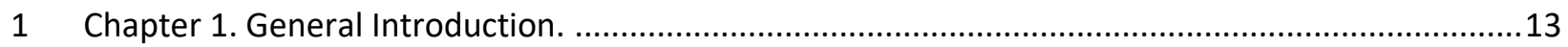

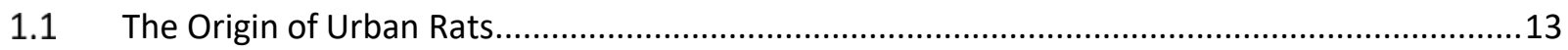

1.2 Taxonomy of rats, and the Emergence of Rattus rattus and $R$. norvegicus .............................14

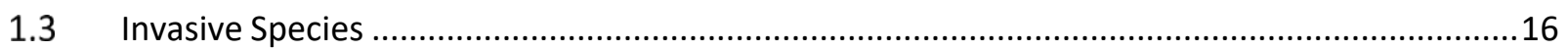

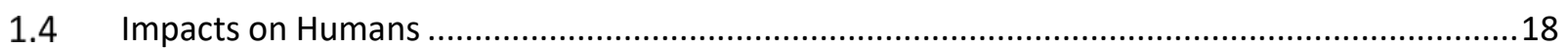

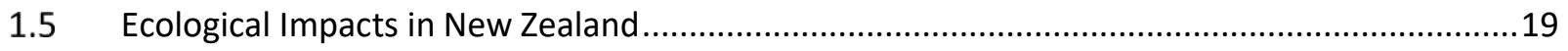

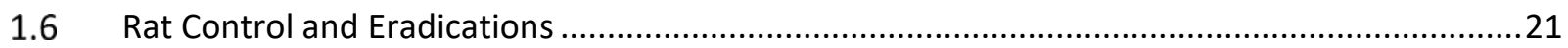

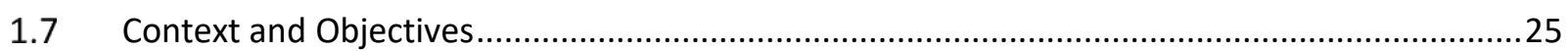

2 Chapter 2. Home Range of Ship Rats (Rattus rattus) In An Urban Bush Fragment in Wellington, New

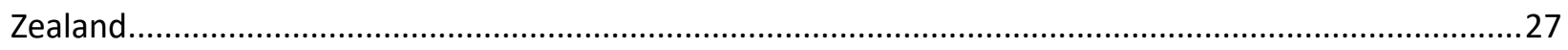

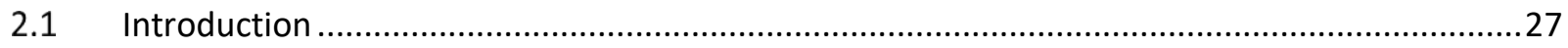

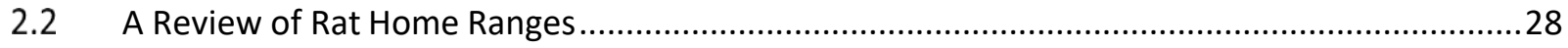

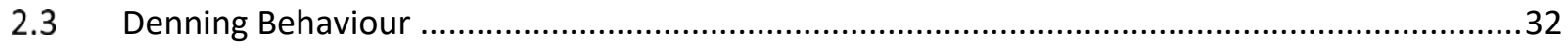

2.4 Spatial Genomics Studies, Dispersal Patterns and Barriers to Movement..............................34

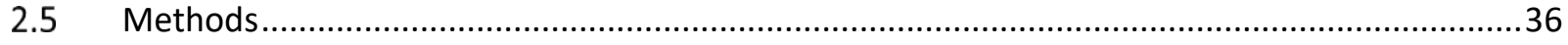

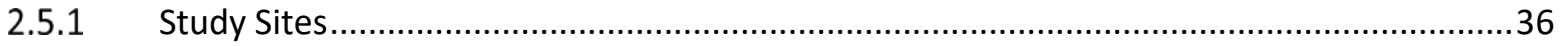

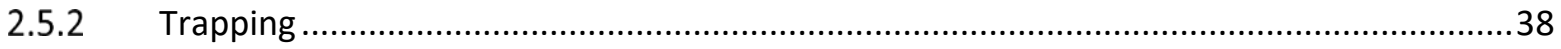

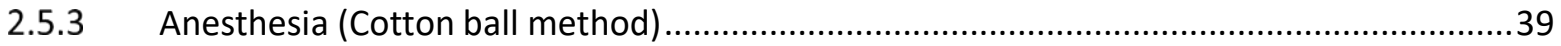

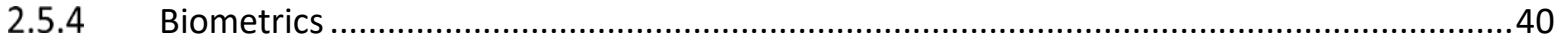

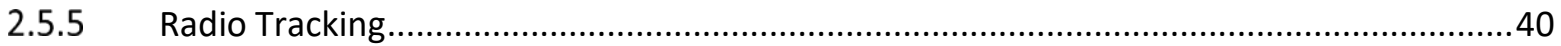

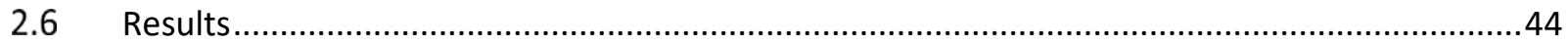

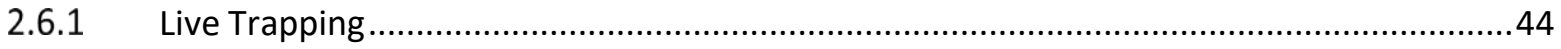




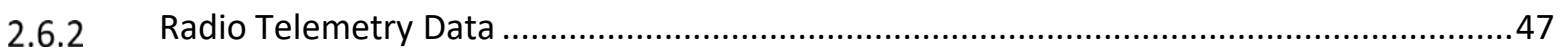

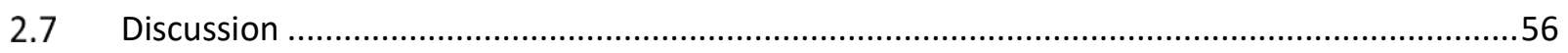

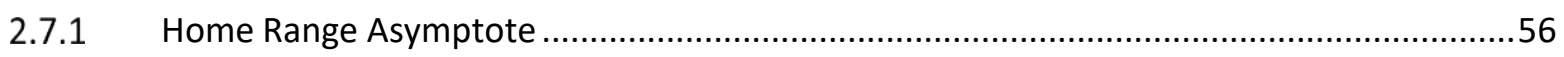

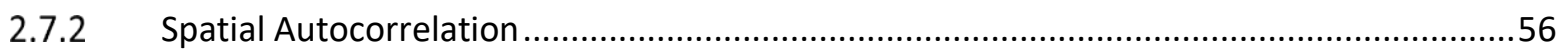

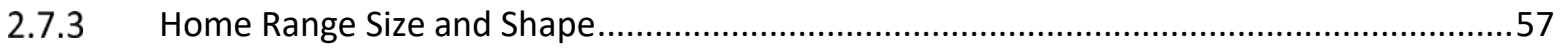

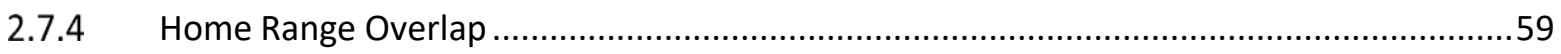

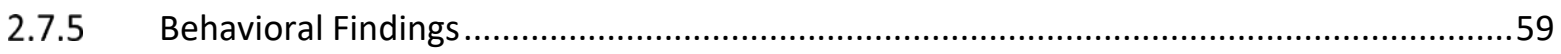

3 Chapter 3. Densities and Detection Probabilities of an Urban Ship Rat Population .........................62

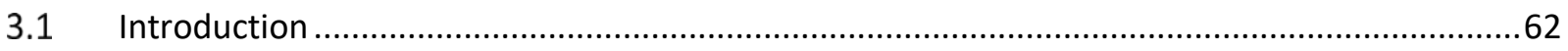

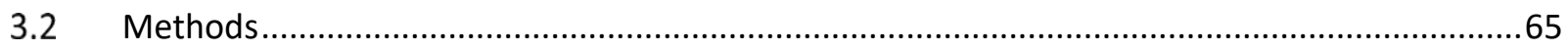

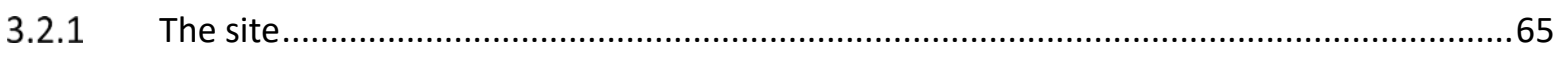

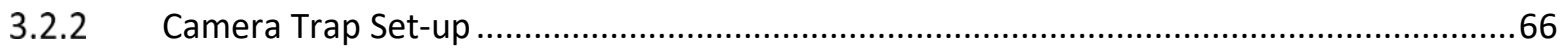

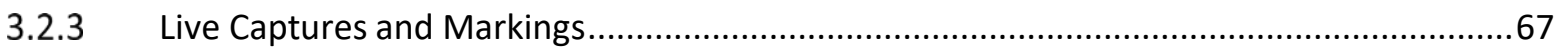

3.2.4 Capture, Mark, Re-sight - Lincoln Petersen ..........................................................67

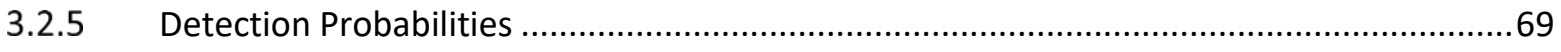

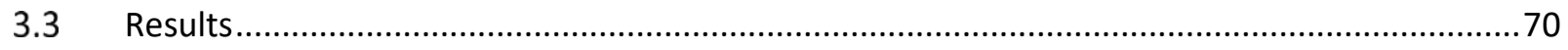

3.3.1 Lincoln Petersen Estimate .................................................................................

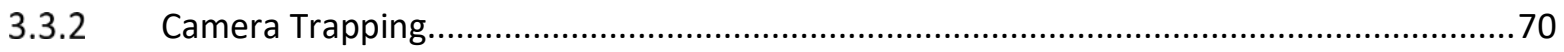

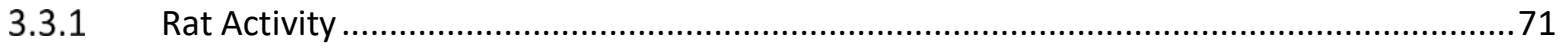

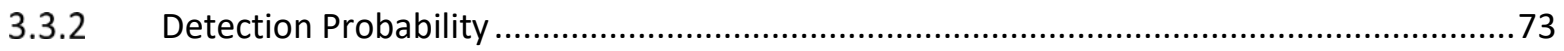

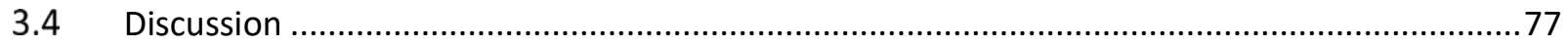

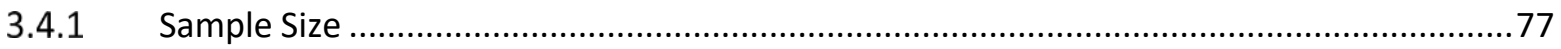

3.4.2 Capture-mark-recapture assumptions .....................................................................

3.4.3 Urban Rat Densities in Wellington ....................................................................... 79

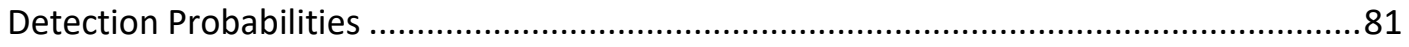

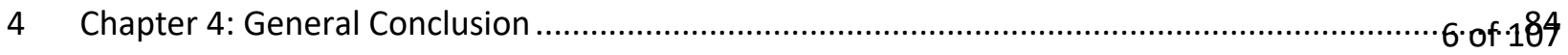




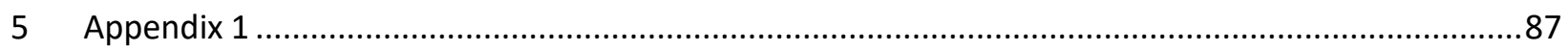

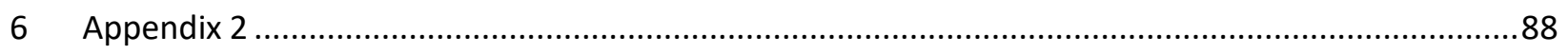

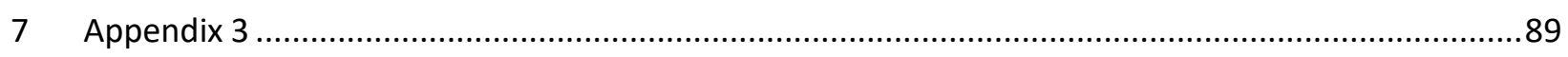

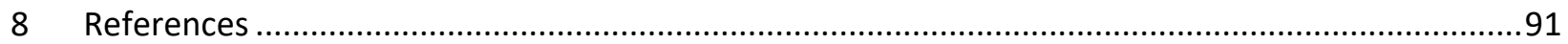




\section{$\underline{\text { List of Figures }}$}

Figure 1: Study field sites Roseneath, Kelburn and Brooklyn within Wellington, New Zealand 35

Figure 2: Spiral technique for close approach radio tracking 39

Figure 3: Weight of ship rats according to sex across all three sites $\quad 44$

Figure 4: Activity of the trapping grid over the first 10 days of trapping 45

Figure 5: Tracking duration of the rats in each suburb $\quad 48$

Figure 6: Incremental area analysis of MCP to 100\% for subjects 25, 33 and 35

Figure 7: Kelburn study site showing 100\%, 75\% and 50\% MCPs for ship rat no. 33

Figure 8: Rat radio telemetry locations at Kelburn $\quad 52$

Figure 9: Rat radio telemetry locations at Brooklyn 53

Figure 10: Rat radio telemetry locations at Roseneath 54

Figure 11: Density and detection probability study site 65

$\begin{array}{ll}\text { Figure 12: Calhoun's (1962) pelage marking code } & 67\end{array}$

$\begin{array}{ll}\text { Figure 13: Rat no.5 with bleach marks } & 67\end{array}$

$\begin{array}{ll}\text { Figure 14: Map of the study site with camera traps and their activity } & 73\end{array}$

Figure 15: Camera trap activity of cats and rats at hourly intervals between 19:00 - 07:00 73

Figure 16: Collar fitting of an anaesthetized ship rat 88

Figure 17: Camera trap locations within the Kelburn study site $\quad 89$ 


\section{List of Tables}

Table 1: Sample of the literature on ship rat home ranges in both and urban and rural habitats 32

Table 2a: Summary of the Norway rats caught at each study site: number, sex and avg. weight $\quad 44$

Table 2b: Summary of ship rats caught at each study site: number, sex and avg. weight $\quad 44$

Table 3: Breakdown of the trapping data by site $\quad 47$

Table 4: Average ship rat home ranges pooled for sex at 100\%, 75\% and 50\% MCP 49

Table 5: Home ranges of all ship rats with $\geq 10$ fixes, in hectares at 100\%, 75\% and 50\% MCP 50

Table 6: Camera trap settings $\quad 66$

Table 7: Camera trap data collected over the first two weeks and Lincoln Petersen density results71

$\begin{array}{ll}\text { Table 8: List of identifiable rats } & 74\end{array}$

$\begin{array}{ll}\text { Table 9: Raw camera data at each study period } & 74\end{array}$

Table 10: Raw camera trap data of unidentified rats $\quad 75$

Table 11: Number of detections per sighting averaged across the three-week study according

$\begin{array}{ll}\text { to age category for each device type } & 76\end{array}$

Table 12a: Detections per sighting for adult rats at each period of the study at each device type 76

Table 12b: Detections per sighting for adolescent rats at each period of the study at each device

$\begin{array}{ll}\text { type } & 76\end{array}$

Table 13: Capture Mark Re-sight data from $1^{\text {st }}$ study $\quad 89$ 


\section{Acronyms}

$\begin{array}{ll}\text { CMR - } & \text { Capture Mark Re-capture } \\ \text { EBRM - } & \text { Ecologically Based Rodent Management } \\ \text { IBD - } & \text { Isolation by Distance } \\ \text { LP - } & \text { Lincoln Petersen } \\ \text { MCP - } & \text { Minimum Convex Polygon } \\ \text { KDE - } & \text { Kernel Density Estimation } \\ \text { AKDE- } & \text { Autocorrelated Kernel Density Estimation } \\ \text { PCAN - } & \text { People Cities and Nature }\end{array}$




\section{Abstract}

The ship rat (Rattus rattus) and Norway rat (Rattus norvegicus) are prolific pest species with a near- global distribution. Their spread has had serious public health repercussions as carriers of disease and by causing considerable agricultural losses. They are also invasive to many native ecosystems, degrading ecosystem processes, and preying upon native species, resulting in significant losses to biodiversity.

This study aims to guide more effective rat management strategies through an increased understanding of the spatial ecology of rats in an urban environment. Three separate studies were conducted, all located in Wellington, New Zealand:

1) A radio-telemetry study looked at the home range and spatial behavior of 10 urban ship rats. Results showed comparatively small home ranges $(0.01-0.45$ ha at $100 \%$ minimum convex polygons) with maximum linear distances within a home range of $19-74 \mathrm{~m}$. There was significant spatial overlap between home ranges- up to 90\% (between two adjacent home ranges); conesting behavior between both sexes; frequent diurnal activity amongst ship rats (9 of 10 rats); and two longer distance dispersal events $(\sim 120 \mathrm{~m})$ by ship rats. Implications for rat management include: a need for tighter spacing of devices in urban habitats for control and detection of survivors, potentially every $20-25 \mathrm{~m}$ if eradication is the goal.

2) A capture mark re-sight study to estimate the minimum density of ship rats in an 0.63 ha urban bush fragment. A total of five rats were live caught in cage traps and uniquely marked before release. An additional eight wild rats were uniquely identified on cameras based on distinctive features of their appearance. A conservative Lincoln-Petersen estimate was used to estimate the number of rats within the bush fragment: this produced an estimate of 14.6 rats with $95 \%$ confidence intervals [7.69-55.6], which translates to a density of 23.2 rats/ha [12.288.25]. These densities are significantly higher than those found in most mainland studies and more comparable to those in island habitats. This could be because ship rats are subsidizing their diet with human-derived foods, although this was not confirmed here. 
3) A detection probability study investigated the sensitivity of three devices (wax tag, chew card and bait station) to ship rat presence and examining age-related differences in detection. The bait station was found to have the highest detection probability ( 0.5 detections/sighting) followed by the wax tag ( 0.44 detections/sighting) and chew card ( 0.37 detections/sighting) although results were based on data retrieved from a low sample size of devices ( $n=2$ of each type). The bait station showed a sharp difference between the adult (0.1 detections/sighting) and adolescent populations (0.89 detections/sighting) detection probability. Furthermore, this difference in detection probability was found, although less pronounced, in both the wax tag and chew card. Implications for rat management include: a recommendation that wax tags be used as the primary means of ship rat monitoring; a need for further behavioral studies looking at detection probabilities across a range of kill and monitoring devices so that the most effective ones can be identified; and the development and testing of devices that are attractive to adult rats that may have become "trap shy".

These three studies together provide useful insights into urban rat ecology with implications for pest management. However, a more comprehensive study with larger sample sizes is recommended to fully substantiate this work. 


\section{Chapter 1. General Introduction.}

\subsection{The Origin of Urban Rats}

Humans and rats were drawn together by huge climactic shifts around 12,000 years ago. At this time the earth was coming out of its last Ice Age - the cold and dry Pleistocene giving way to the warmer and wetter conditions of the Holocene epoch. For humans, this new climate made wild grains (ancient varieties of modern-day wheat and barley) easier and more reliable to cultivate (Richerson et al. 2001). Over the next two thousand years, early humans, who had previously lived as hunter-gatherers, were able to adopt agriculture as their main means of food procurement, with only those in the most marginal environments still adhering to a hunter-gatherer lifestyle (Richerson et al. 2001).

This transition had pronounced sociological effects. With humans now capable of producing their own food, they were able, for the first time in history, to create a surplus. As a result, human populations began to increase rapidly, and large scale-societies began to form which grew into larger towns and cities. These early urban settlements provided both food and harborage in abundance, thereby creating the perfect niche for the rat (Jones et al. 2013). This commensal relationship, discussed further below, has endured and strengthened in the thousands of years thence, becoming one of the most successful in the animal kingdom. Today rats can be found almost everywhere there are humans - in the Arctic and even in submarines beneath the sea.

In the following sections I will explore: the taxonomy of Rattus - the genus where the most successful commensal rats reside, including the ship and the Norway rat, the two focal species of this thesis; what makes an animal invasive, and rats particularly so; what are the ecological impacts of rats in New Zealand; and what are the ways in which we control these species. 


\subsection{Taxonomy of rats, and the Emergence of Rattus rattus and $R$. norvegicus}

The order Rodentia, its name deriving from the Latin "rodere" meaning "to gnaw", is the largest of the mammalian orders and makes up over $40 \%$ of all species (Carleton and Musser, 2005). The sub-family Murinae, also referred to as the Murines or Old-World rats and mice, contains well over 570 species and is larger than all but two other mammalian families, both of which are rodent families (Carleton and Musser, 2005; Rowe et al. 2008). The Murines are thought to have arisen 20 Mya (million years ago) with a presumed origin in South/Southeast Asia (Robins et al. 2008). Around 8 Mya, a series of radiations occurred across Southeast Asia, Australia, Africa, New Guinea and the Philippines, followed by mass speciation (Watts and Baverstock, 1995).

There is still debate on when and where the genus Rattus emerged, with different methods of phylogenetics producing different results. However, most agree that it was somewhere between 3-4 Mya (Jansa et al. 2006, Robins et al. 2007, Robins et al. 2008) and in the Greater Sunda Islands. Their progenitors then spread quickly over to New Guinea, Australia, and continental Asia (Aplin et al. 2003a) in a mass speciation event that is thought to be amongst the most rapid of all vertebrates (Rowe et al. 2011). Currently, the genus is comprised of 65 species, as described by Carleton and Musser (2005).

Of these, five have been designated true commensals with humans: a relationship where one species obtains food or other benefits from the other without harming or benefiting the latter (Aplin et al. 2003a). These five species include: the Pacific rat $R$. exulans, the Himalayan field rat $R$. nitidus, the Turkestan rat $R$. pyctoris and, by far the two most widespread, $R$. norvegicus, the Norway rat and $R$. rattus, and the ship rat (Aplin et al. 2003a). The Norway rat and the ship rat are the focus of this study and go by other names; the Norway rat also known as the brown rat, sewer rat or city rat, and the ship rat synonymous with the black rat, roof rat or house rat. The ship rat's native range is within tropical southern India, from there it spread across into 
Europe (Puckett et al. 2020). Its history in Europe suggests that it was initially confined to the major communication routes of the Roman empire, and that its geographic coverage increased mainly between the 11 and $13^{\text {th }}$ centuries AD during a period of rapid urbanization (AudoinRouzeau and Vigne, 1994). It was not until the 1700s that the ship rat achieved a worldwide distribution by boarding the vessels of European maritime explorers, and from there colonizing the Americas, Africa and New Zealand (Innes, 2001).

The Norway rat was thought to have originated further north in the more temperate climate of China and Mongolia. From here its range expanded across central and western Asia, possibly incrementally by populating urban settlements along the Silk Road trade routes (Schmid et al. 2015). By the 1500s the Norway rat was well-established in Europe and from there, in the same manner as the ship rat, went worldwide. Both species were introduced accidentally to the New Zealand archipelago by European whalers, missionaries, traders and, finally, starting in 1840, by settlers (King, 2019). The Norway rat is thought to have arrived by the mid to late $18^{\text {th }}$ century and the ship rat in the late $19^{\text {th }}$ century (Atkinson, 1973). Incidentally these two invasions coincided with the rapid decline in a third introduced species of Rattus - the Polynesia or Pacific rat (Rattus exulans) that had arrived with Polynesian settlers in the late $13^{\text {th }}$ century.

Today the ship rat is the dominant species in New Zealand, with the Norway rat patchily distributed across the mainland and some offshore islands (Russell et al. 2019). King et al. (2011) found this was largely due to different foraging strategies as explained by the Marginal Value Theorem (MVT) (Charnov, 1976). This theory states that an animal will balance the declining yield of a resource patch with the cost and benefits of moving to another. Ship rats spend less time exploiting one resource, and instead choose to move on in search of other potential sources - a strategy called 'cream-skimming'. Norway rats adopt the opposite strategy, choosing to stay at one patch and thoroughly harvest it - a strategy known as 'crumbpicking' (King et al. 2011). In New Zealand this leads to a dynamic of exploitation competition where ship rats are advantaged by their superior arboreal agility enabling them to exploit canopy and shrub food sources. Interestingly in the UK, ship rats cannot exploit this niche due to the competitive exclusion of another arboreal foraging rodent, the red squirrel (Sciurus 
vulgaris) (King et al. 2011). Left to the ground the Norway is the more physically dominant of the two and so outcompetes the ship rat for food.

\subsection{Invasive Species}

Invasive species are plants, animals and pathogens that are introduced outside their native range, and if established, produce adverse effects for the native ecosystem. It is generally accepted that the process of invasion takes place in three successional stages: introduction, establishment, and spread (Williamson and Fitter, 1996; Richardson et al. 2000).

Ecologically damaging invasive species are not a new phenomenon; they have been occurring since the formation of early civilizations and ancient trade routes. Over the last 200 years, since the industrial revolution and the invention of key technologies, their incidence has increased dramatically (Hulme, 2006).

Today, globalization has seen the modernization of these trade routes so that they now make up a global and intricately interconnected system. For potential invasive species, these systems are essentially vectors acting as artificial conduits over huge distances - across continents and oceans rather than meters or kilometers - introducing species to habitats not previously possible. But not all species that are introduced into a new region become invasive. Many fail to establish themselves, and of those that do, not all become invasive.

Propagule pressure has been recognized as playing an important role in the establishment of non-native species (Simberloff, 2009). A "propagule" is defined to mean either a group or individual arriving in a place. Propagule pressure has two components: propagule size (size of the propagule) and propagule rate (the number of propagules arriving per unit time) (Simberloff, 2009). These combine to increase the probability of effective establishment by diminishing the effects of demographic stochasticity by preventing genetic bottlenecks, and environmental stochasticity by consistent additions to the population.

The degree of invasiveness really depends on the last two stages (establishment and invasion), with two key considerations. What are the characteristics that make a species a successful 
invader? - and what characteristics of the local environment make it vulnerable or resistant to invasion? (Simberloff, 2009). In the past, ecologists have focused on trying to determine common traits in invasive species. This has proven to be a difficult task due to the heterogeneity of taxa and ecosystems affected by invasions (Kolar and Lodge, 2001). A pervasive belief was that those species with faster life histories or $r$-selected characteristics are more invasive - the $r$-strategy hypothesis. However, this hypothesis was thrown into question under modern theories of life-history evolution, that suggest $r$-strategy evolved under a low sensitivity at early life stages to competition (Mueller, 1997). This is demonstrated by the invasive Suminoe oyster (Crassostrea ariankensis) in Chesapeake Bay, USA whose r-selected traits do not give it advantage as it is accompanied by a low investment in defense, making them vulnerable to predation by native blue crabs (Callinectes sapidus) (Bishop and Peterson, 2006).

For $r$-selected species to be invasive depends on 1) whether the invaded habitats are similar or dissimilar to the habitats that favor them in their native range, and 2) whether invasion is limited by their ability to spread and grow in that habitat (Duyck et al. 2007). No single set of life history traits will be successful everywhere (Facon et al. 2004). Instead, the result of a potential invasion depends on the interaction between the invading species' traits and the ecosystem being invaded (Shea and Chesson, 2002).

For invading rats in New Zealand, the circumstances were ideal. A large and sustained propagule pressure from arriving European explorers, and later settlers, would have aided the ship rat and Norway rat in establishing in human settlements. Furthermore, natural traits such as an omnivorous diet, intelligence and a commensal nature would have facilitated this establishment (Feng and Himsworth, 2013). Additionally, these urban areas may have acted as dispersal hubs, providing a foothold and overcoming many of the barriers to invasions faced by other species (Banks and Smith, 2015). Once established, New Zealand would have provided a great niche opportunity for rats - conditions that promote invasion in terms of the resources available, the presence of natural enemies and abiotic factors.

Native species (especially birds and invertebrates) that were not adapted to escaping or 
avoiding mammalian predators provided rats with high potential food availability (Bull and Whitaker, 1975; Shea and Chesson, 2002). Few natural enemies, either predators or competitors, present in New Zealand would have reduced the competition for resources and population suppression through predation. And a mild climate not to dissimilar from that in their native range would likely have combined to make New Zealand an ideal site for invasion.

\subsection{Impacts on Humans}

Rats present significant health risks for humans as reservoirs for various zoonotic diseases. Bacteria (Leptospira interrogans, Yersina pestis, Rickettsia typhi, Bartonella spp., Streptobacillus moniliformis), viruses (Seoul hantavirus), and parasites (Angiostrongylus cantonensis) carried by rats result in a significant number of human mortalities every year (Himsworth et al. 2013). These disproportionally affect poorer communities that tend to have high population densities and lack access to health care and decent sanitation (Costa et al. 2014). As such, the prevalence of rat-borne diseases is exceptionally high in, for example, the slums of Brazil and Venezuela (Costa et al. 2014; Garcia et al. 2019).

Commensal rats are also regarded as serious agricultural pests. In Asia, rodents are responsible for a pre-harvest loss of rice Oryza sativa of about $5 \%$ of production or 30 million metric tons (Stenseth et al. 2003). In the USA, the agricultural losses due to introduced rats are estimated to be more than $\$ 19$ billion per year (Piment el et al. 2000). Of particular concern are the preharvest losses in developing nations. In South-East Asia, rodents inflict consistent losses of 5$10 \%$ per annum of rice production (Stenseth et al. 2003). These significant losses, made worse during rodent irruptions, can lead to severe food shortages which disproportionately affect the most disadvantaged and vulnerable communities (Singleton, 2010). In developing nations, rodents are in direct competition with humans for food. This has raised the question of whether commensal is an accurate description of our relationship with rats with other terms perhaps more appropriate such as obligate pests, parasites or synanthropes (Aplin et al. 2003b) 


\subsection{Ecological Impacts in New Zealand}

Holdaway (1989) describes three major extinction events that took place in New Zealand over the last 1000 years. The first coincided with the arrival of Polynesia settlers and the introduction of the Pacific rat between 1000-1200 AD. The second, between $1200-1780$ AD was a more gradual decline and occurred as habitats were cleared for the establishment of Polynesian settlements, and the third was the arrival of European settlers from 1780 AD to the present, carrying with them the ship and Norway rat. All told, New Zealand suffered a huge erosion of its biodiversity - losing $50 \%$ of its avifauna, $50 \%$ of its frog fauna and unknown numbers of invertebrate and reptile fauna (Holdaway, 1989).

These losses to biodiversity through invasive species have been particularly extreme in New Zealand. New Zealand is well known for its unique fauna, and particularly its birdlife.

Evolutionarily distinct clades have evolved here through prolonged geographical isolation, such as the Kakapo (Strigops habroptilus) a flightless nocturnal parrot, and the Kea (Nestor notabilis) the only alpine parrot in the world. These species lack the ability to recognize, avoid or escape mammalian predators; traits typically acquired through co-evolution, a property known as evolutionary naivety.

Rats are omnivore generalists with a varied and wide-ranging diet. They consume vegetation (seeds, seedlings, fruit and flowers) invertebrates (especially weta, moths and larger beetles), amphibians, lizards, tuatara, and small birds as well as the chicks and eggs of larger birds (Innes, 2005; McQueen and Lawrence, 2008; Clapperton et al. 2019). With the presence of multiple invasive species on the mainland, including mustelids, ungulates and other rodent species, parsing out the specific effects of rats is difficult (but see below for impacts on islands). Additionally, the ecological impacts are complex and operate at multiple trophic levels through indirect and direct effects.

Oceanic islands make perfect field sites for isolating the ecological impacts of rats. Comparative and post-eradication monitoring studies have been commonly used for this (Wilson et al. 2003). One such study by Mulder et al. (2009) compared three groups of New Zealand islands with 
varying rat densities. Comparisons highlighted interesting insights into how rats were affecting vegetation structure. Rats were found to reduce floral diversity by preferentially predating certain varieties of seeds and seedlings, and thereby reducing recruitment of those particular species (Campbell and Atkinson, 2002; Wilson et al. 2003).

This preferential predation is more severe on islands where rat densities are naturally higher than on the mainland (Harper and Bunbury, 2015; Harper and Rutherford, 2016) and can eventually lead to the local extinction of certain island species. For example, Campbell and Atkinson (2002) found Pacific rats to be responsible for the local extinction of the milk tree (Streblus banksii) and the coastal maire (Nestegis apetala) on some of New Zealand's northern offshore islands. Seed predation can also have knock-on effects for other species through competitive exclusion. The kereru (Hemiphaga novaeseelandiae) shares the rat's food preference for large fleshy fruits and seeds of species such as tawa (Beilschmiedia tawa), taraire (B. tarairi), puriri (Vitex lucens) and karaka (Corynocarpus laevigatus) due to their high nutritional value (Campbell and Atkinson, 2002; Wotton, 2007). The kereru is a critical seed disperser for such species as the only extant frugivore capable of swallowing their large seeds (Clout and Hay, 1989). The presence of rats has shown to reduce kereru visitation, depriving plants of an important seed disperser (Wotton, 2007). Other examples of competitive exclusion by rats include the North Island Kiwi (Apteryx mantelli) where there is a significant overlap between their diets, where both eat insects (Shapiro, 2005). The same is true for weka, takahe, rails and kakapo, contributing to a decline in all these species (Campbell and Atkinson, 1999).

Invasive rats are one of the largest contributors to local seabird extinction (Jones et al. 2008), predating seabird eggs, chicks, and adults (Martin et al. 2000; Jones et al. 2008). As keystone species, seabirds have an exceptional impact on their environment. Where they establish colonies, they have drastic effects on soil, sediment and water eutrophication through the deposition of guano (Otero et al. 2018). This enhances the primary productivity of the terrestrial, inter-tidal and subtidal zones (Jones et al. 2008), which in turn affects floral succession, regenerating plant communities and invertebrate and reptile populations (Towns and Broom, 2003; Jones,2010). Their removal from an environment can therefore have 
drastic impacts on ecological functions and processes, ultimately reducing local biodiversity.

\subsection{Rat Control and Eradications}

Given the aforementioned impacts of rats on human health, food production and biodiversity, it is not surprising that rat populations are frequently the target of human management.

Management of rat populations can take two general approaches. Control, where the objective is to continually harvest rats, maintaining low densities and thereby reducing their impacts, and eradication where the elimination of every last individual is sought.

Control strategies are often adopted in urban areas where eradications are not possible due to the potential for re-invasions - but their success is varied. An experimental area in Baltimore, USA in the 1940s underwent a trial rat control scheme under the direction of the Rodent Ecology Project - made up of the leading rodentologists of the time (Emlen et al. 1949; Davis and Christian, 1956) Through strict sanitary regulations governing proper storage of waste and the removal of any potential harborage sites, the rat population virtually vanished from the area. However, the expensive costs of site management and a waning political and public will, meant the program did not last, and rat populations quickly recovered to their original levels. In Budapest, Hungary, control operations1 reduced the rat population to under $1 \%$ of carrying capacity and have maintained this since 1972 (Bajomi and Sasvari, 1986). The control of Budapest's rats has been managed by a single agency which initially carried out an intensive and well-orchestrated rat removal. This was followed by suppressive methods and a long-term monitoring program informed through public engagement (Bajomi and Vamos, 1983). Control methods can be effective but multiple elements are required for success, such as a wellorganized top-down management, continuous suppression and monitoring, an engaged political and public sphere and substantial financial commitment. The coming together of all these components are rare, which is why examples of successful urban control are relatively few.

${ }^{1}$ An organized de-ratization program conducted by Babolna Pest Control Centre, covering the whole of Budapest. The program used 1,632,000 kilos of bait laced with the anticoagulant coumatetralyl and maintained by repeated inspections and replenishments (Bajomi and Sasvari, 1986) 
Eradication is the preferred approach as it does do not commit authorities to perpetual suppression which is expensive (Pascal et al. 2008). However, eradications are even more difficult to achieve than suppressions, because they require that all individuals are exposed to the eradication process, that the animals must be killed at a rate exceeding their rate of natural increase, and that immigration must be zero (Cromarty et al. 2002). The latter precludes mainland sites, where connectivity makes re-invasions far too likely. As such, eradications have almost exclusively been carried out on offshore islands and primarily for conservation purposes. Islands are high priority conservation targets due to their high degree of endemism and biodiversity; they are also naturally defendable against re-invasions as they are surrounded by water (Russell and Holmes, 2015). New Zealand is regarded as a world leader in rat eradications, although the first island eradications of rodents did not begin until after the 1970s. Previously only large mammal species were targeted, using simple methods of trapping or shooting - for example, goats (Capra hircus) from South East Island in 1912, rabbits (Oryctolagus cuniculus) from Tiritiri Matangi in 1920 and cattle (Bos taurus) from Kapiti Island in 1912 (Clout and Russell, 2006). Attempting to eradicate anything smaller was thought too difficult until second generation anti-coagulants became available e.g. Brodifacoum in the 1980s. These class of poisons work by effectively inhibiting the clotting mechanism in the blood causing internal bleeding and eventually death. The $2^{\text {nd }}$ generation of drugs have a far higher potency and a delayed onset, which allows rats to consume a lethal dose before experiencing symptoms (Taylor and Thomas, 1989). Not long after this development, the first coordinated island eradications were achieved in New Zealand, removing Norway rats from the nine ha Hawea Island and the 170 ha Breaksea Island in 1988 (Taylor and Thomas, 1993). An early adoption of an adaptive management style approach alongside technological advances was central to achieving eradication from successively larger and more complex islands and at progressively lower cost/hectare (Towns and Broom, 2003). Key technological advancements include the use of Global Positioning Systems (GPS) units which allowed coordinated eradications and the ability to identify un-baited areas - which left untreated would otherwise provide refuge for target species (Towns and Broom, 2003). Helicopters and the use of aerial 
drops of rodenticide have dramatically expanded the list of sites that can be tackled by allowing access to areas previously unreachable by foot (Howald et al. 2007). They have also hugely reduced the cost of eradications by cutting down on the labor required to either service traps or distribute bait (Clout and Russell, 2006)

However, the most significant advances in rat management have really taken place in the last few decades, with a gradual transition into Ecologically Based Rodent Management (EBRM). EBRM integrates specific knowledge of a rodent species biology, behavior, and ecology in order to manage them (Singleton et al. 1999; Singleton, 2000). An example of this being used in practice is the successful eradication of rats on South Georgia Island - now currently the largest rat-free island at 352,800 ha. Genetic studies carried out on the island revealed that the rat population was separated by glacial ice into distinct meta-populations. This allowed the division of the island into 'eradication units' facilitating a manageable and sequential eradication (Martin and Richardson, 2019). Designating eradication units requires knowledge of rat's spatial ecology - these population genetic studies revealing which landscape features create barriers to their movement (Robertson and Gemell, 2004). Knowledge of rat population ecology has also proved to be important in guiding the timing of eradication efforts. For example, eradications targeting the Pacific rat are done in spring and winter as they correspond with natural lows in population size making the operation easier and cheaper (Moors, 1985). The population lows are brought about due to reduced food availability and colder temperatures which have been found to affect the reproductive rates of rats (Vadell et al. 2014). However, EBRM is still not the industry standard with many agencies continuing to take a 'prescriptive' approach of rodenticide use and pest management (Singleton, 2000).

Similar methods to those used in EDRM are currently being used by Predator Free Wellington an ambitious project, making Wellington the first city in the world to attempt eradication of its invasive urbanspecies of rats, possums, and mustelids. Eradication is planned to be conducted in phases, within defensible spatially isolated areas. This strategy takes advantage of urban barriers to movement. These are features of the urban environment that restrict the movement of rats and are identified through population genetics, wildlife radio tracking and 
capture mark re-capture studies (Calhoun,1962; Oyedele et al. 2015; Combs et al. 2018.)

Furthering the ecological understanding of rats is essential if more ambitious targets are to be achieved. A prime example is the Predator Free New Zealand (PFNZ) project that aims to create pest-free "island sanctuaries on a national scale". First proposed by Sir Paul Callaghan in 2012, it aims to eradicate eight invasive mammalian predators including three species of rat - the pacific, ship and Norway. Wellington, as of writing, has just completed the first phase of its eradication program, by successfully removing all rats from the Miramar Peninsular. Over the next few years, the eradication will be rolled out across Wellington and eventually other cities across New Zealand. This is a monumental task that will require the development of new technologies and methods, all rooted in those species' ecology. However urban rats are very under-studied with relatively little known of their general ecology (Himsworth et al. 2013; Parsons et al. 2015; Low et al. 2013). This perhaps seems counterintuitive considering the vast numbers of potential study subjects. However, in practice, conducting research with these animals is difficult and has been described as a 'wicked problem' (Parsons et al. 2017); a term traditionally used in sociology which refers to a subject made difficult to study due to economic, social and logistical issues factors (Parsons et al. 2017). These issues are interrelated and ultimately make access to urban rats as study subjects difficult. Land ownership in cities is a patchwork of different kinds of public and private property, from residencies to municipally owned utilities. The logistical issues of gaining access to these properties and in the numbers, extent and frequency needed can require the consent of many $3^{\text {rd }}$ parties - a prospect that is often prohibitive for a potential research project. Furthermore, urban rats are heavily stigmatized animals, symbolic in many cultures of disease, squalor, and low social standing. Indeed, a study conducted on the psychological effects of cohabiting with these urban pests has shown it to be independently associated with a higher prevalence of depressive symptoms (German and Latkin, 2016). It is unsurprising then, that when an infestation is found, a hasty extermination is sought rather than a protracted ecological study. As a result, there are many prominent knowledge gaps of urban rat ecology, that if filled, could be applied to deliver more effective rat management. Some important 
examples include: 1) understanding seasonal behavior or how rats' 'personalities' vary between seasons; Gracceva et al. 2014 found that summer born voles (Microtus Arvalis) allocated to winter conditions exhibited a more cautious behavioral phenotype compared to under summer conditions (Gracceva et al. 2014). Information here could be used to time control operations for maximum effect; 2 ) identifying immigration patterns, which could help manage rat re-invasions into eradicated areas (Gracceva et al. 2014) and 3); characterizing urban rat's age and sex-related behaviors, both of which have implications for what methods of pest management are used (Parsons et al. 2017).

\subsection{Context and Objectives}

This thesis contributes to the strategies for solving a serious global conservation problem - the destruction of natural heritage and native biota by invasive alien species. In New Zealand, the ship and Norway rat, introduced in the 18th and 19th have had a devastating impact on native species. This has culminated in New Zealand's Predator Free 2050 initiative and its goal to remove all invasive predators from the mainland by 2050 . The eradication of rats from the New Zealand landmass presents fresh challenges of how to eradicate rats from urban areas. Of all the habitat types in which the ship rat and Norway rat live, the urban environment is the least studied. This thesis aims to improve our understanding by 1) evaluating the home ranges of rats in Wellington, 2) providing estimates of true abundance and densities of a wild ship rat population in Wellington, and 3) evaluating the detection probability (sensitivity) of three devices commonly used to support pest control and pest monitoring: the bait station, wax tag and chew card; and to look for any age-related differences in detection probability between adolescent and adult ship rats. It is hoped that the information found here will be incorporated into current and future pest eradication operations and so contribute to the conservation of affected species. 


\section{Chapter 2. Home Range of Ship Rats In An Urban Bush Fragment in Wellington, New Zealand}

\subsection{Introduction}

The concept of an animal's home range wherein it restricts its movement to a particular area has been around for some time. Seton (1909) observed that 'No wild animal roams at random over the country; each has a home-region, even if it has not an actual home.' This definition has been further refined and expanded upon in the years since, the most commonly quoted by Burt (1943) and reads 'that area traversed by the individual in its normal activities of food gathering, mating and caring for young.' Occasional sallies outside the area, perhaps exploratory in nature, should not be considered as being within part of the home range'. This definition illustrates important features of the home range, primarily that it encompasses key resources for the animal. However, it suffers from ambiguous wording - "occasional sallies" that makes the task of quantifying the home range unclear: what constitutes an occasional sally and how do we identify them? Furthermore, it lacks ecological detail, not accounting for the dynamic nature of the home range which is capable of changing over time and with environmental conditions. Powell and Mitchell's more recent definition is more satisfactory in that regard and reads "that part of an animals cognitive map that it chooses to keep updated", this map changes as the animal learns more of its environment, or its environment changes as new resources become available or old ones disappear (Powell and Mitchell, 2012).

Home range analysis falls into two categories, the non-probabilistic and probabilistic methods. The two most commonly employed of these are Minimum Convex Polygons (MCP) and Kernel density estimation (KDE), respectively. Minimum Convex Polygon is the simplest and most widely used technique for estimating home range and is often used in Very High Frequency 
(VHF) telemetry studies where an animal is fitted with a tag emitting radio waves which can then be used to triangulate the animals position using an antenna and receiver. MCPs are highly favored because they are standardized and therefore can be readily compared with estimates from other studies. Home ranges are constructed by delineating a boundary around all fringe locations, and then constructing a polygon that represents the subject's home range. However, the method does have its disadvantages - most importantly, how strongly peripheral locations can affect the home range size estimate. This may give a slightly superficial and misleading rendering based on locations rarely visited and therefore giving a larger home range that is not functional. It is also a simple analysis, offering little beyond an estimated home range. Other richer analyses, which provide insight into the behavior of subjects, come in the form of the probabilistic methods. These require larger datasets to be viable, usually gathered using Global Positioning Systems (GPS) telemetry, and attempt to describe an animal's probability of occurrence at each point in space - the utilization distribution - and so provide information on things like habitat preference and movement behavior. Kernel Density Estimation is the most statistically efficient of these and is supported by extensive literature, offering extensions and refinements (Terrell and Scott, 1992; Fleming and Calabrese, 2016); Peron, 2019). KDE is a non-parametric estimation of probability density which uses random variables - data that is taken to be both independent and identical (IID). The method assumes that each location data point is independent of another and that each point has an equal probability of occurrence. The result is a 3-dimensional map in which 'bumps' of probability at each location have overlapped to produce kernels; these can then be read to provide an estimate of probability at any location in the home range. However, issues arise when you consider the nature of the data collected from a living subject. It is neither completely independent nor has equal probability. These assumptions are violated by autocorrelation and non-stationarity inherent in any data set derived from living creatures. Autocorrelation is a result of the continuous nature of an animal's movement where each subsequent location is dependent on the previous one to some degree, this is particularly pronounced in GPS datasets where locations are taken in quick succession. Non-stationarity occurs when an underlying process has a variance and mean that are not constant. This is true 
of animal movement data, as it changes over time and is subject to obscure motives. As a result, KDEs have been observed to underestimate home range area, often considerably (Fleming et al 2014a). Refinements to KDEs have been designed to account for autocorrelated data in the form of Autocorrelated KDEs (AKDE). AKDEs have been shown to successfully account for autocorrelated data and provide accurate estimates of animal home ranges (Fleming et al, 2015).

Understanding home range size and shape can reveal many aspects of an animal's ecology, for example: their habitat preferences, the distribution of important resources, population size, and foraging behavior. Knowing an animal's home range also has practical conservation applications for example in designating protected areas, a vital tool for the management of threatened species. Home range data is equally important for pest management in order to design effective control or eradication schemes. For example, by identifying pest species' habitat preferences and targeting them more intensely, or by setting the spacing of control devices, ensuring that at least one device is within every animal's home range, and so increasing the probability of eliminating that individual (a pre-requisite to a successful eradication program, where every individual in a population must be exposed to kill methods (Cromarty et al. 2002)). Furthermore, if the detection probabilities of these methods are known, they can be applied to parameterize proof of freedom models: models that can then be used to infer the success or failure of an operation to a preset degree of confidence (Anderson et al. 2015; Nathan, 2016). Pest control operations often have a limited budget. In New Zealand, funds for pest management are allocated between invasive plant, invertebrate and vertebrate control projects, and in the competition for these limited financial resources, being as cost-efficient as possible is important.

The purpose of this chapter is to quantify the home range of rats in an urban habitat in Wellington, New Zealand using VHF telemetry: primarily so that this information can be used by current and future pest control operations for the protection of native species. Beyond just enumerating home range size this data will also be used to expand on the limited body of 
work that has been done around urban rats and try to further the understanding of their spatial behaviors. Topics such as sex-bias home ranges, dispersal behavior, diurnal activity and nesting behavior will be investigated. 


\subsection{A Review of Rat Home Ranges}

Much of what we know about urban rat home ranges and their ecology in general comes from classic field experiments conducted in the 1940s and 50s in Baltimore, USA. Seminal papers by Allen Stokes, David Davies, John Emlen and John Calhoun described experiments that could simply not be attempted today (Calhoun, 1948; Emlen et al. 1948; Davis and Christian, 1956). For example, releasing 121 rats into a densely populated urban area where the residents, uninformed and unaware of the social experiment in which they were participants, remarked to researchers how much worse they thought their rat problem had become! (Calhoun, 1948). These early studies laid the groundwork in the field and still constitute the majority of the sparse scientific literature on studies conducted in an urban habitat. More contemporary studies have brought new methods to bear, such as radio telemetry and genetic analysis, that have brought a better resolution to the picture of urban rat spatial ecology. That said, many of the findings from the last few decades echo insights obtained over 60 years earlier. This section will summarize the current understanding of rat home ranges in an urban environment drawing on both classic and contemporary studies.

Before the advent of radio tracking in the 1960s, all studies investigating rat home ranges were conducted using capture mark recapture techniques (CMR). In its most basic form, a population is randomly sampled and marked, and then, after a short interlude, the population is resampled - this is the Lincoln Petersen approach and is one of the most widely used for population estimates in wildlife ecology. By using a proportionality argument, the size of the population is then estimated from the fraction of re-caught individuals. CMR methods have the drawback of garnering very few data points on each rat, and so tend to underestimate home range (Oyedele et al. 2015). 
Davis et al. (1948) conducted a CMR study in inner city Baltimore in order to estimate the home range of urban Norway rats. Of the 128 rats that were marked and released, 62 individuals were recaptured and of these, none were more than 120 feet $(37 \mathrm{~m})$ away from the initial capture site and only three were captured more than 80 feet $(24 \mathrm{~m}$ ) away (Davis et al. 1948). The study concluded that the Norway rats' home ranges rarely extend beyond $100-150 \mathrm{ft}$ $(30-46 \mathrm{~m})$ in width or were instead limited to the area of a city block (Davis et al. 1948). A similar study was done by Petrie and Todd (1923) in El Motia, Egypt on ship rats using the same method. They found similar results - that most rats appeared to move over short distances between contiguous houses.

The advent of radio telemetry has allowed many data points on more individuals to be collected which permits richer analyses, and thereby providing much greater detail on rat home ranges, revealing features such as size and shape, as well as interesting behavioral patterns.

One such study by Recht et al. (1983) investigated the home range of ship rats in an urban habitat in southern California. Conducted at two sites, on a university campus and city block in Orange County, the study found that the rats had an average home range size of between 0.2 and 0.5 ha and that these were irregularly shaped (for reference, a circle with $50 \mathrm{~m}$ diameter has an area of approximately 0.2 ha and a rectangle of $50 \times 100 \mathrm{~m}$ has an area of $0.5 \mathrm{ha}$ ). The study by Oyedele et al. (2015) on Norway rats in George Town, Malaysia, also found irregularly shaped home ranges, but these were much smaller, averaging just 0.007 ha.

Other studies have further demonstrated how the size and shape of home ranges vary with the method used, the species of interest and the habitat type. The most drastic differences in home range size are between rural and urban habitats (Table 1). The smaller home ranges found in urban habitats are most likely due to greater food availability, coupled with significant barriers to movement e.g. roads. Variation is also seen between urban habitats, with sites such as Baltimore and George Town having very different home ranges. These are likely to be due to the unique characteristics of any given urban habitat. This is discussed in greater detail in the section on spatial population genetics. 
Oyedele et al. (2015) and Recht et al. (1983) found that home range size and shape were strongly influenced by access to food sources and harborage. Further, routes between these sites were regularly used and infrequently deviated from. This was described in detail by Calhoun (1962) who set up controlled field studies, constructing several 'rat villages' - large, enclosed spaces where he could observe rat behavior. From months of observational data, Calhoun concluded that rat movement through space fell into two categories: goal-orientated and investigatory. Goal-orientated movements are those that are directed toward a food source or harborage that is permanent enough for the rat to have learnt its location. These movements typically use the shortest route, requiring least energy which, once formed are then used regularly. Investigative movements are enacted after basic needs have been fulfilled and exhibit more random exploratory patterns of movement, seeking out new food sources or areas of interest (Calhoun, 1962). Furthermore, he concluded that key food sources were encompassed within a rat's core range. He found evidence of a 'center-point of orientation' in a home range, from which there was a decreasing frequency in visitation (Calhoun, 1962). These core areas contained key features such as harborage and consistent food sources and were highly channelized by frequent use - consistent with findings of Oyedele, (2015), Recht et al. (1983) and Low et al. (2013).

Core Range can be defined as the space in which an animal spends $50 \%$ of its time (Downs and Horner, 2008) - 50\% minimum convex polygons are regularly used to estimate this. For Norway rats in an urban habitat this is estimated to make up 11\% of the total home range (Oyedele et al. 2015) and 31\% of the space used by ship rats (Low et al. 2013).

It is important to distinguish between home range and territoriality. A territory is a space held exclusively by an individual or group, often for resources and mating opportunities, and involves the territory holder marking and defending that area from other conspecifics. In social animals living in colonies, like the Norway rat, territoriality is a difficult concept to define because home ranges are highly overlapping. Territories are shared among individuals of a colony and defended against outsiders. Inside the group, territory is best considered under the lens of hierarchy, where higher-ranking individuals maintain a 'territory' over lower-ranked 
ones. For example, within a colony, a few males will dominate a harem of females, and will protect that general locality of burrows from other males (Calhoun, 1962). Often this competitive exclusion will be so severe that the low-ranked male is forced to leave - a prime mechanism for rat dispersal. For juveniles that are introduced into a colony it will be largely ignored. The same is true for adult females, unless in estrus, in which case males will attempt to mate with her. However, if an adult male is introduced it will be vigorously attacked (Barnett, 1967). Ship rats do not live in large colonies, but they do regularly co-nest in small groups (see Denning Behavior below), and as a result, they show substantial overlap in home ranges in both rural and urban habitats (Low et al. 2013).

A sex-dependent relationship with home range size has been found in several studies, with males having a significantly larger home range than females. This is a common pattern in mammals, thought to be due to respective reproductive strategies. Males increase their home range in search of estrus females, while females maintain an area that has good den sites and food availability to raise young (Brock and Harvey, 1978; Dowding and Murphy, 1994). In Norway rats the area of male home ranges were found to be as much as 15 times larger than female home ranges (Oyedele et al. 2015). However, for ship rats the sex-biased home range relationship is not so clear, with some studies confirming its existence and others not. A study by Low et al. (2013) compared home ranges of radio-collared rats in an urban and rural habitat. They concluded a significant correlation between sex and home range existed in both habitats: in urban habitat 0.57 ha (M) and 0.17 ha $(F)$ and rural habitat 0.54 ha $(\mathrm{M})$ and 0.38 ha $(F)$, however the study suffered from low sample sizes and data points/individual - having just two males in their urban study and between 19-24 fixes/individual. A similar study by Harper and Rutherford (2016) on Big South Cape Island reached the same conclusion, with an improved sample size of seven males and seven females. In contrast, Dowding and Murphy (1994) found no significant relationship between sex and home range size with similar samples and conducted in rural Kauri forest. 


\subsection{Denning Behavior}

Norway rats are social animals that live in local colonies of up to 12 individuals, often as part of mega-colonies of up to 150 (Calhoun, 1962). They inhabit large burrows with interconnected tunnel systems. Their complex hierarchical social systems can be observed here. Higher ranking individuals occupy the central positions within the burrow whilst lower-ranking individuals and juveniles are kept within the less desirable and peripheral areas of these burrows. Rat societies are complex hierarchical structures stratified into groups of social class. These social classes can be described by how well an individual of that class can fulfil its drives: higher-ranking individuals will often be antagonistic to juveniles when feeding for example (Calhoun, 1962).

No comprehensive behavioral study, comparable to Calhoun's, has been conducted for ship rats and so less is known of their denning behavior and social structure. There's no doubt that ship rats are social animals, however they do not live in large colonies as does the Norway rat. Ship rats build and use a series of separate nests all around their home range. These nests are often arboreal and woven from twigs and leaves, and are similar in appearance to a sparrow's (Best, 1968; Hooker and Innes, 1995). A study by Rutherford et al. (2009) found that on average 15.80 nest sites were used per male and 12.43 per female and at least three individuals have been observed co-nesting at the same time. These nests were not exclusive but shared, with $24 \%$ of monitored rats sharing dens on a given day. Furthermore, both intraand intersex co-nesting has been observed, suggesting that rats in the same area may be related (Dowding and Murphy, 1994). 
Table 1: Showing a sample of the literature on ship rat home ranges in both urban and rural habitats $(100 \% \mathrm{MCPs})(M=$ male, $F=$ female $)$

Author Species $\quad \underline{\text { Method }}$ Habitat $\quad$ Location $\quad$ Home range (ha)

Avg. (unless range

given)

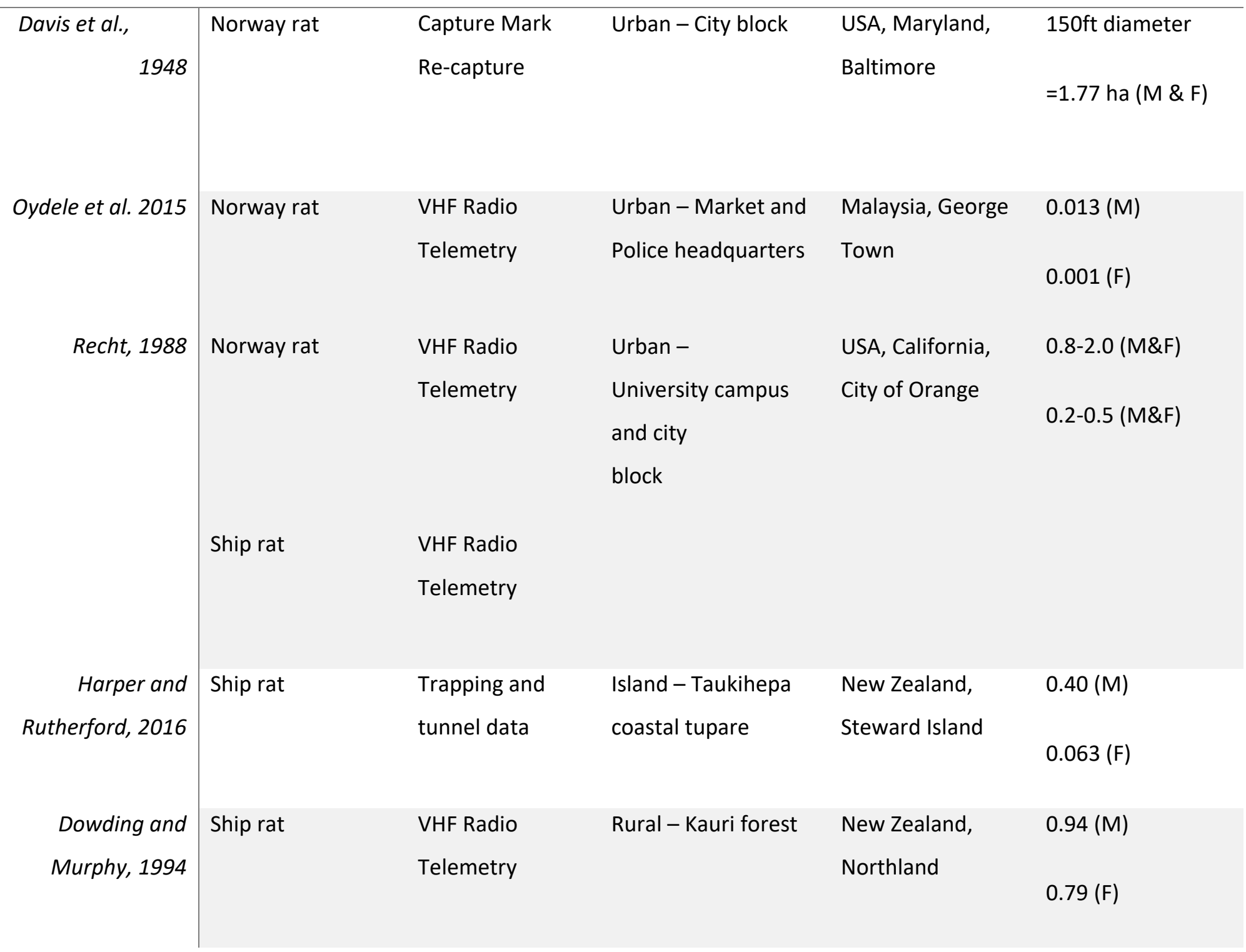




\subsection{Spatial Genetic Studies, Dispersal Patterns and Barriers to Movement}

Interesting genetic studies have been undertaken in the last few decades, most notably those conducted by Gardner-Santana et al. (2009); Kajdasci et al. (2013) and Combs et al. (2018) on the Norway rat. Spatial genomic studies have become the cutting edge in the field of urban rat spatial ecology. These studies attempt to understand urban dispersal patterns, through paternity/maternity analysis and the evolutionary processes of genetic drift and gene flow. Gene samples are taken from several metapopulations within a city and a series of Single Nucleotide Polymorphisms (SNPs) are examined, and from these, the extent of genetic differentiation between populations can be assessed.

A stepping-stone model of isolation-by-distance (IBD) has been put forward as a broad model for the dispersal patterns of the Norway and ship rat (Combs et al. 2019). The model describes a dispersal pattern that involves small migrations between populations over successive generations. When a species inhabits a much larger area than any individual's home range or migration distance, there is a drive from both genetic drift and local selection pressures toward local differentiation. This local differentiation can cause geographical races to emerge and within those races, numerous colonies of even greater relatedness (Kimura and Weiss, 1964). The effects that geographical or environmental barriers have on species formation is well documented. However, the Isolation-by-Distance (IBD) model formally specifies distance as a barrier and a propagator of genetic diversity within a species. Within a continuous population, genetic differences will occur progressively between more distant groups; these differences will be most profound when a tipping point is reached where the effect of genetic drift outweighs gene flow. This model is exhibited by several urban commensals e.g. the house mouse (Mus musculus), the racoon (Procyon Lotor), the Norway rat (Lippens et al. 2017; Combs et al. 2019). Combs et al. (2018) in their study of Norway rats in New York City found that spatial autocorrelation of IBD is detectable up to a distance of $1,400 \mathrm{~m}$. A comparative study of Norway 
rat metapopulations within four American cities: Salvador, Brazil; New Orleans, USA; Vancouver, Canada; and New York City, USA; found values similar to this, which indicated that patterns of isolation-by-distance were primarily driven by social factors and dispersal behaviors that do not vary (Combs et al. 2019). Interestingly though, typical demographics expected of mammalian dispersal, such as male-bias dispersal and female philopatry, were not found within urban Norway rat populations (Gardner-Santana et al. 2009).

However, no model is perfect, and deviations from the IBD model were found in numerous studies where fine-scale heterogeneity was present (Gardner-Santana et al. 2009; Richardson et al. 2017; Combs et al. 2018). For example, Richardson et al. (2017) observed sharp genetic breaks between populations in two valleys separated by less than $50 \mathrm{~m}$. These valleys had a $50 \mathrm{~m}$ elevation gain to their dividing ridge with two busy roads on top. Combs et al. (2018) also discovered that midtown NYC was acting as a barrier to migration, leading to genetic clustering in uptown and downtown. Midtown is a largely industrial area with few residential properties and high levels of human activity and its low food/den availability and high levels of disturbance made it a strong barrier to rat dispersal. Despite the Norway rat's adaptability to the urban landscape, aspects of the landscape do clearly pose significant barriers to their movement. Understanding exactly what those barriers are and how they function, are important outstanding questions in designing effective eradication schemes. 


\subsection{Methods}

\subsubsection{Study Sites}

Field work was conducted in Wellington, New Zealand within three suburbs: Roseneath, Kelburn and Brooklyn. The Brooklyn and Roseneath sites were selected from a list of suburbs
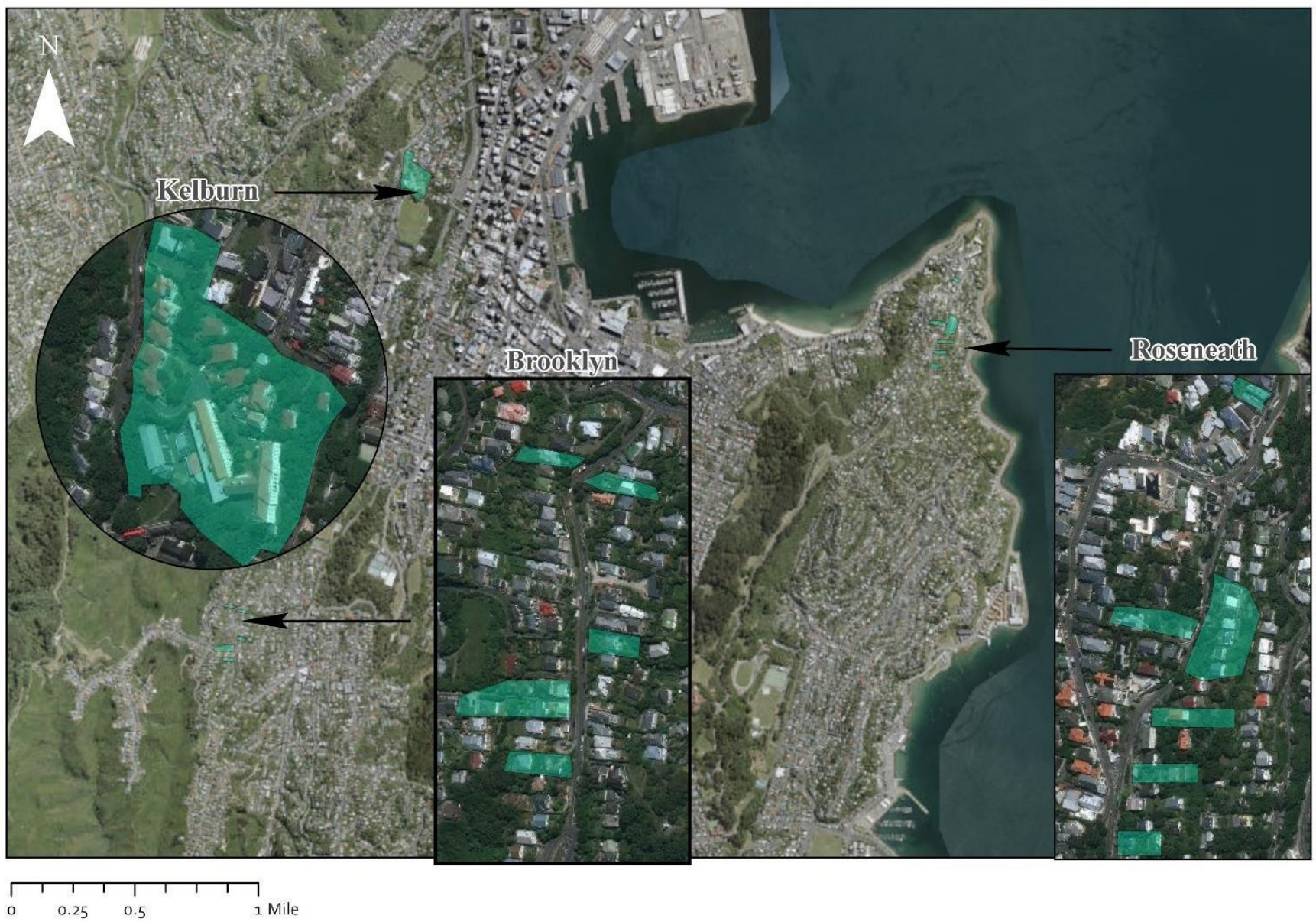

Figure 1: Showing the three field sites Roseneath, Kelburn and Brooklyn within Wellington, New Zealand. Green shaded polygons show participating areas. 
where residents had participated in an earlier urban mammal monitoring project by Peoples, Cities and Nature (PCAN)2.

The Roseneath and Brooklyn sites consisted of a single road with access to 10 and 6 residences respectively: these were spread out along each road (Figure 1). Participants were contacted independently and consent to set traps and conduct radio-tracking was sought. The Kelburn site is a campus accommodation belonging to Victoria University of Wellington. Permission to conduct work there was obtained through Victoria University of Wellington and the hall residents were notified of the work and its nature via email.

Brooklyn has an active trapping community, Predator Free Brooklyn, with approx. 15 active traps along Mitchell Street (Trap.nz). The street consisted of multi-story housing, stacked closely in succession. The gardens were enclosed by fences and typically contained a manicured lawn with tended flower beds. The vegetation consisted mainly of ornamental plants with little overstorey.

Roseneath has an active trapping community, Predator Free Mt Vic, with approx. 15 active traps (Trap.nz) along Grafton Road. Lying on the eastern slope of Mt Victoria, Roseneath was a steep site. Its multi-story housing was more spread out and the green spaces larger than in Brooklyn. Its gardens were not enclosed by fences and would often merge into neighboring ones. The gardens themselves were much wilder and less well tended, with lawns less common and taking up a smaller relative area. There were many more native plant species and a continuous overstorey was found in many places.

The Kelburn site had no recent history of trapping. The site was made up of 14 residential bungalows spread across a flat 2.5 ha area (Figure 1). The site was bordered by Salamanca Road to the East, Claremont Terrace to the North, Kelburn field to the South and a walkway connecting Kelburn field and Claremont to the East. One of the residences was a large complex (Weir House) split into two buildings, accommodating some 300 students. Each property had a

${ }^{2}$ PCAN is a multi-disciplinary program leading urban ecological restoration research in New Zealand (https://www.peoplecitiesnature.co.nz/) 
garden, consisting of a lawn and lined with flower beds and were well-tended by gardeners. However, wilder bush was present in peripheral areas.

The suite of invasive mammals present at these sites is typical of a New Zealand urban habitat. Several of them were regularly encountered in this study, either caught in live traps or observed in camera traps. The rodents: the house mouse (Mus musculus), the ship and the Norway rat were all caught in live traps. The European hedgehog (Erinaceus europaeus) was also encountered but only at the Kelburn site. Invasive species expected to be present at lower densities and not observed in this study, were the brushtail possum (Trichosurus vulpecula), the stoat (Mustela erminea), the least weasel (Mustela nivalis) and the ferret (Mustela furo).

\subsubsection{Trapping}

Live trapping started in mid-July 2019 in Brooklyn and continued until mid-December that year, finishing in Kelburn. There was no set weekly schedule during this time, as I could only carry out trapping if the assisting vet was free on a given morning. Trapping was done across each of the three study sites in Roseneath, Kelburn and Brooklyn. The live traps used were spring traps of a custom design donated by Landcare Research. The trapping mechanism consisted of a doubleended hook either side of the roof of the trap. The hook hanging into the cage was baited and the other end held the trap door open and its springs in tension. If a rat took the bait this would dislodge the hook holding the door open and spring the trap. A total of 25 live traps were used in Brooklyn, 20 in Roseneath and 15 in Kelburn. The number of traps decreased as the study progressed due to thefts/breakage and were down to 15 at the conclusion. Traps were spread evenly across all participants' gardens. Areas thought to have a high chance of capture were selected, such as in tall grass or shrubbery, along walls, and in proximity to potential food sources. Initially traps were baited with apple and peanut butter, but the bait was later switched to hazelnut chocolate after a few weeks, which was found to be more successful. The traps were checked and serviced each morning and any signs of bait activity recorded. Any triggers and any bycatch were noted and released. 


\subsubsection{Anesthesia (Cotton ball method)}

The method used for anesthetizing rats in the field was developed under the guidance of Wellington Zoo vet, Craig Pritchard. The procedure was carried out in the back of a university van. All appropriate hygiene measures were taken: vet gloves were worn throughout, hand sanitizer applied post-procedure and the van was disinfected after use. Rats were only collared if the weight of the collar was below $5 \%$ of the rat's total body weight.

To collar a rat, it was first placed into an airtight container whilst still inside the trap. Several cotton balls were then doused with isoflurane until saturated. The number of cotton balls used varied according to the size of the rat: two cotton balls for juveniles and sub-adult ship rats $(90 \mathrm{~g}-120 \mathrm{~g})$, three for adult ship rats $(120 \mathrm{~g}-190 \mathrm{~g})$ and four or five for adult Norway rats $(180 \mathrm{~g}$ -350g). The appropriate number of balls was then placed inside the container and the container sealed. The rat was monitored for signs of induction. To test whether the rat was safely under anesthesia, the container was tilted, if the rat made no movement to regain balance it was considered safe to proceed. Once under anesthesia, the container was opened, the rat removed, biometric measurements recorded (see below), and the VHF collar fitted. The cotton balls were kept close to the subject's nose to maintain induction and the distance adjusted based on how 'light' or 'heavy' the subject appeared to be. In this way, I maintained control over the subject's state of induction. Additionally, the breathing rate was monitored for any signs that the breathing rate was slowing and if this happened the procedure was stopped. Once completed, the cotton balls were removed, and the subject placed into a fresh container to recover. This container had a heating pad and apple inside - as common issues whilst anaesthetizing rats are a drop in body temperature and hypoglycemia (Flintoff, 2014). Once the rat showed signs of recovery e.g. appearing mobile and energetic, exploring its surroundings - it was released at its original point of capture. The time for recovery ranged between one minute and four hours with the average at close to 10 minutes. 


\subsubsection{Biometrics}

The rat's body length and tail length were measured, the rats sexed and weighed. The species of rat was identified according to Cunningham and Moors (1983). Identifications were usually made according to tail length, ear size and shape of head.

\subsection{5 $\underline{\text { Radio Tracking }}$}

\subsubsection{Equipment}

The tags used in this VHF study were V1C 118B COLLAR (Lotek, Haverstock North, New Zealand) weighing 4.5g and programmed at 30 pulses per minute for a battery life of 365 days. Radio-

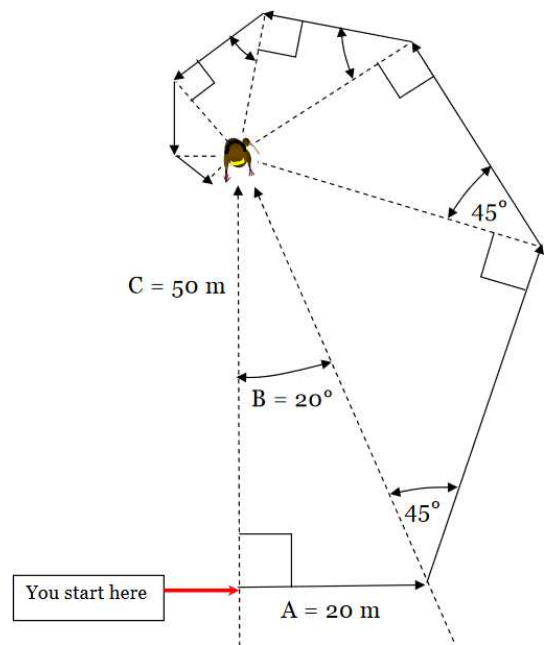

Figure 2 Showing the spiral technique for close approach radio tracking Source:

Neill and Jansen, (2004) Ground-based radio tracking: a best protocol.

tagged individuals were located using a R-1000 telemetry receiver (Telonics, Mesa, Arizona, Unites States) and a three element Yagi antenna (Lotek, Havelock North).

\subsubsection{Choice of Tracking Method}

Radio tracking typically employs one of two methods: close approach method or triangulation. 
The close approach method was used for radio tracking in this study, as described in Neill and Jansen (2014). This method is designed to avoid disturbing the animal under observation and involves taking continuous bearings on the target in a spiraling formation as shown in Image 1. First the receiver and radio collars are calibrated, noting the gain setting at which a signal was just audible for a preset distance of seven meters. This distance was chosen to maximize the accuracy of my fixes whilst also ensuring the rats remained undisturbed. A seven-meter distance was thought to be sufficient given that urban rats are accustomed to being in close proximity to humans.

The close approach method was also chosen over triangulation as it resolved many of the problems associated with effective radio tracking such as signal interference (diffraction, reflection, and interference) within the urban habitat, the tracking of a highly mobile animal, and signal dark spots. Importantly, the spiraling technique allowed bearings to be taken in a continuous manner, so they could be constantly updated. This method of continuous refinement allowed accurate fixes to be made on mobile animals - as well as making it easier to identify and adapt to rogue signals from sources of interference.

To compare the accuracy of triangulation versus a close approach technique in an urban habitat some testing was carried out. A transmitter was hidden by an assistant, and then attempts, by either close approach or triangulation were made to identify its position. The distance between the presumed location and true location were then recorded. These were carried out at different locations and an average error taken for each method. The close approach method was far more accurate with an average error of $1.5 \mathrm{~m}(\max 3 \mathrm{~m}$, $\min 1 \mathrm{~m})$ compared with triangulation's seven meters ( $\max 15 \mathrm{~m}, \min 6 \mathrm{~m}$ ).

\subsubsection{Radio Tracking: Field Work}

Radio tracking started on the 24th of July 2019 and finished on the 20th of February 2020. It was carried out across all three suburbs with both night-time and daytime tracking. Rats are primarily nocturnal and most active around sunset until a few hours before sunrise (Taylor, 
1978). As the study took place over seven months the time range for nighttime tracking was varied accordingly.

I sampled across hourly intervals from sunset until sunrise attempting to get an even number of fixes across this time range. This was done to account for any temporal patterns in movement e.g. if a rat is more likely to be at its furthest distance from its nest at later times than earlier. On each tracking night a single fix was made for as many rats as I could locate. Multiple fixes on individual rats in a night were not attempted in order to keep the fixes as independent as possible and reduce autocorrelation in my data. Once a fix was made the time was recorded and the estimated location was marked on a $1 \mathrm{~m}$ resolution map ${ }^{3}$.

At the Kelburn site, the activity status (active or inactive) of the subject was also recorded for each fix: changes in the signal's amplitude was indicative of an active subject (Neill and Jansen, 2014). To confirm that a rat was inactive, it was monitored for 10 minutes, if the rat remained stationary for that time it was taken to be inactive. Daytime fixes were carried out anytime between 10:00 - 17:00 to locate nesting sites. When a signal was picked up it was homed in on, and if the subject remained stationary, I then tracked it directly to its source and confirmed the nest visually.

I aimed to get 30 fixes for each rat; this was based on the number of fixes an analogous study found reached an asymptotic value of home range size (Harper and Rutherford, 2016). There was no weekly tracking schedule, but I attempted to go out at least three times a week. As the study progressed the sites where the rats were collared earlier became less productive as more collars became inactive/undetectable. In order to maximize data gathered, I prioritized the sites that had the most active rats. The less productive sites were consequently visited less frequently.

A typical tracking night involved walking a preset route across a site. This route was designed to cover an area that encompassed the upper estimates of a rat's home range to ensure we did

\footnotetext{
${ }^{3}$ Trials with GPS units were done but they proved too unreliable, often not being able to communicate with satellites and inaccurate with errors up to $\pm 10 \mathrm{~m}$ (Appendix 1)
} 
not exclude any part. To do this, the range of the collars was tested with the help of a field assistant who carried a VHF tag throughout the site whilst in communication with myself holding the antenna and receiver. The range of the collar varied depending on obstacles to the signal, however the max range was estimated at $\sim 200 \mathrm{~m}$. Note, if a rat could not be found then I extended the route walked to monitor a larger area.

Prior to the study, the trapping communities of Brooklyn and Roseneath were both contacted. They agreed to inform all members of the work we were doing, and to report any caught radiocollared rats to myself. In addition to this I also distributed information across all three sites by letter-drop. In it I informed them of the upcoming study and requested that if they practice backyard trapping that they report any collared rat killed in their traps to me via email. There was no current pest control taking place within the Kelburn site, however residences along Salamanca road and Claremont Terrace were contacted in the same way.

\subsubsection{Home Range Estimation Method}

To estimate the home ranges, I used Minimum Convex Polygons (MCPs) for my analysis rather than the any utilization distribution method such as Kernel Density Estimation. Utilization distribution methods require a larger sample size to achieve accuracy: with over 30 fixes recommended in the case of KDEs (Seaman, 1999). A series of MCPs were done at $100 \%, 75 \%$ and $50 \%$ of the data points. These were done in order to identify any core ranges within the rat's home range. I used the R package adehabitatHR (Calenge, 2006) to do this, the package peels back MCPs by removing locations furthest away from the arithmetic mean of the coordinates of locations for each animal.

The incremental area analysis was made by running successive MCPs through ArcGIS's Minimum Bounding Geometry tool with temporally ordered relocations. 


\subsection{Results}

\subsubsection{Live Trapping}

\subsubsection{Trapping Results}

In total 42 rats were caught between July and December 2019 with a total 64 trapping nights. Of these 42 rats, biometric data was collected on 30 with three Norway rats and 27 ship rats caught and a total of 12 females and 18 males (Table 3). All rats caught had excellent body condition being at good body weights and with healthy coats. Observations of bite wounds were rare. Trap bycatch included hedgehogs, blackbirds, and mice.

The rats caught in Brooklyn in July were considerably smaller than those caught in both Roseneath and Kelburn - 23\% smaller for females and 62\% smaller for males from Brooklyn compared to Kelburn. All rats caught in Brooklyn were thought to be pre-adults judging by their weight: all the ship rats caught were under the typical adult weight of $120 \mathrm{~g}$ and the one Norway under the typical adult weight of $180 \mathrm{~g}$. The female ship rats caught in Brooklyn were $25 \%$ heavier on average than the males. Ship rats caught in Roseneath were the heaviest, with the males $19 \%$ heavier than those caught in Kelburn. Table $2 \mathrm{~b}$ shows a comparison of the weights of male and female ship rats across all three sites.

All rats caught throughout the fieldwork are recorded here. However, some of the rats were released without being measured, sexed, or fitted with a collar when unanticipated circumstances did not allow for collaring. 
Table 2a: Details of Norway rats caught at each site with the species, sex and avg. weight (Wt.g).

\begin{tabular}{|l|c|c|c|c|c|c|}
\hline \multirow{3}{*}{ Study Site } & \multicolumn{5}{|c|}{ Norway Rat } \\
\cline { 2 - 7 } & \multicolumn{2}{|c|}{ Male } & \multicolumn{2}{|c|}{ Female } & Un-sexed & Total \\
\cline { 2 - 7 } & No. & Wt g & No. & Wt g & & No. \\
\hline Roseneath & & & 2 & 325 & 1 & 3 \\
\hline Brooklyn & & & 1 & 170 & 0 & 1 \\
\hline Kelburn & & & & & 0 & 0 \\
\hline TOTALS & & & 3 & & 1 & 4 \\
\hline
\end{tabular}

Table 2b: Details of ship rats caught at each site with the species, sex and avg. weight (Wt g).

\begin{tabular}{|c|c|c|c|c|c|c|}
\hline \multirow{3}{*}{ Study Site } & \multicolumn{6}{|c|}{ Ship Rat } \\
\hline & \multicolumn{2}{|c|}{ Male } & \multicolumn{2}{|c|}{ Female } & \multirow[t]{2}{*}{ Un-sexed } & \multirow{2}{*}{$\begin{array}{c}\text { Total } \\
\text { No. }\end{array}$} \\
\hline & No & Wt g & No & Wt g & & \\
\hline Roseneath & 3 & 175 & 0 & & 7 & 10 \\
\hline Brooklyn & 3 & 90 & 3 & 113 & 3 & 9 \\
\hline Kelburn & 12 & 146 & 6 & 140 & 1 & 19 \\
\hline TOTALS & 18 & & 9 & & 11 & 42 \\
\hline
\end{tabular}

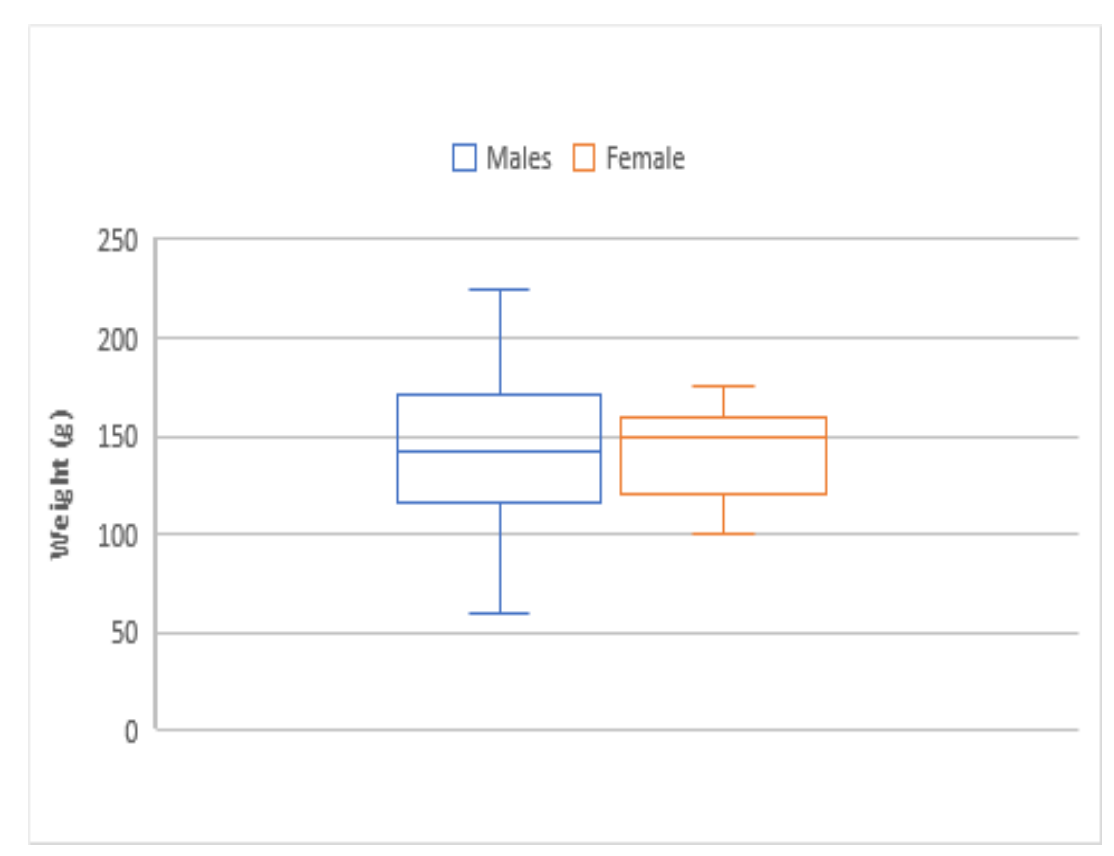

Figure 3: Weight of ship rats according to sex (male $n=16$, female $n=15$ ), across all three sites 


\subsubsection{Average Trap Time and Trap Activity}

The average time taken for a rat to be captured per trap was calculated at each site (Table 3). Note that the rats included here are all the rats caught whilst collaring, rats caught for my capture mark re-sight study (Chapter two) are not included. The first 10 days of activity within the trap network at each site was also measured. Activity was calculated as the total number of rat captures plus the occasions where the full bait was taken, per night (Figure 4). Rats were reasoned to be the only species capable of taking the full bait without triggering the mechanism: other species such as the hedgehog and blackbird lack the dexterity to take the bait without triggering the mechanism whereas mice where found to just take a small quantity of bait.

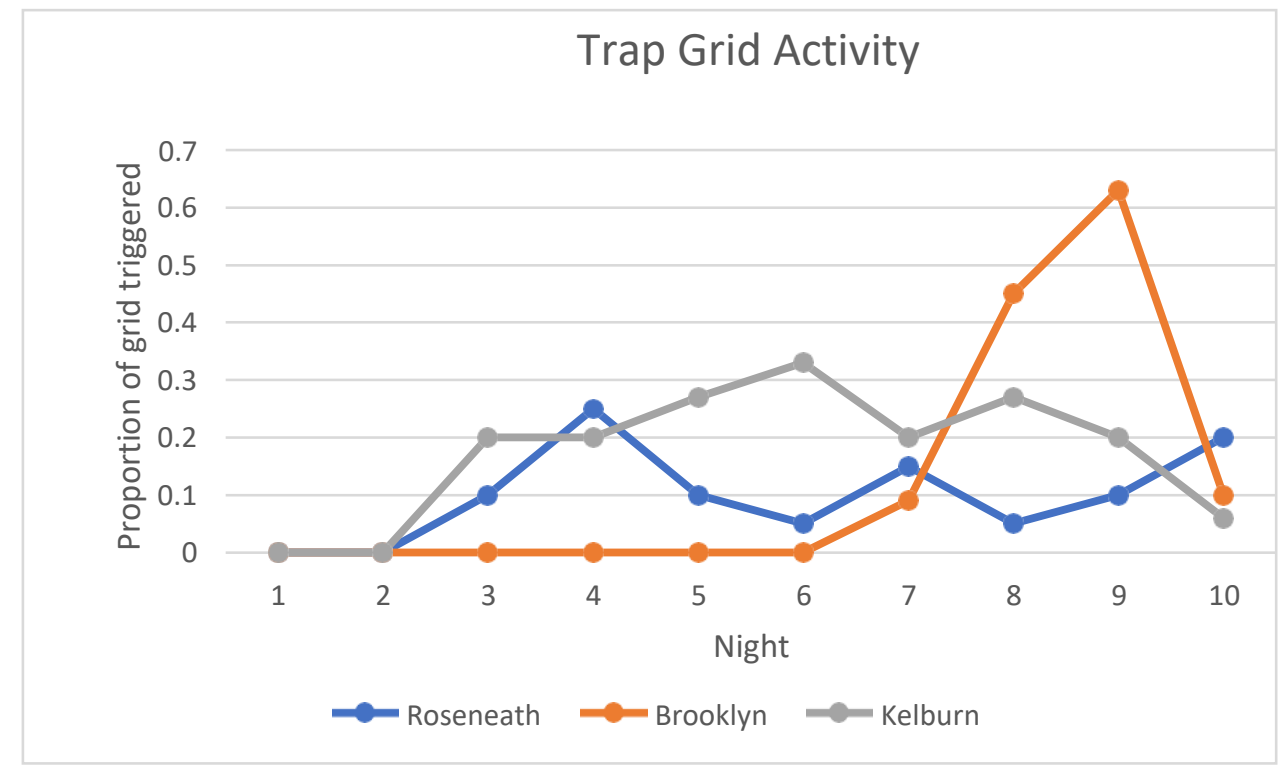

Figure 4: Activity on the trapping grid over the first 10 days of trapping

Brooklyn, at 55 days/rat/trap, was found to have a significantly longer average trap time per capture than both Kelburn and Roseneath. Roseneath and Kelburn were similar at 30.7 and 
27.5 days/rat/trap, respectively. Figure 4 shows activity of the trapping network at each suburb over the first 10 active nights. Kelburn and Roseneath had a lag period of two days where no activity was recorded, whilst Brooklyn's was longer at six days. Brooklyn showed a quick rise in grid activation after day 6, reaching a peak activity with $63 \%$ of traps activated on day 9 and was followed by a sharp decline the next night. 
Table 3: Breakdown of the trapping data by site, showing number of rats caught, the number of active traps and duration traps were active

\begin{tabular}{lccccc} 
Study Site & Rats Caught & $\begin{array}{c}\text { Trapping } \\
\text { duration } \\
\text { (nights) }\end{array}$ & $\begin{array}{c}\text { Active } \\
\text { Traps }\end{array}$ & $\begin{array}{c}\text { Average trap time } \\
\text { per capture } \\
\text { (days/rat/trap) }\end{array}$ & $\begin{array}{c}\text { Average catch per } 100 \text { trap } \\
\text { nights }\end{array}$ \\
\hline Brooklyn & 10 & 22 & 25 & 55 & 1.81 \\
Roseneath & 13 & 20 & 20 & 30.7 & 3.25 \\
Kelburn & 12 & 22 & 15 & 27.5 & 3.63
\end{tabular}

\subsubsection{Radio Telemetry Data}

\subsubsection{Tracking Subjects}

A total of 28 rats (three Norway and 25 ship rats) were fitted with radio-collars: seven subjects in Brooklyn, nine in Roseneath and twelve in Kelburn. Of the rats that were sexed, nine were female and 14 were male. A total of 79 tracking nights and 34 tracking days were completed. From which, significant data (considered to be 10 or more fixes) was gathered for 10 rats. All 10 of these rats were ship rats (Table 5).

Three collars were 'slipped' by the rats, with one of these recovered and recycled onto another rat. By the end of the study there were just three collars left active. Possible explanations for this include collar malfunction, dispersal beyond the area of cover, units damaged by the rats themselves or by a cat or a kill trap. However, there were no mortalities either confirmed directly via radio tracking or reported by the trapping communities or residences. 


\subsubsection{Tracking Duration}

The tracking duration of a rat was calculated as the number of days between the first and last fix. Rats released in Brooklyn disappeared from tracking efforts most quickly, with a mean track duration of 2.42 days. Kelburn was the most successful with a mean duration of 33 days, with 6 of the 11 rats having a tracking duration of over a month. Roseneath was slightly worse with a mean of 33 days and with 5 of 9 rats having a tracking duration of under 20 days. At the end of the fieldwork there were three subjects that were still transmitting, two in Kelburn and one in Roseneath.

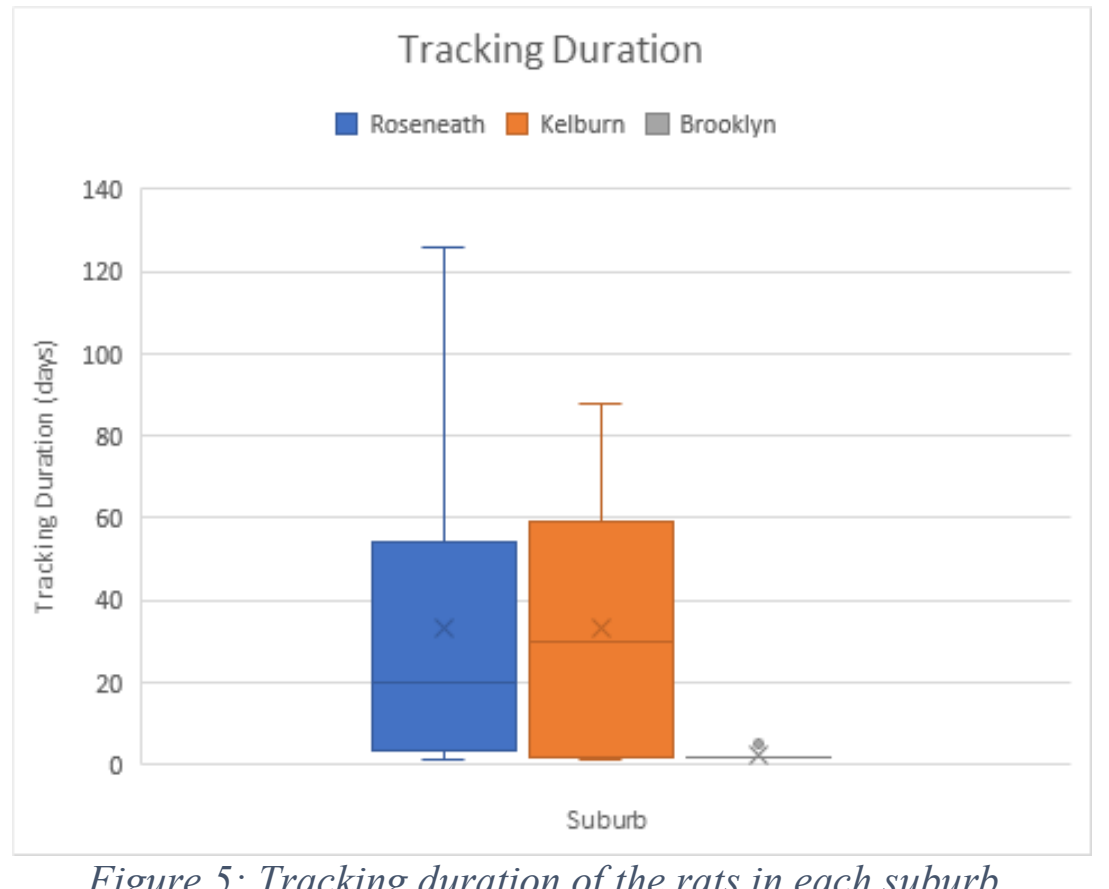

Figure 5: Tracking duration of the rats in each suburb

\subsubsection{Home Ranges}

Home range size was calculated from $100 \%$ MCPs for all rats with at least 10 fixes ( $n=10$, Table 5). The home range for males was calculated at 0.11 ha and for females at 0.067 ha with a range of values between 0.01 and 0.45 ha for both sexes. The maximum linear distance (the distance between the farthest points) was also measured for rats with over 10 fixes which 
ranged from $19 m$ to $74 m$

(Table 5). The Core Home Range (defined as the 50\% MCP) for males was calculated at 0.024 ha and 0.018 ha for females. There was no relationship between home range size and sex for either the full home range (Mann Whitney $U$ test, $p=0.83$ ) or core home range (Mann Whitney $U$ test, $p=0.76$ ). The largest home range recorded was 0.45 ha for a pre-adult male ship rat (rat no. 25). The smallest recorded was 0.01 ha for a male adult ship rat (rat no. 29).

All the tracked rats with $\geq 10$ fixes remained within the bush fragments they were captured in, with the exception of rat nos. 25 and 30 that made two long distance jumps of $\sim 120 \mathrm{~m}$ to new fragments (Figure 8). Overlapping home ranges were common amongst rats caught in a similar area with nine rats demonstrating this in total. At one area in the Kelburn site there were four rats with overlapping home ranges: rat nos. 30(f), 31(m), 32(f), 35(f). Many of the home range overlaps were substantial with a maximum recorded overlap of $90 \%$ (between rats $31(\mathrm{~m})$ and $35(f))$.

Table 4: Average ship rat home ranges pooled for sex at 100\%, 75\% and 50\% MCPs for rats with 10 or more fixes

\begin{tabular}{cccc} 
& \multicolumn{3}{c}{ Average Home Range Size (ha) } \\
Sex & $100 \%$ MCP & $75 \%$ MCP & $50 \%$ MCP \\
\hline $\begin{array}{c}\text { Female } \\
(n=4)\end{array}$ & 0.067 & 0.024 & 0.018 \\
$\begin{array}{c}\text { Male } \\
(n=6)\end{array}$ & 0.11 & 0.05 & 0.024 \\
\hline
\end{tabular}


Table 5: Showing the home ranges of all ship rats with $\geq 10$ fixes, in hectares (ha) at 100\%, 75\% and 50\% MCPs. The number of den sites, fixes and maximum linear distances for each rat are also shown.

\begin{tabular}{|c|c|c|c|c|c|c|c|c|c|c|}
\hline Subject & Suburb & $\begin{array}{l}\text { No. of } \\
\underline{\text { fixes }}\end{array}$ & $\begin{array}{l}\text { Date of } \\
\underline{\text { first fix }}\end{array}$ & $\begin{array}{l}\text { Date of } \\
\text { final fix }\end{array}$ & $\underline{\text { Sex }}$ & $\begin{array}{l}100 \% \text { MCP } \\
\text { (ha) }\end{array}$ & $\begin{array}{l}\text { 75\% MCP } \\
\text { (ha) }\end{array}$ & 50\% MCP (ha) & $\begin{array}{l}\text { Maximum } \\
\text { linear distance } \\
\underline{\text { (m) }}\end{array}$ & $\begin{array}{l}\text { Number of } \\
\text { nests located }\end{array}$ \\
\hline 25 & Kelburn & 31 & $7 / 11 / 19$ & $11 / 01 / 20$ & $\mathrm{M}$ & 0.45 & 0.25 & 0.1 & 63 & 4 \\
\hline 31 & Kelburn & 19 & $7 / 12 / 19$ & $20 / 01 / 20$ & M & 0.03 & 0.006 & 0.0002 & 30 & 2 \\
\hline 32 & Kelburn & 15 & $9 / 12 / 19$ & $15 / 01 / 19$ & $F$ & 0.08 & 0.05 & 0.04 & 74 & 2 \\
\hline 33 & Kelburn & 27 & $14 / 12 / 19$ & $18 / 01 / 20$ & $\mathrm{M}$ & 0.21 & 0.05 & 0.03 & 62 & 5 \\
\hline 35 & Kelburn & 19 & $15 / 12 / 19$ & $10 / 02 / 20$ & $F$ & 0.03 & 0.017 & 0.016 & 30 & 3 \\
\hline 29 & Kelburn & 10 & $4 / 12 / 19$ & $3 / 01 / 20$ & $M$ & 0.01 & 0.002 & 0.0005 & 19 & 3 \\
\hline 30 & Kelburn & 16 & $5 / 12 / 19$ & $30 / 01 / 20$ & $F$ & 0.10 & 0.019 & 0.008 & 34 & 2 \\
\hline 12 & Roseneath & 10 & $16 / 08 / 19$ & 19/10/19 & $M$ & 0.05 & 0.015 & 0.014 & 52 & 2 \\
\hline 20 & Roseneath & 22 & $21 / 09 / 19$ & $24 / 01 / 20$ & $\mathrm{M}$ & 0.05 & 0.008 & 0.003 & 65 & 3 \\
\hline 19 & Roseneath & 10 & $1 / 09 / 19$ & $13 / 10 / 19$ & $\mathrm{~F}$ & 0.06 & 0.012 & 0.0007 & 67 & 2 \\
\hline
\end{tabular}




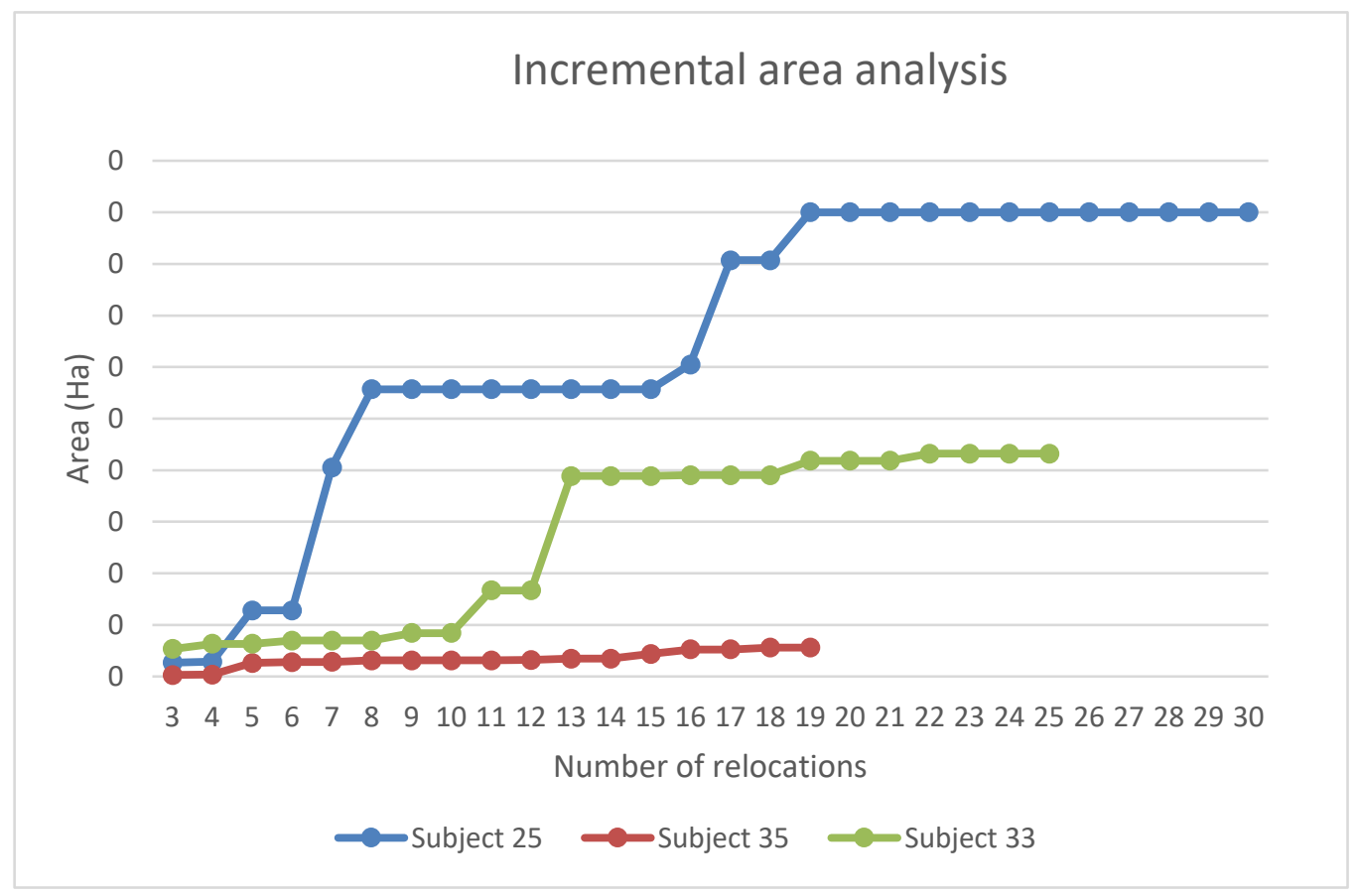

Figure 6: Incremental area analysis of MCP to 100\% for subjects 25, 33 and 35 


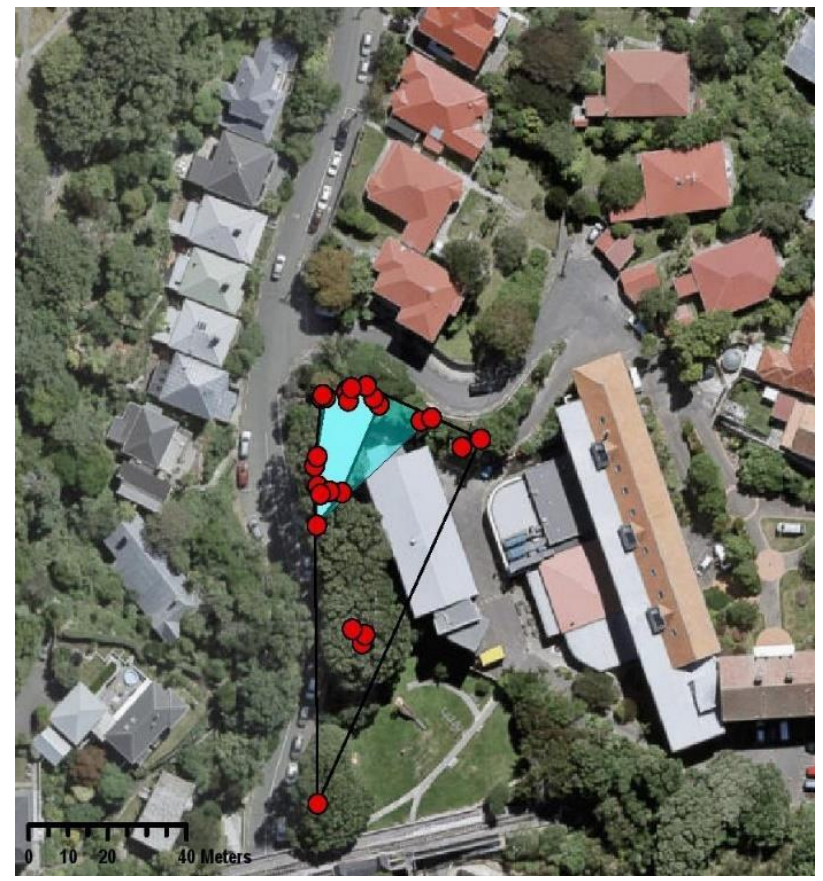

Figure 6: Kelburn study site showing 100\% (black outline), 75\% (transparent blue) and 50\% (opaque blue) MCPs for a male ship rat, subject 33, number of fixes $=27$ over a period of 36 days. 


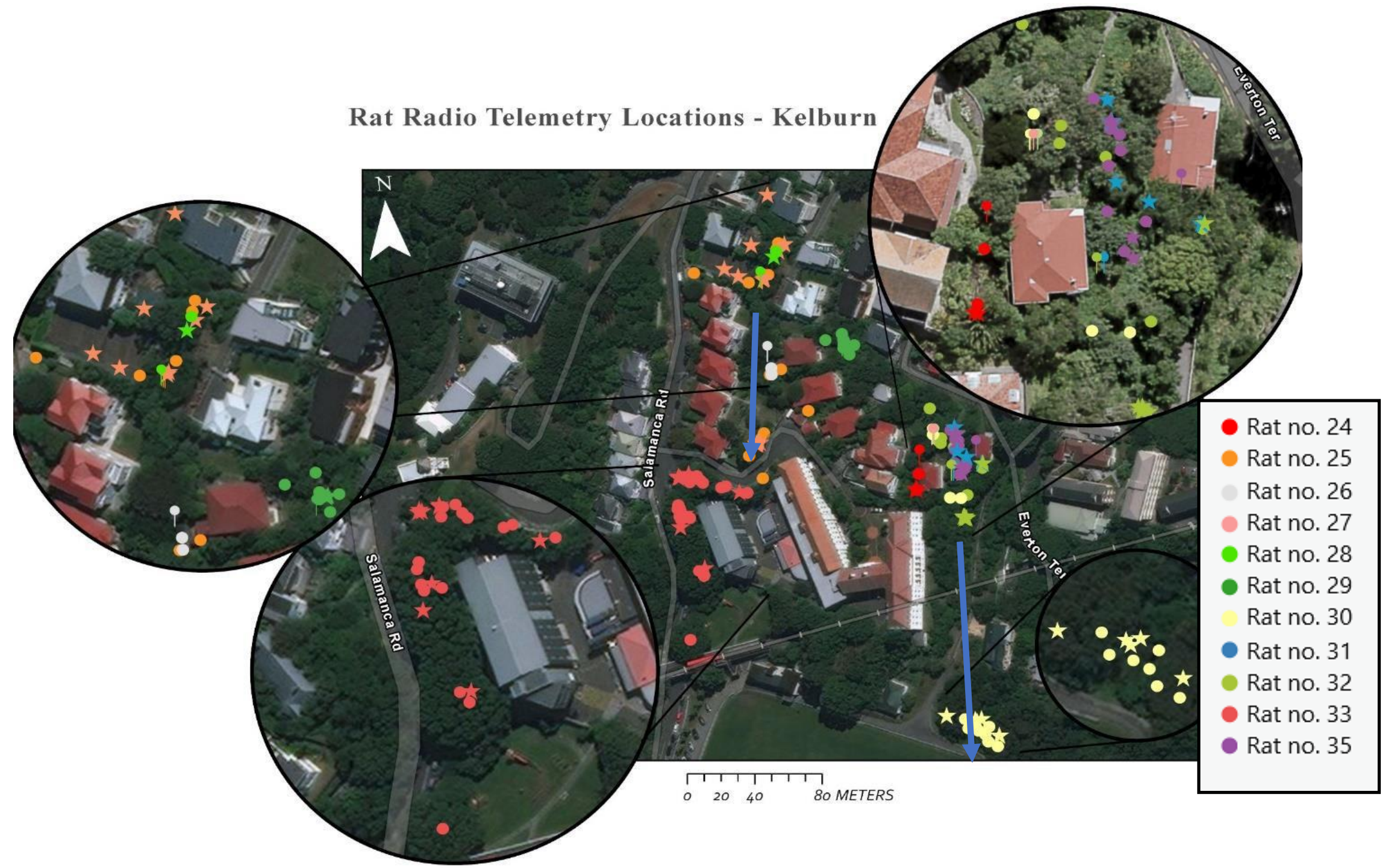

Figure 8: Rat Radio Telemetry Locations - Kelburn. Daytime fixes - Stars; Nighttime fixes - Circles; Capture location - Pins . Blue arrows show two long distance movements $>100 \mathrm{~m}$ by rat.25 (Orange) and rat.30 (Yellow) 


\section{Rat Radio Telemetry Locations - Brooklyn}

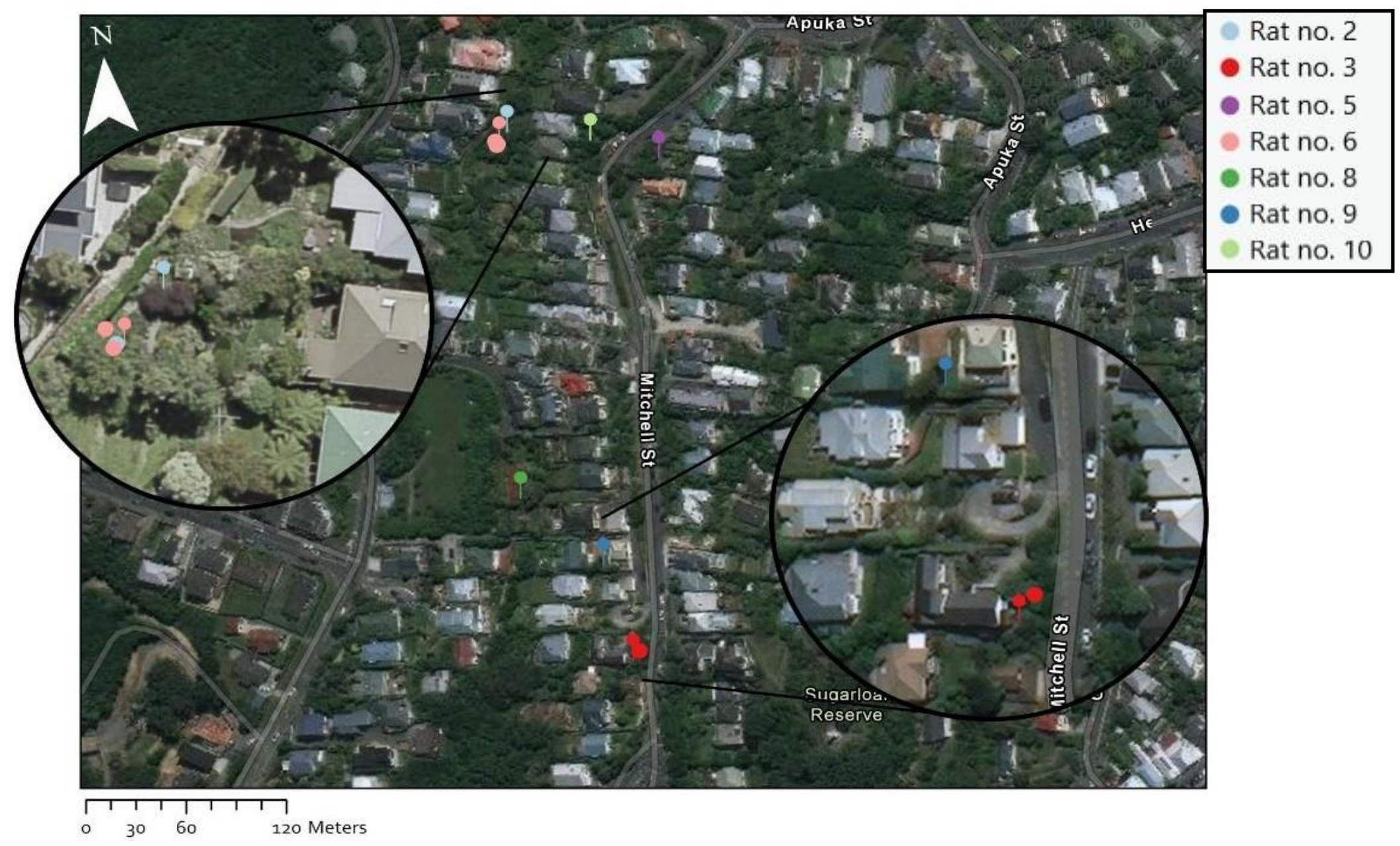

Figure 9: Rat Radio Telemetry Locations - Brooklyn. Daytime fixes - Stars; Nighttime fixes - Circles; Capture location - Pins 
Rat Radio Telemetry Locations - Roseneath

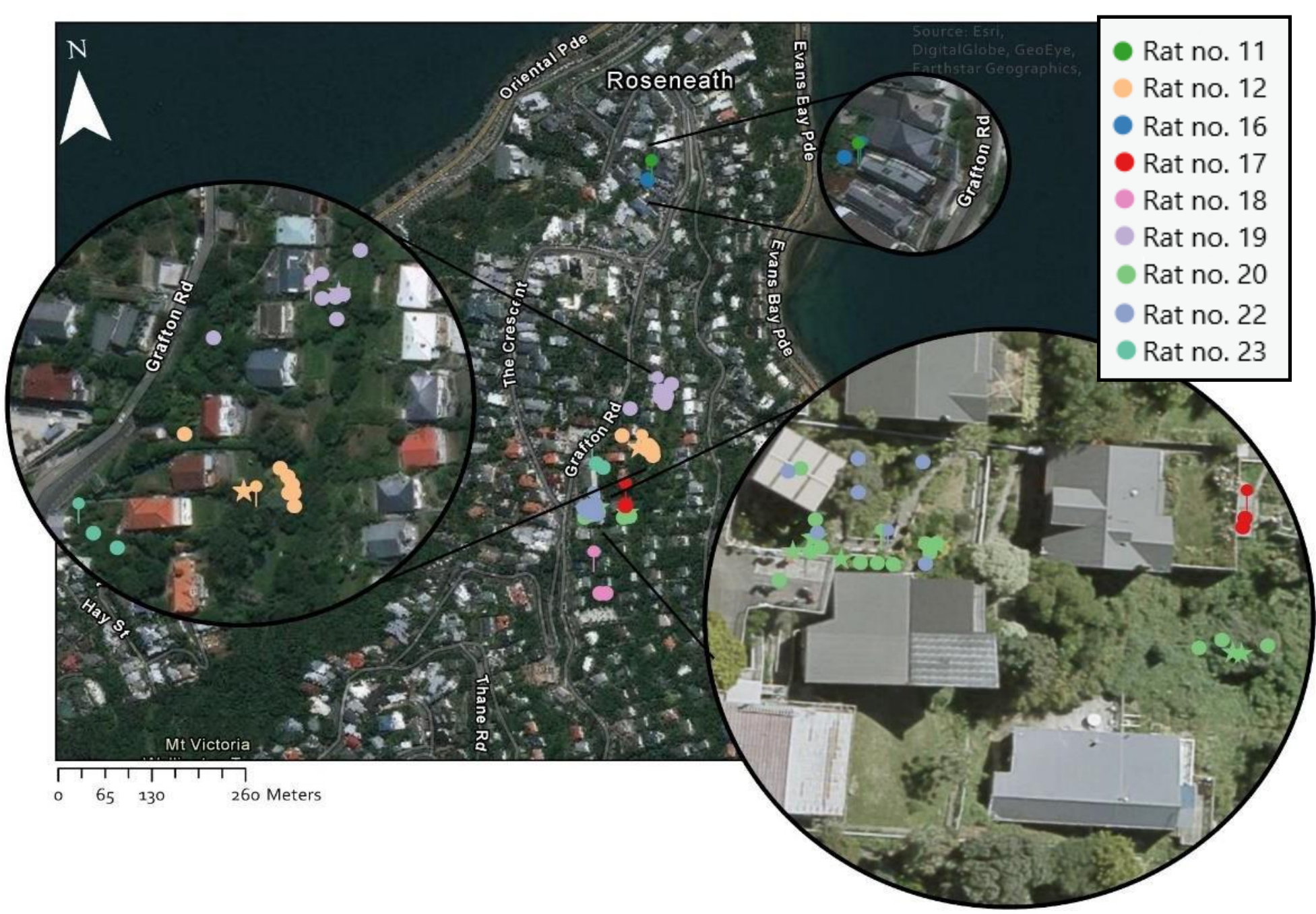

Figure 10: Rat Radio Telemetry Locations - Roseneath. Daytime fixes - Stars; Nighttime fixes - Circles; Capture location - Pins 


\subsubsection{Activity and Nesting}

All the night-time fixes, taken from the 28 collared rats, were active. Of the 58 fixes taken during the day, $32 \%$ of them were active, and of the 10 rats that were monitored for diurnal activity only the ship rat (no.29) did not display it. The average number of nest sites was calculated from rats with 10 or more fixes ( $n=10$ subjects). All but one rat had multiple nest sites and they ranged between two and five sites with a mean of 2.5 sites per rat. Den sites were all either within or on trees: Cabbage trees (Cordyline australis), an Oak tree (Quercus robur) and a dead Pohutukawa (Metrosideros excelsa) are a few examples of nesting sites found in the study. These den sites had a mean separation of $23 \mathrm{~m}$ and were quite spread out across the rat's home range. Three rats demonstrated nest-sharing with one another: rats no. $31(\mathrm{~m}), 32(\mathrm{f})$ and $35(\mathrm{f})$. No more than two individuals were recorded co-nesting at any one time, and this was documented on several occasions with both same sex and opposite sex co-nesting observed. 


\subsection{Discussion}

\subsubsection{Home Range Asymptote}

The estimated size of a home range obtained through radio tracking will increase with the number of fixes taken until an asymptote is reached, at which point a maximum estimate of home range is made (Harris et al. 1990). Harper and Rutherford (2016) estimated $~ 30$ fixes per rat were required to achieve the asymptote and this target was adopted for my study. However, by the end of the study, the target of 30 fixes was achieved for just one rat (subject 25). A threshold of 10 fixes/rat was set to calculate MCPs from: this yielded 10 individuals, with an average of 17.9 fixes/rat and a range of 10-31 fixes. A minimum of 10 fixes/rat was used as it provided this study with a decent sample size whilst also, it was reasoned, yielding reasonably accurate home range estimates due to minimal spatial autocorrelation within the dataset (discussed in the following section). However, despite this it is likely the majority of home ranges reported here are not asymptotic and will be an underestimation of home range. This is supported by the incremental area analysis shown in figure 6 where the home range of subject 25 reaches an apparent peak at 19 fixes; it is likely this peak seen at 0.45 ha for subject 25 is just a plateau and with more relocations this would be higher, although this cannot be confirmed.

\subsubsection{Spatial Autocorrelation}

Spatial autocorrelation is an issue with telemetry studies because successive fixes are not independent in space or time. Regardless of the time elapsed between movements, they will be related to each other to some degree and so autocorrelation will be present in any data set despite the method used (Fortin and Dale, 2005). Data that is autocorrelated will tend to under-estimate the true home range size, and the magnitude of the error will be related to the time between successive fixes (Swihart and Slade, 1985). This is because there is inherently less information on an animal's movements in two fixes taken sequentially quickly rather than taken a time apart. Additionally, there is a misconception that non- probabilistic methods are unaffected by this, however Swihart and Slade (1997) found that MCP home range estimates were actually more biased by autocorrelated data than by utilization distribution methods. For this reason, I took a sparse sampling 
approach, taking a maximum of one fix at nighttime and one fix at daytime, to reduce the autocorrelation in my data as much as possible. This produced fixes that were more independent of each other and therefore contain more positional information on the rats when compared with other studies that elected to take fixes in closer succession e.g. Harper and Rutherford (2016), Oyedele (2015), Nathan (2016) and Latham, 2006) and so lessening, to a degree, the effect of a small sample size.

\subsubsection{Home Range Size and Shape}

The home range sizes reported here seem comparable to those found in Recht et al. (1983) and Low et al. (2013). Recht et al.'s (1983) radio-telemetry study of ship rats in City of Orange, California calculated 100\% MCPs for five rats (with an unknown number of fixes per rat). They recorded home ranges of between 0.2 and 0.5 ha using $100 \%$ MCPs. Low et al.'s (2013) calculated 95\% MCPs for 6 individuals in urban gardens on Christmas Island for six rats with between 19 and 24 fixes per rat, recording home ranges of between ( 0.175 ha \pm 0.054 and 0.569 ha \pm 0.273 ). My study was based on 10 individuals (Table 5 ) and found a similar range of between 0.01 and 0.45 ha (median $=0.09$ ha; no. of fixes $10-31$ ). However direct comparisons between the two studies is difficult given that the number of fixes per rat differs, as in Low et al. (2013) and are an unknown parameter, as in Recht et al. (1983).

When compared to similar studies - those conducted using radio telemetry in the same season in mainland rural habitats and using MCPs (e.g.: Avg. 0.95 ha (M) and 0.79 (F) ha, 100\% MCP, Dowding and Murphy 1994; Avg. 1.52 ha (M) and 0.49 ha (F), 100\% MCP, Hooker and Innes, 1995; 9.43 ha (M) and 0.27 ha (F), 95\% MCP, Pryde et al. 2005), we found the home range to be smaller for urban rats compared to their rural cousins. This has been suggested to be the result of higher food availability in the urban environment (Glass et al. 1988; Low et al. 2013) as home range size is dependent on an animal's energy requirements and by the density of available foods (McNab, 1963). This explanation seems to be corroborated by the small home ranges found on seabird island habitats (Avg. 0.25 ha $\pm 0.27(\mathrm{M})$ and 0.06 ha \pm 0.008 (F), 0.40 ha \pm 0.044

(M) and 0.063 ha \pm 0.007 (F), Harper and Rutherford, 2016; 0.29 ha \pm 0.19 (M) and 0.21 ha \pm 0.04 (F), Latham, 2006). Seabird islands have exceptionally high productivity due to the 
seabird colonies that cycle nutrients from marine to terrestrial ecosystems by the deposition of guano (Towns and Broom, 2003; Jones, 2010; Otero et al. 2018).

The evidence for male ship rats having larger home ranges than females is mixed (Harper and Rutherford, 2016; Dowding and Murphy, 1999; Low et al. 2013). Some rural studies have found significantly larger home ranges, as in Pryde et al. (2005): 9.3 ha for males ( $n=3$ ) and just 0.58 for females $(n=2)$. Other studies found no evidence of a difference (Dowding and Murphy 1999). I found no evidence for sex-biased home ranges, neither with the full data, nor when comparing rats with 15 or more fixes (male $n=4$, female $n=3$ ). Note that despite carrying out the work in winter I would still expect to observe larger male home ranges if they were present - as urban populations are known to breed year-round (1953a; Young et al. 2000). It is possible that typical mammalian demographics where males increase their home ranges size during mating season in search of mate are suspended in an urban environment. This could be due to a lack of space, or a consequence of the fragmented urban bush, with barriers to movements such as busy roads, open spaces, restricting movement (Combs et al. 2018 ; Gardner-Santana et al. 2009 ) and so preventing larger home ranges.

The shapes of urban ship rat home ranges were highly varied and irregular. Other radiotelemetry studies on urban rats have also documented this (Recht, 1982; Recht et al. 1983; Low et al. 2013; Oyedele et al. 2015). Oyedele et al. (2015) reported similarities in Norway rat home range shape amongst multiple individuals at one of their sites but not another. They proposed that certain features of the urban environment influence the shape of home ranges. This seems consistent with my findings where I observed that several home range boundaries seemed to coincide with urban barriers: these included busy roads, public walkways, concrete fences and open spaces. This is particularly well-observed in one of the rats (no. 20) where its movement appears to be restricted to a narrow pathway between a house and garden path (Figure 10). In contrast, the rats with fewer urban features within their home range were much less defined and their use of it appeared to be more even (e.g. rat no. 19 figure 10; rat no. 30, 32, figure 8). However, it is possible that the accuracy of my fixes - estimated at $1.5 \mathrm{~m}$ - might have obscured more directed movement within the home range.

This information can be used to inform pest management of their placement of monitoring 
and control devices in a number of key respects. Given the maximum linear distances found in this study $(19 m-74 m)$, the raw data would suggest that devices be placed every 15 to $20 \mathrm{~m}$ on average. However, because of the irregular and varied shape of urban home ranges, it would be inappropriate to rely on a distribution matrix of control/detection devises based solely on a broad measure of average home range area. For example, a rat colony occupying a long, thin-shaped home range would be far less likely to be trapped by a uniform, area-based grid of control devices. Once the various eradication zones have been identified, then traps should be preferentially placed in specific locations within those zones with the highest probability of rat density.

This would introduce a degree of subjectivity into the design of the overall eradication strategy, and it would require the individual surveying of each eradication zone by staff with a sound knowledge of rat behavior. However, it would make a considerable difference to overall kill/detection rates. Obvious examples of preferential setting of kill traps would be to disproportionately target areas of dense vegetation, as all rats in this study appeared to stay within the areas of bush in which they were caught.

\subsubsection{Home Range Overlap}

This study found significant overlap in home ranges between rats. Of rats with 10 or more fixes and caught in the same vicinity $(n=5)$ all had overlapping home ranges to some extent. In some cases, it was extreme, with overlaps of $90 \%$ (rat no. 35 and no. 31; figure 8). Home range overlap has been documented in other ship rat studies in both urban (Low et al. 2013) and rural habitat (Dowding and Murphy, 1994; Harper and Rutherford, 2016). However, here I did have a case where significant overlap (mean $=65 \%$ ) was observed between four individuals in Kelburn - two males and two females. Low et al. (2013), in contrast, found female ship rat home ranges to be exclusive. Dowding and Murphy (1999) suggests that the tolerance rats display within a similar/shared range could be because they are related - in their study they attribute this to co-nesting behavior. The lack of territoriality shown here could be an extension of that familiarity.

\subsubsection{Behavioral Findings}

\subsubsection{Activity}


The activity data showed that rats are primarily nocturnal, as all rats were active at all times during the night. Of the 10 rats monitored for daytime activity nine of them exhibited it. Diurnal activity has been documented in other studies for both the ship and Norway rat (Recht,1982; Low et al. 2013). However, it has not previously been shown for urban ship rats (Recht et al. 1983; Low et al. 2013). Diurnal activity could be a behavioral adaptation to a lack of food (Hut et al. 2011), where lower-status individuals are forced to risk foraging during the day to avoid intraspecific competition (Calhoun,1963). However, this would not seem consistent with our data, where 9 of 10 subjects exhibited daytime activity. An alternative explanation could be that due to a lower risk of predation in urban habitats, daytime foraging is a viable strategy and so more widely adopted. The ship rat's primary predator in New Zealand, the stoat, is believed to be absent from urban habitats or present in densities too small to detect (Daniel, 1972; Murphy \& Bradfield, 1992; Morgan et al. 2009). Their only natural predator in urban settings, present in any numbers, is the domestic cat. Whilst cats do predate ship rats they are not thought to do so in significant numbers (Davis et al. 1948; Marsh, 1994; Parsons et al. 2017). This would represent a temporal expansion in activity patterns in response to reduced predation risk: similar findings have been observed in bearded pigs in response to clouded leopard absence (Ross et al. 2013).

\subsubsection{Nesting Behavior}

This study found multiple nesting sites per individual, as well as co-nesting behavior. The number of nests per individual ranged between two and five sites with an average of 2.8 (Calculated with rats with $n>10$ fixes; Table 5). This is relatively small compared to $>10$ sites/individual found by Harper and Rutherford, 2016. This is likely due to the smaller home ranges of urban ship rats and perhaps fewer viable nest sites.

Of the nesting sites found, all were arboreal and on mature medium to large-sized exotic and native trees, for example: oak, sycamore (Acer pseudoplatanus), cabbage trees and pohutukawa trees. This may represent a nesting preference for the ship rat where larger, more stable trees are favored. Interestingly, no man-made structure was used as a nesting site. This is in contrast to findings by Fernández et al. (2007) in Buenos Aires, Argentina where buildings were used as nesting sites. This could be due to the more abundant green 
spaces in Wellington, New Zealand, and may represent a preference for 'natural' nesting sites over man-made ones.

Unlike Recht et al. (1983), this study did not find that nesting sites were arranged around the perimeter of the home range. Instead, they were well distributed throughout it. This arrangement would be more advantageous, providing quick access to safe harborage throughout the home range.

\subsubsection{Dispersal Behavior}

Rats will undertake relatively short distance dispersals primarily responding to resource availability, competition and mating behaviors (Calhoun, 1963; Glass et al. 1988). I documented long distance movements of $\sim 120 \mathrm{~m}$ by two rats (rat no. 25 and rat no.30) at the Kelburn site (Figure 8) and suggest that these were two dispersal events. These appeared to be relocations because the distance moved was uncharacteristic of home range movements observed up to that point, and that they remained in this new area for the remainder of the study -54 days and 56 days. Additionally, these movements were unusual in that they were made across urban barriers (a road and public walkway).

Although rat dispersal is known to occur, this is the first time to the author's knowledge that a dispersal event has been documented in an urban habitat for the ship rat. The only other study to attempt to measure the dispersal distance of urban ship rats was conducted by Mangombi et al. (2016) in Franceville, Gabon (Central Africa). They estimated this distance to be comparatively large at $496 \mathrm{~m}$. However, the estimate was made using population genetic methods which are thought to be highly imprecise (Bohonak, 1999). The significance of our finding is limited by the low number of observations. However, it does show that rats can move readily across the Wellington landscape and that urban barriers such as public walkways and roads can be crossed to do this.

\subsubsection{Neophobic Response}

In the data (Figure 4) there was a lag period between the time the trapping network was established and the first capture. Assuming the rats were encountering the traps in this time, the lag suggests a neophobic response. Neophobia is a behavioral response to a novel 
stimulus where the animal will choose to avoid the new situation presented to it (Clapperton, 2006). Fundamentally it is about how an animal manages risk vs reward bolder animals exhibit a lower level of neophobic response and shyer animals a higher one. Inglis et al. (1996) suggested that rats that have been subject to population control evolve a heightened neophobic response. This appeared to be the case with the Brooklyn population, which displayed a much longer lag period than the other two sites. The longer neophobic response could be due to the trapping history of Brooklyn which was more intensive and prolonged than at the other two sites. 


\section{Chapter 3. Densities and Detection Probabilities of an Urban Ship Rat Population}

\subsection{Introduction}

The conservation and management of ecological systems involves making informed decisions on what action to take in order to deliver a desired outcome. Knowing how many individuals there are within a population can be applied to many conservation endeavors: for example, in setting management objectives and evaluating the effectiveness of interventions; in creating population dynamics models, including species interactions with competitors, predators and prey; and in conducting population viability analyses - to name a few.

Abundance estimates are the metric of choice for managing invasive species (Nichols, 2014). There are two categories of abundance estimates used: relative estimates which indirectly measure abundance through an index, and true estimates that directly measure them. In rat management both kinds of abundance estimates are important, and useful for different reasons.

Making estimates of true abundance of rat population is a costly and difficult task owing to the cryptic nature of rats: they are neophobic, intelligent, highly mobile, small- bodied, and nocturnal. However, these estimates are needed to understand the population dynamics of rats and the major factors that control and regulate their growth (Aplin et al. 2003b). Knowing these has proven to be useful for pest management for example, the successful eradication campaign of the coypu (Myocastor coypus) a large semi- aquatic rodent invasive in Britain. Gosling and Baker (1989) conducted a long-term population study of coypu and found that periods of cold weather were limiting abundance by reducing breeding success and juvenile survival. This information was used to time eradication efforts when populations were low. The majority of rat population studies have been conducted at island and mainland forested locations with little attention paid to urban sites (Hooker and Innes, 1995; MacKay and Russell, 2005; Christie et al. 2015; Harper and Rutherford, 2016). As such, very little is 
known of how their population biology responds to an urban habitat (Parsons et al. 2017).

Capture/mark/re-capture (CMR) methods are the most commonly used method for estimating rat abundance today. In its most basic form, a population is randomly sampled and marked, and then, after a short interlude, the population is resampled - this is the Lincoln Petersen approach and is one of the most widely used for population estimates in wildlife ecology. By using a proportionality argument, the size of the population is then estimated from the fraction of re-caught individuals. However, this approach is flawed in that in violates the equal catchability assumption, fundamental to CMR. Rats have been shown to be less trappable on the whole once trapped previously (Inglis et al. 1996). This bias results in overestimates of abundance.

Relative abundance indices are regularly used in rat management as they are cheap, low labor, can be deployed at large scales and ultimately are fit for purpose. They do not attempt to enumerate the number of individuals within a population. Instead, they use standardized and repeatable indexing methods to give an indication of how populations change over time or space. In the past, bushcraft tracking techniques have been used, where an experienced researcher can assess the relative rat population by interpreting visual clues such as rat scat, runways, burrow holes, food marks etc. (Davis, 1953b). Today more standardized measures or indices are used, such as the amount of bait consumed, visual counts of live rats, records of trapping success and the more commonly employed chew card and wax tag surveys. These methods are frequently used by rat management to direct control methods, evaluate the efficacy of interventions and for post intervention monitoring. However, they encounter biases such as saturation at high densities allowing non-linear relationships to form (Caughley, 1977) and interference from non-target species affecting detection (Sweetapple and Nugent, 2011). They also are limited by the inherent assumption that the detection probability index remains constant over a range of variables such as habitat type, species demographics, individual personalities, time etc. (White, 2005; Michelangeli et al. 2016).

This chapter has two component studies that were conducted under the same overarching methodology: 
Firstly, a capture mark re-sight study that aims to provide a true abundance and density estimate of a ship rat population in an urban bush fragment. This data will be used to compare with other studies conducted in island and mainland sites providing an insight into how population biology varies in an urban habitat.

Secondly, a probability study that has two aims 1) To evaluate the relative sensitivity of three devices commonly used in pest management: the chew card, the wax tag and the bait station. This data will be used to evaluate their effectiveness in pest management operations 2) To look for any age-related differences in the detection probability. This data will be used to provide insights into how age-specific behaviors can affect detection, and the implications for pest management. 


\subsection{Methods}

\subsubsection{The site}

A camera trap survey was conducted for three weeks from the middle of February until early March 2020. Within the broader Kelburn site, a 0.63 ha urban fragment was chosen as the area for this study as it was clearly delimited: bordered by Salamanca Road, Gladstone Terrace and the Weir House residence (Figure 11). The vegetation was mostly native species. Large pohutukawa trees providing a canopy over most of the site. An understory was present, with natives like kawakawa (Piper excelsum), taupata (Coprostnu repens) and juvenile lancewood (Pseudopanax crassifolius). Open spaces beneath the canopy were present where a ground cover of wandering willie (Tradescantia fluminensis) dominated. A fair amount of litter was scattered throughout the site, especially at the border of Salamanca Road. These included things like soda cans, plastic bags, beer bottles etc. There had been no comprehensive pest management done on the site, although the

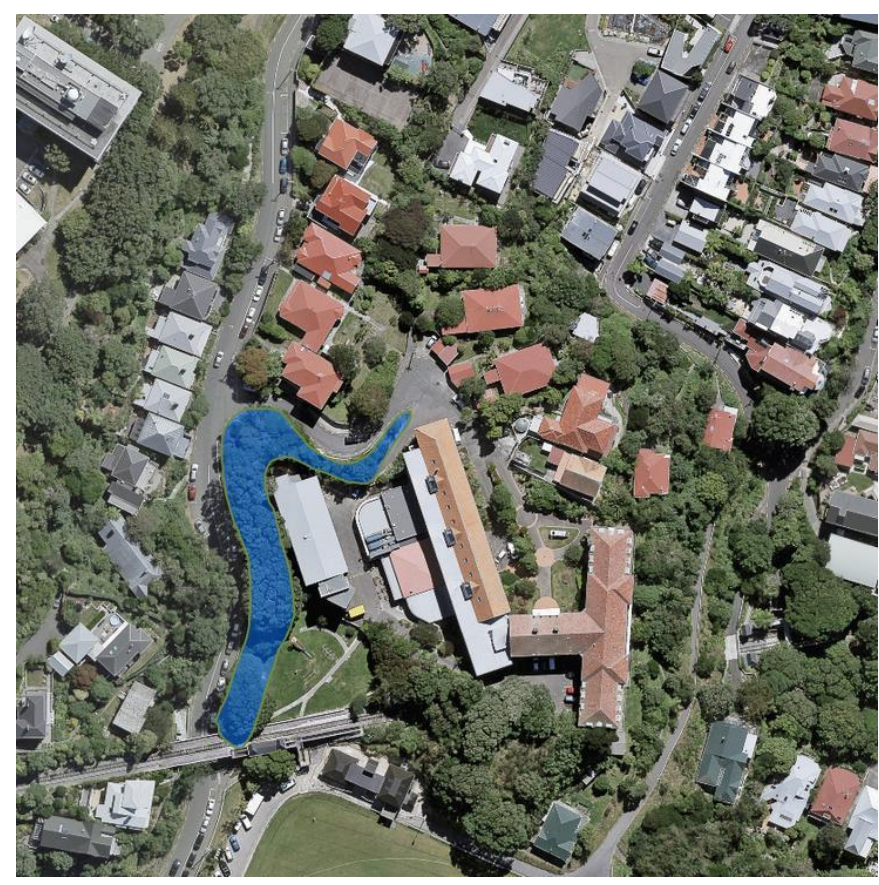

Figure 11: Density and detection probability study site (Blue polygon, 0.63 ha) within the Kelburn site.

occasional inactive DOC 200 was encountered. These had not been maintained for at least two years, according to the university. However, the Wellington Botanic Gardens, that border the other side of Salamanca Road do have an active pest management plan. They 
take an integrated approach that 'combines cultural, biological and chemical methods of control' with DOC 200s actively maintained throughout the gardens (Wellington City management plans). Additionally, some residencies along Salamanca Road were actively trapping although no census was done.

\subsubsection{Camera Trap Set-up}

A total of 13 camera traps (Aggressor Model 119777, Bushnell, Overland Park, Kansas, USA) were used to establish a grid covering the entire site. The cameras were set-up with approximately $10 \mathrm{~m}$ spacing between them. This spacing was used to ensure every rat in the area could be detected i.e. the spacing was smaller than their minimum home range (values taken from the VHF study, Chapter 2).

To standardize the camera's field of view they were placed at a height of $0.5 \mathrm{~m}$ - the field site provided plenty of suitable trees for this, however when none presented, a wooden stake was used. Each camera was then tilted downwards by 20 degrees pointing at an area $1.5 \mathrm{~m}$ in front, following Anton et al. (2018). The cameras were set to record video with the settings shown in table 6 . All obstructing elements such as low branches were removed to provide a good field of view, reduce false triggers, and save battery life. Each camera was paired with a bait in the form of a detection device: either a wax tag, chew card or bait station. This served the dual purpose of comparing detection probabilities of different devices and a capture mark re-sight study for estimating the density of rats in the site. A previous attempt to estimate rat density was made in Kelburn using a capture mark re-sight approach, with no kind of lure used with the cameras, but it produced too few sightings to allow abundance estimates to be made (See Appendix 2, Table 13).

\section{Table 6: Camera trap settings}

\begin{tabular}{|c|c|}
\hline Camera Type & Bushnell - Trophy Cam Aggressors \\
\hline Model Number & 119777 \\
\hline Capture mode & Video \\
\hline Delay & $1 \mathrm{~s}$ \\
\hline Duration & $20 \mathrm{~s}$ \\
\hline LED control & Low \\
\hline Sensor level & Auto \\
\hline Time stamp & On \\
\hline
\end{tabular}




\subsubsection{Live Captures and Markings}

A total of 15 live capture cage-traps were set up across the site. The methods of capturing and anesthetizing the rats were as stated in the methods of chapter two. To mark the rats, a variation of Calhoun's (1962) method was used. The method works by creating uniquely identifiable patterns on the subject's fur by dividing the rat's dorsum into sections (Figure

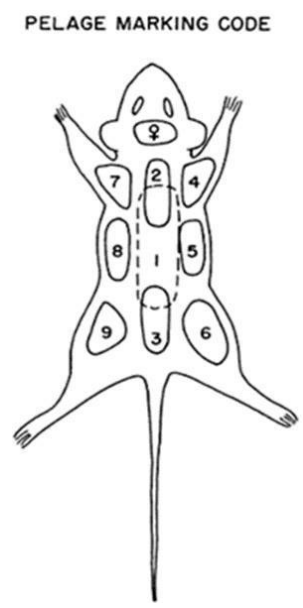

Figure 12: Showing Calhoun's pelage marking code. Source: Calhoun (1962)

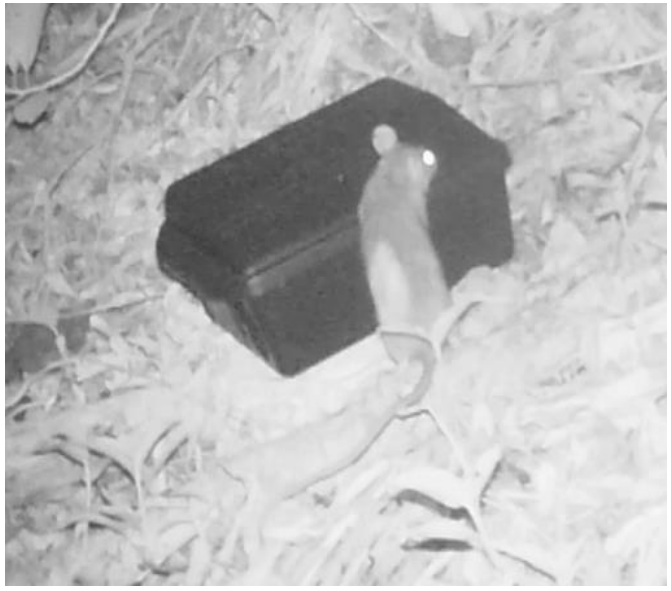

Figure 13: Rat no.5 with bleached mark on bottom left of dorsum, investigating a bait station 
7): I used six sections for my rats, starting from the left shoulder going clockwise. These patterns can be read as a number, for example, if the first and third section was marked this would identify the rat as number 13 . To mark the rats, a permanent blonde hair dye was applied, in this case Loreal Quick Blue Powder Bleach Extra Strength.

\subsubsection{Capture, Mark, Re-sight - Lincoln Petersen}

A Lincoln Petersen (LP) analysis with a capture mark re-sight approach was used to estimate the abundance of rats at the site. Data from two of the possible three weeks was sampled for this to maintain the closed population assumption as far as possible. An unbiased LP was calculated (see equation below) from the data on account of the studies' small marked sample size as there is a tendency to overestimate the actual population using a bias LP (Seber 1982). Binomial confidence intervals (95\%) were calculated based on the ratio of the number of re-captured rats to total sighted in my data, as per Seber (1982).

$\hat{\mathrm{N}}=$ True abundance estimate

$$
\mathrm{N}=\frac{(M-1)(S-1)}{(R-1)}
$$

$M=$ Number of marked animals

$\mathrm{S}=$ Number of re-sampled animals

$\mathrm{R}=$ Number of marked animals re-captured

For the LP's proportionality argument to work, the number of marked individuals re-sighted relative to the total number of all individuals sighted in the re-captured period must be known. For a capture mark re-sight approach this usually requires that all individuals within the population must be visually and uniquely identifiable. This posed an issue as not all rats possess inherent unique identifiers. To overcome this limitation, two LP estimates were made, each with a different approach to sampling the data and each with its own assumptions. These were a low estimate designed to make a minimum density estimate from the data and a high estimate designed to make a maximum density estimate. 


\subsubsection{Conservative (low) estimate}

To make the low estimate I conservatively assumed each unmarked rat to be the same individual provided it could not be distinguished by either a bleach mark or some other unique characteristic. I was also able to accurately distinguish between five different size classes of rat: large adult, adult, sub-adult, juvenile and weaned. In this way five more 'individuals' could be identified. Additionally, if two rats of the same size class were seen on two separate cameras and at the same time or separated by an interval too short for them to be the same rat, they were taken as two individuals. A list of the identifiable rats present in the study site are shown in table 8.

\subsubsection{Liberal (high) estimate}

To make a high estimate I assumed that every unmarked rat sighted was a separate individual, provided that the rats could not be identified as being the same individual by other unique characteristics.

\subsubsection{Detection Probabilities}

The three devices used in this study were standard chew cards, peanut butter-infused wax tags and bait stations (Bell laboratories, Inc, WI USA, Model: PROTECTA Sidekick) as used by Predator Free Wellington for monitoring and eradication in the Miramar peninsula. Both the wax tag and chew cards were baited with peanut butter and a non-toxic cereal bait pellet used for the bait stations. Thirteen devices (four wax tags, four bait stations and five chew cards) were distributed evenly over the site and mixed so that no two adjacent cameras were trained on the same type of detection device. This was done to ensure all devices would be present within a home range (estimated from my radio-telemetry study minimum home range value of $0.01 \mathrm{ha}$ ) and so exposing all rats to each device. Small quantities of cereal bait were used so as not to satiate any rat and in so doing affect the attractiveness of adjacent devices. Additionally, after baiting the stations their weight was then recorded to confirm whether bait was subsequently taken, this process was repeated each evening. After a three-week period, the camera traps were collected, and all cameras still had live batteries at the time of collection. 
The images were processed by classifying each event within the footage as either a sighting, an encounter or interaction. A single event was defined as a continuous stream of footage capturing a rat with a maximum break in the videoing of 30 seconds. A sighting was defined as any event where an animal could be identified as being present. An encounter with a device was defined as a sighting where the rat came within a $1 \mathrm{~m}$-by-1m square perimeter of the device - this was demarcated using black pegs. An interaction was defined as any encounter that produced a detection: for the bait station this was taken as a rat entering the device, for wax tags and chew cards this implied chewing behavior on the device. This data was recorded for all identifiable rats listed in table 8 and the detection probability calculated as the proportion of sightings that ended in an interaction. Detection probabilities were calculated in two ways: firstly, averaged across the entire three-week study according to the age category of the rat: adolescent rats, made up of juvenile and weaned rats; and adult rats, made up of sub-adult and adult rats (Table 11) (Martin et al. 2001); and secondly averaged within each period (Table 12a and 12b). 


\subsection{Results}

\subsubsection{Lincoln Petersen Estimate}

A total of five individuals were caught and marked with a trapping effort of 105 trap nights (7 nights and 15 live capture cage traps). During the re-sampling period, which lasted two weeks, four of the five marked rats were re-sighted and between eight and sixteen additional individuals depending on whether the conservative or liberal assumptions were made concerning identity. A total of 12 re-sights were made using the minimum sampling approach and a total of 20 were made using the maximum sampling approach. The two LP density estimates are 14.6 and 25.5 individuals active within the 0.63 ha urban forest fragment (Table 7). By multiplying the $\hat{N}$ estimates by $1 / 0.63$, these scale up to a conservative density estimate of 23.2 rats/ha (12.2-88.25) and a liberal estimate of 40.5 rats/ha (18.41-139.2) within an urban bush fragment.

Table 7: Breakdown of the camera trap data collected over the first two weeks ( $n=14$ nights and 10 functioning cameras), with the results of the Lincoln Petersen density estimates.

\begin{tabular}{|c|c|c|c|c|c|c|c|}
\hline $\begin{array}{c}\text { Total } \\
\text { Footage } \\
\text { (minutes) }\end{array}$ & $\begin{array}{l}\text { No. of } \\
\text { marked } \\
\text { rats (M) }\end{array}$ & $\begin{array}{c}\text { Total no. of } \\
\text { sightings } \\
\text { (events) }\end{array}$ & $\begin{array}{c}\text { No. of } \\
\text { marked } \\
\text { rats } \\
\text { resighted } \\
\text { (R) }\end{array}$ & $\begin{array}{l}\text { Minimum } \\
\text { number of } \\
\text { individuals } \\
\text { sighted, (S) }\end{array}$ & $\begin{array}{c}\text { Low } \\
\text { Lincoln } \\
\text { Petersen - } \\
\hat{N}(95 \% \mathrm{Cl})\end{array}$ & $\begin{array}{l}\text { Maximum } \\
\text { number of } \\
\text { individuals } \\
\text { sighted, (S) }\end{array}$ & $\begin{array}{c}\text { High Lincoln } \\
\text { Petersen - } \hat{N} \\
(95 \% \mathrm{Cl})\end{array}$ \\
\hline 150 & 5 & 101 & $4(80 \%)$ & 12 & $\begin{array}{c}14.6(7.69- \\
55.6)\end{array}$ & 20 & $\begin{array}{c}25.2(11.6- \\
87.7)\end{array}$ \\
\hline
\end{tabular}

\subsubsection{Camera Trapping}

There was a total of 160 minutes of camera trap footage recorded during the three-week sampling period and a total of 125 sightings were made. Three cameras failed to gather any data and were classified as non-functional. The cause of this failure was not found but suspected to be due to a faulty camera unit rather than SD card. The cameras that failed 
were number 1 (chew card), 5 (wax tag) and 8 (chew card). Four other cameras recorded zero sightings through no obvious fault - these were numbers 2, 3, 6 and 12 (Figure 14). This left a total of six cameras which gathered positive data on two wax tags, two chew cards and two bait stations

Other species captured on camera included cats, blackbirds and house mice. Neither hedgehogs nor Norway rats were recorded on camera. However, hedgehogs were regularly caught in the live capture cage traps (on 20 occasions and at least four individuals), at the northern half of the site.

\subsubsection{Rat Activity}

Rat activity peaked about an hour after sunset ( 20:00) with a total of 35 sightings between 21:00 and 22:00. This was followed by a sharp decline in activity and a relative lull between the hours of 22:00 and 00:00. Another peak in activity (20 sightings) was reached at between 00:00 and 01:00 followed by a gradual decline finishing with two sightings in the hour between 06:00 and 07:00. The total number of cat sightings was 12 and made up of an estimated four individuals. Cats had a low-level activity between 19:00 and 2:00, then decreasing to zero until 06:00 when the sightings peaked at four (Figure 15). No correlation was found between cat activity and rat activity (Spearman $r_{s}=-0.50, p=0.091$ ). Sunrise and sunset in Wellington at the start of the study were 06:45 and 20:20 (summertime) respectively. 


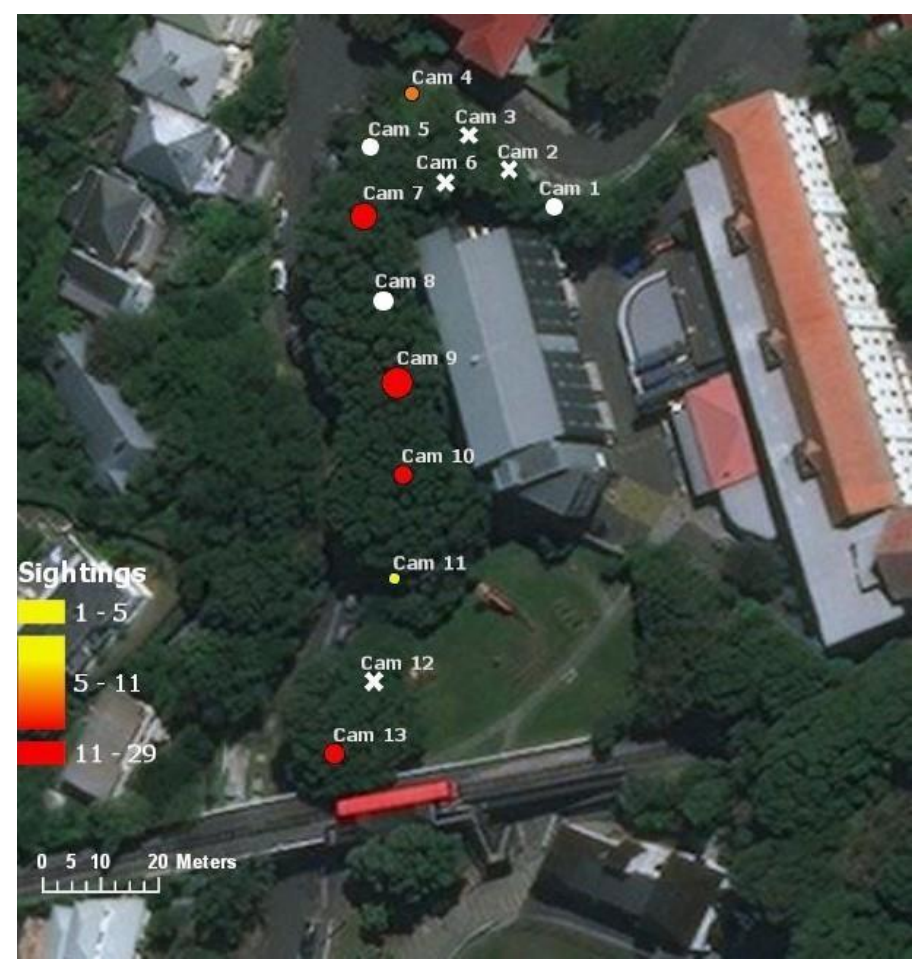

Figure 14: Map of the study site with camera traps and their activity (No. of sightings). White crosses - cameras where no data was collected; White circles-cameras that malfunctioned.

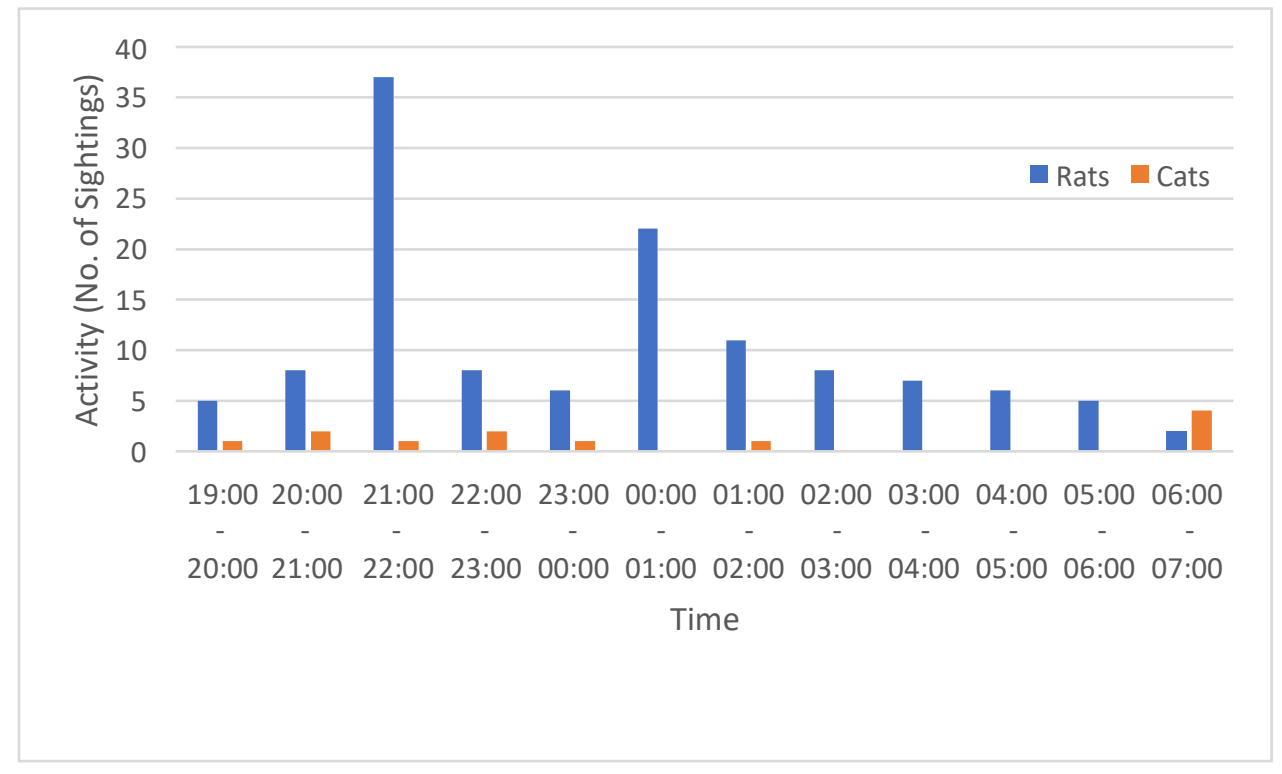

Figure 15: Camera trap activity of cats and rats at hourly intervals between 19:00 - 07:00. activity was measured as the total number of sightings across all functioning cameras $(n=10)$, over a three-week period. 


\subsubsection{Detection Probability}

A total of 12 'individual' rats were identified from the camera footage: four of them bleach marked, three of them with unique characteristics, and five by size class (Table 8). Data was retrieved from six devices (Figure 14). The breakdown of sightings encounters and interactions for the identifiable rats (bleach marked rats and rats with unique characteristics) for each device are given in table 9 , this data has been grouped into periods of three days. This was done in order to smooth the data making any trends in detection probability clearer. This was similarly done for the unidentified rats and is summarized in table 10.

The bait station had the highest detection probability, pooling both adults and adolescents, across the three-week study at 0.5 detections per sighting, followed by the wax tag at 0.44 and then chew card at 0.37 . The wax tag recorded detections for the duration of the study, the bait station for first 15 days and the chew card for first 12 days (Table 9 and 10). All three devices recorded lower detection probabilities for adult rats than adolescent rats (Table 12). This was particularly pronounced for bait stations where the detection probability of adolescent rats was very high (0.89) and for adults was low (0.10). 
Table 8: Shows a list of identifiable rats. These are divided into: marked - rats that were live-caught and dyed with a unique mark; Unique - rats that had uniquely identifiable features; and Unidentified

- rats not uniquely marked or identifiable but differentiated on size.

\begin{tabular}{|c|c|c|c|c|c|}
\hline & ID & Identifier & Age Group & Sex & Weight \\
\hline \multirow{5}{*}{ 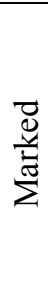 } & Rat 1 & Radio collar & Adult & Male & $145 \mathrm{~g}$ \\
\hline & Rat 2 & Dyed: 9 & Adult & Female & $150 \mathrm{~g}$ \\
\hline & Rat 3 & Dyed: 6 & Adult & Female & $140 \mathrm{~g}$ \\
\hline & Rat 4* & Dyed: 5 & Adult & Male & $170 \mathrm{~g}$ \\
\hline & Rat 5 & Dyed: 7 & Adult & Female & $160 \mathrm{~g}$ \\
\hline \multirow{3}{*}{$\stackrel{\mathscr{g}}{\widetilde{\sigma}}$} & Rat 6 & Crooked tail & Sub-adult & N/A & N/A \\
\hline & Rat 7 & $\begin{array}{l}\text { Docked tail }+ \\
\text { wound at mid } \\
\text { tail }\end{array}$ & Sub-adult & N/A & N/A \\
\hline & Rat 8 & Split right ear & Juvenile & N/A & N/A \\
\hline \multirow{5}{*}{ 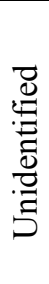 } & Rat/s 9 & None & Weaned & N/A & N/A \\
\hline & Rat/s 10 & None & Juvenile & N/A & N/A \\
\hline & Rat/s 11 & None & Juvenile 2 & N/A & N/A \\
\hline & Rat/s 12 & None & Sub-adult & N/A & N/A \\
\hline & Rat/s 13 & None & Adult & N/A & N/A \\
\hline
\end{tabular}

*Rat no.4 not re-sighted after release 
Table 9: Showing the raw camera data of the identifiable rats at each period of three days; broken down into sightings (S), encounters (E) and interactions (I). The left most column shows the list of uniquely identified rats, according to table 5, and the device they presented at. Only one uniquely identifiable rat (Rat 2) out of eight presented at more than one device, and only one camera (CC2) detected more than one uniquely identifiable rat.

\begin{tabular}{|c|c|c|c|c|c|c|c|c|c|}
\hline \multicolumn{2}{|l|}{ ID } & Period 1 & Period 2 & Period 3 & Period 4 & Period 5 & Period 6 & Period 7 & Totals \\
\hline \multirow{3}{*}{$\begin{array}{l}\text { Rat 1, } \\
\text { CT4 at } \\
\text { CC } 1\end{array}$} & $S$ & 1 & & & & & & & 1 \\
\hline & $E$ & 1 & & & & & & & 1 \\
\hline & $I$ & 0 & & & & & & & 0 \\
\hline \multirow{3}{*}{$\begin{array}{l}\text { Rat } 2 \text { at } \\
\text { CC } 2\end{array}$} & $\mathrm{~S}$ & 4 & & & 1 & 3 & 3 & 1 & 12 \\
\hline & $E$ & 2 & & & 1 & 2 & 2 & 1 & 8 \\
\hline & $I$ & 0 & & & 1 & 0 & 0 & 0 & 1 \\
\hline \multirow{3}{*}{$\begin{array}{l}\text { Rat } 2 \text { at } \\
\text { BS } 1\end{array}$} & $S$ & 4 & & 7 & 7 & & & & 18 \\
\hline & $E$ & 4 & & 7 & 6 & & & & 17 \\
\hline & $I$ & 0 & & 0 & 0 & & & & 0 \\
\hline \multirow{3}{*}{$\begin{array}{l}\text { Rat } 3 \text { at } \\
\text { WT } 1\end{array}$} & $S$ & 2 & 3 & 15 & 12 & 3 & 5 & 7 & 47 \\
\hline & $E$ & 1 & 3 & 6 & 7 & 1 & 3 & 5 & 26 \\
\hline & $I$ & 1 & 1 & 2 & 3 & 1 & 1 & 1 & 10 \\
\hline \multirow{3}{*}{$\begin{array}{l}\text { Rat } 4- \\
\text { Not seen }\end{array}$} & $S$ & & & & & & & & \\
\hline & $E$ & & & & & & & & \\
\hline & I & & & & & & & & \\
\hline \multirow{3}{*}{$\begin{array}{l}\text { Rat } 5 \text { at } \\
\text { BS } 2\end{array}$} & $\mathrm{~S}$ & 6 & & 1 & & & & & 7 \\
\hline & $E$ & 6 & & 0 & & & & & 6 \\
\hline & I & 2 & & 0 & & & & & 2 \\
\hline \multirow{3}{*}{$\begin{array}{l}\text { Rat } 6 \text { at } \\
\text { WT } 1\end{array}$} & $\mathrm{~S}$ & & & & & 1 & & & 1 \\
\hline & $E$ & & & & & 1 & & & 1 \\
\hline & $I$ & & & & & 0 & & & 0 \\
\hline \multirow{3}{*}{$\begin{array}{l}\text { Rat } 7 \text { at } \\
\text { WT } 2\end{array}$} & $S$ & & & & & 1 & & & 1 \\
\hline & $E$ & & & & & 0 & & & 0 \\
\hline & I & & & & & 0 & & & 0 \\
\hline \multirow{3}{*}{$\begin{array}{l}\text { Rat } 8 \text { at } \\
\text { CC } 2\end{array}$} & $S$ & & 2 & 2 & 2 & & & & 6 \\
\hline & $E$ & & 1 & 1 & 0 & & & & 2 \\
\hline & $I$ & & 1 & 1 & 0 & & & & 2 \\
\hline
\end{tabular}


Table 10: Raw data of the unidentified rats, for each three-day period of the study. With sightings (S), encounters (E) and interactions (I) for each device type: wax tag (W), chew card (C) and bait station (B).

\begin{tabular}{|c|c|c|c|c|c|c|c|c|c|c|c|c|c|c|c|c|c|c|c|c|c|c|c|c|c|}
\hline \multirow{2}{*}{\multicolumn{2}{|c|}{ ID }} & \multicolumn{3}{|c|}{ Period 1} & \multicolumn{3}{|c|}{ Period 2} & \multicolumn{3}{|c|}{ Period 3} & \multicolumn{3}{|c|}{ Period 4} & \multicolumn{3}{|c|}{ Period 5} & \multicolumn{3}{|c|}{ Period 6} & \multicolumn{3}{|c|}{ Period 7} & \multicolumn{3}{|c|}{ Total } \\
\hline & & W & C & B & W & $\mathrm{C}$ & B & W & $\mathrm{C}$ & B & W & $\mathrm{C}$ & B & W & C & B & W & $\mathrm{C}$ & B & W & C & B & $\mathbf{W}$ & C & B \\
\hline \multirow{3}{*}{$\begin{array}{l}\text { Rat/s } \\
9\end{array}$} & $S$ & & 1 & & & 9 & & 2 & 2 & & & 2 & & & & & & & & & & & 2 & 14 & \\
\hline & $E$ & & 1 & & & 8 & & 1 & 1 & & & 0 & & & & & & & & & & & 1 & 10 & \\
\hline & I & & 1 & & & 5 & & 1 & 1 & & & 0 & & & & & & & & & & & 1 & 7 & \\
\hline \multirow{3}{*}{$\begin{array}{l}\text { Rat/s } \\
10\end{array}$} & S & & & & & & & & & 5 & & & 1 & & & 2 & & & & 1 & & & 1 & & 8 \\
\hline & $E$ & & & & & & & & & 5 & & & 1 & & & 2 & & & & 1 & & & 1 & & 8 \\
\hline & I & & & & & & & & & 4 & & & 1 & & & 2 & & & & 1 & & & 1 & & 7 \\
\hline \multirow{3}{*}{$\begin{array}{l}\text { Rat/s } \\
11\end{array}$} & S & & & & & & & & & & & & 1 & & & & & & & & & & & & 1 \\
\hline & $E$ & & & & & & & & & & & & 1 & & & & & & & & & & & & 1 \\
\hline & I & & & & & & & & & & & & 1 & & & & & & & & & & & & 1 \\
\hline \multirow{3}{*}{$\begin{array}{l}\text { Rat/s } \\
12\end{array}$} & $S$ & & & & & & 4 & & & & 1 & & & & & & & & & & & & 1 & & 4 \\
\hline & $E$ & & & & & & 1 & & & & 0 & & & & & & & & & & & & 0 & & 1 \\
\hline & I & & & & & & 1 & & & & 0 & & & & & & & & & & & & 0 & & 1 \\
\hline \multirow{3}{*}{$\begin{array}{l}\text { Rat/s } \\
13\end{array}$} & S & & & & & & & & & & & & & 1 & & & & & & & & & 1 & & \\
\hline & $E$ & & & & & & & & & & & & & 1 & & & & & & & & & 1 & & \\
\hline & 1 & & & & & & & & & & & & & 1 & & & & & & & & & 1 & & \\
\hline
\end{tabular}


Table 11: Number of interactions per sighting averaged across the three-week study according to age category for each device type. Adolescent rats being made up of juveniles and weaned rats, and adult rats made up of sub-adult and adult rats.

\begin{tabular}{|c|c|c|c|c|c|c|c|c|c|c|c|c|}
\hline Age category & \multicolumn{4}{|c|}{ Number of Sightings } & \multicolumn{3}{|c|}{$\begin{array}{c}\text { Number of } \\
\text { Encounters }\end{array}$} & \multicolumn{3}{c|}{$\begin{array}{c}\text { Number of } \\
\text { Interactions }\end{array}$} & \multicolumn{3}{c|}{$\begin{array}{c}\text { Interactions per } \\
\text { Sighting }\end{array}$} \\
\hline & WT & CC & BS & WT & CC & BS & WT & CC & BS & WT & CC* & BS \\
\hline Adolescent & 3 & 20 & 9 & 2 & 12 & 9 & 2 & 9 & 8 & 0.67 & 0.45 & 0.89 \\
\hline Adult & 51 & $* 6$ & 29 & 29 & 4 & 27 & 11 & 1 & 3 & 0.22 & 0.16 & 0.10 \\
\hline
\end{tabular}

*For chew card p(det) the last three periods of sightings were excluded

Table 12a: Interactions per sighting for adult rats (sub-adults and adults) at each period of the study at each device type

\begin{tabular}{|c|c|c|c|c|c|c|c|c|c|}
\hline $\begin{array}{c}\text { Detection } \\
\text { Device }\end{array}$ & $\begin{array}{c}\text { No. of } \\
\text { sightings }\end{array}$ & $\begin{array}{c}\text { No. of } \\
\text { individuals }\end{array}$ & Period 1 & Period 2 & Period 3 & Period 4 & Period 5 & Period 6 & $\begin{array}{c}\text { Period } \\
\mathbf{7}\end{array}$ \\
\hline Wax Tag & 51 & 5 & 0.5 & 0.33 & 0.13 & 0.25 & 0.33 & 0.2 & 0.14 \\
\hline Chew Card & 13 & 2 & 0 & - & 0 & 1 & - & - & - \\
\hline $\begin{array}{c}\text { Bait } \\
\text { Station }\end{array}$ & 29 & 3 & 0.2 & 0.25 & 0 & 0 & - & - & - \\
\hline
\end{tabular}

Table 12b: Interactions per sighting for adolescent rats (juveniles and weaned) at each period of the study at each device type

\begin{tabular}{|c|c|c|c|c|c|c|c|c|c|}
\hline $\begin{array}{c}\text { Detection } \\
\text { Device }\end{array}$ & $\begin{array}{c}\text { No of } \\
\text { sightings }\end{array}$ & $\begin{array}{c}\text { Minimum } \\
\text { no. of } \\
\text { individuals }\end{array}$ & Period 1 & Period 2 & Period 3 & Period 4 & Period 5 & Period 6 & Period 7 \\
\hline Wax Tag & 3 & 2 & - & - & 0.5 & - & - & - & 1 \\
\hline Chew Card & 20 & 2 & 1.0 & 0.54 & 0.50 & 0 & - & - & - \\
\hline $\begin{array}{c}\text { Bait } \\
\text { Station }\end{array}$ & 9 & 1 & - & - & 0.75 & 1.0 & 1.0 & - & - \\
\hline
\end{tabular}




\subsection{Discussion}

\subsection{1 $\underline{\text { Sample Size }}$}

The sample size was an issue both for the detection probability study and the density estimate. Small sample sizes reduce the reliability of my findings and my ability to make inferences from the data.

Due to time constraints on this study, just five individuals were able to be marked. According to Seber (1982) to obtain a moderate degree of accuracy it is often necessary to mark $50 \%$ or more individuals from a population. Given the minimum number of re-captures I found in the sampling, this has not been achieved. It is therefore likely this will cause a degree of inaccuracy in my abundance estimate.

For the interaction probability study, the relatively few numbers of individuals used to calculate the detection probabilities will make any heterogeneity present in individual behavior more pronounced in my data, potentially biasing the probabilities reported here.

\subsubsection{Capture-mark-recapture assumptions}

The Lincoln Petersen model requires that several assumptions be met in order to make accurate estimates of abundance. In this section I discuss how these assumptions guided my approach, how well they held in my study and how that could have affected my results.

A fundamental assumption of the capture-mark-recapture framework is that the marked population is representative of the entire population in terms of recapture probability - the 'equal catchability' assumption (McClintock et al. 2009). In a capture-mark-recapture scenario this rarely holds as animals that are caught in the initial sampling are often less likely to be recaught due to a learned avoidance behavior or trap shyness. This would lead to an overestimation of the population size according to the strength of that avoidance behavior. As 
an exceptionally intelligent species rats are capable of learning from and adapting to previous experience: trap-shyness is a well-documented consequence of this (Hogarth, 1929; Taylor et al. 1974). Therefore, it is likely that this approach would have strongly violated this assumption. And this effect would be even more pronounced given the small number of marked individuals in our study. By using a different approach to my re-sampling method through a capture-markre-sight approach, this was avoided.

The Lincoln-Petersen method assumes a closed population, meaning that no births, deaths, immigrations, or emigrations occur between the initial sampling and re-sampling period. Assuming no deaths and no births is difficult to maintain given the life history traits of rats: they have both high rates of mortality and fecundity (Tobin et al. 1994; Gomez and Busch, 2007). However, if both marked and unmarked rats have an equal probability of mortality this does not bias the abundance estimate. And, if no rats were weaned during this sampling interval the size of the catchable population does not change and so neither will the estimate. The likelihood of new pups being weaned at some point within the entire sampling period of three weeks is high given their weaning period of a month (March, 1944, Watson, 1950). I attempted to mitigate this bias by sampling just two weeks of the data.

Dispersal of rats through urban areas is limited by barriers to their movement such as busy roads, steep topography, and open spaces, however it does happen (Combs et al. 2018; Kajdasci et al. 2013). In order to minimize the relative impacts of immigration and emigrations my study, I selected a site surrounded by urban barriers. These would have acted as deterrents to both immigrating and emigrating rats. Furthermore, both the Botanical Gardens and Salamanca residencies that border my site are actively suppressing rat populations through pest control, decreasing their effect as population sources, although potentially acting as neighboring sinks. Each rat, unmarked and marked must have an equal probability of detection given the sampling design. In order to ensure that every rat had a chance of being detected the spacing of cameras must be less than the smallest rat home range. From other studies and the results found here I set the distance between cameras at 10m (Recht et al. 1983; Low et al. 2013). However, rat movement is highly channelized towards areas of interest, to which they travel regularly (Recht 
1982; Recht 1983; Oyedele et al. 2015; Calhoun, 1962). This introduces the possibility that the camera grid was set-up in such a way that did not encounter these paths meaning that a portion of the population avoids detection. This is a problem if that population is biased to either marked or unmarked individuals. If it is biased to marked individuals, there will be an overestimation of abundance and vice versa. Furthermore, three of the camera traps malfunctioned gathering no data: again, if the portion of the population excluded is biased this will affect my estimate in the same way. The magnitude of these effects is impossible to know. But given the short spacings and that each camera was baited - which would attract rats from an area around the camera traps - it is likely our results will not be bias in this way.

\subsubsection{Urban Rat Densities in Wellington}

Considering the high rat densities found in this study, the minimum estimate and the lower bound of my confidence interval will be used to make the most conservative comparisons possible. The minimum best estimate value of 23.2 rats/ ha and lower confidence interval of 12.2 rats/ha are toward the upper end of density estimates when compared to studies conducted in rural New Zealand, and often elevated by an order of magnitude. When compared to similar studies (conducted in the same season, using CMR methods), mainland sites had lower density estimates (6.2 rats/ha, Hooker and Innes, 1995; 6.6 rats/ha, Brown et al. 1996; 2.0 - 2.5 rats/ha Hickson et al. 1986 (Stewart Island taken as mainland site given size $-1,746 \mathrm{~km}^{2}$ ).

Densities found here were more comparable to those found by studies ${ }^{4}$ on island habitats with seabird colonies (6.06-10.2 rat/ha, (Shapiro, 2005); 6.52-36.4 rats/ha, (Harper and Rutherford, 2016); 12-20 rats/ha, (Graig, 1977). The higher rat densities found on these islands has been explained by a marine subsidized effect (Harper and Rutherford, 2016). Seabirds act as nutrient cyclers between marine and terrestrial ecosystems depositing, nitrogen and phosphorous in the form of guano enhances primary productivity and consequently has positive knock-on effects for invertebrate and reptile populations (Otero et al. 2018; Towns and

\footnotetext{
${ }^{4}$ Note these studies are not directly comparable as the methods used were different. For example, Shapiro (2005) used capture mark-recapture which tends to overestimate abundances.
} 
Broom, 2003; Jones, 2010). This increases the food availability to rats, exaggerating population density as food availability is determinant of a habitat's carrying capacity for rats (Calhoun, 1962; Emlen et al. 1948). A similar explanation could be derived in this study, where ship rats are supplementing their diet with human refuse: this has been suggested previously by Glass et al. (1988) to explain the higher reproductive rates of urban rats. Rural ship rats are known to consume mainly insects, nuts, fruits and seeds (Yabe, 1979). However, to my knowledge little work has been done on the feeding habits of urban ship rats. Urban Norway rats are known to consume human foods and may be more anthrodependent in this respect (Guiry and Buckley, 2018). Understanding to what extent do urban ship rats take advantage of human foods and what the sources are is an interesting question with implications for pest management.

An alternative/additional explanation for the increased densities of ship rats found here, compared to mainland sites, could be due to a lack of predation in urban habitats. The stoat is the rat's main predator in New Zealand and has been shown to suppress ship rat populations by keeping them in a semi-predator pit' (Blackwell et al. 2002). However, stoats are present in very low densities in an urban environment, if at all (Daniel, 1972; Murphy \& Bradfield, 1992; Morgan et al. 2009). And, domestic cats, the only other natural predator in an urban habitat are likely to have a minimal impact on rat populations (Marsh, 1994; Glass et al. 2009; Parsons et al.2017). Without regulation by any significant sources of predator control, the urban ship rat population could maintain comparatively high densities.

These density estimates provide preliminary data on urban ship rat populations. However, densities of rats can vary drastically over a fine scale in an urban environment (Himsworth et al. 2014b). Additional research is needed that incorporates more sampling units and over a range urban habitat types in Wellington. These studies could help isolate features of the urban environment that promote high rat abundance. 


\subsubsection{Detection Probabilities}

This study had two components: to evaluate the effectiveness of three devices in their role in pest management; and to look for any age-related differences in detection probability between adolescent and adult ship rats that might be suggestive of differences in behavior.

The bait station had the highest detection probability averaged across the entire three-week study (0.5), followed by the wax tag (0.44) and then the chew card (0.3). Of the two detection devices tested in this study the wax tag performed the best with the higher averaged detection probability. Rats can avoid monitoring networks for long periods (Mackay and Russell, 2005), therefore having the most sensitive devices allows pest management to co-ordinate a response to re- invasions in a timely manner and before a population can rebound.

The bait station was active for the entire three-week study, in comparison the chew card's bait was thought to have expired after 12 days because despite the device registering many encounters no rats were interacting. A longer activity time is especially useful when monitoring rat populations with low densities meaning the devices can be left out for longer without needing to be replaced. This saves on both labor and cost and is especially beneficial when monitoring in remote locations such as islands.

The bait station had the highest averaged detection probability, however there was a stark difference in its sensitivity to adolescent (0.89) and adults (0.10). Its low sensitivity to adults is a serious flaw in its function as a kill method. The adult population represents the sexually mature proportion and so is a high priority target for pest management. Given the high fecundity of rats missing just a few can undermine the efforts of a control operation. This finding is especially relevant to urban control where bait stations are the only means of delivering poisoned bait.

However, the small sample size in this study is likely not representative of the range of 'personalities' or behaviors present within a rat population. Therefore, the detection probabilities are likely to be biased by the individuals that we sampled. A more comprehensive study, sampling a much larger rat population is needed to confirm the findings here. 
Across all three devices there was a significantly higher probability of detecting adolescent rats than adult rats (Table 12). The differences here are likely down to how each react to novel situations. Research in mice has shown that the outcome of an encounter with a novel object or situation is determined by the stress system (Macrı et al. 2002). Developmentally, the neural pathways underlying stress and anxiety do not become fully developed in rats until they reach adulthood (Choi and Kelloff, 1996; Choi et al. 1997). Similarly, juvenile mice have been shown to produce less stress hormones than adult mice when faced with a novel environment (Macrı et al. 2000)).

This reduced anxiety in novel situations make adolescent rats natural risk takers, explaining their high detection probabilities. This was seen in our camera trap footage where adult rats displayed many investigative behaviors like climbing and sniffing at devices, but often did not interact with them. Conversely the adolescent rats, upon encountering a device would often interact with it straight away (Table 5).

However, characterizing adolescents as risk takers and adults as more risk-averse is overgeneralized. Adult rats have been shown to exhibit quite individualistic behavioral responses to novel situations (Mitchell et al. 1977; Cowan 1977; Bramley et al. 2000; Dall et al. 2004). This was demonstrated in Spurr et al.'s (2007) experiments where wild caught ship rats' responses to four kinds of bait station were tested - they found a variable response between test subjects and across the four devices. I found this here as well: where rat five and three immediately interacted with a detection device as soon as they encountered it, whereas rat two encountered a device 17 times without doing so (Table 5).

In summary it appears that there is a spectrum of detectability in rat populations - from the risk-takers to the risk-averse. In general, the risk-takers are primarily made up of adolescent rats and the risk-averse are represented mainly by the adult population. There are several implications here for pest management. Firstly, adolescent sub-populations that are more easily detectable and controlled could provide misleading impressions of eradication or control success. Where comparisons of relative abundance indices indicate sharp drops in the population, it is likely this represents a clearing out of the adolescent population, whilst leaving 
less detectable sexually mature rats relatively untouched. Secondly, although a 'trap-shy' adult subpopulation is not a new concept to pest control it does require special considerations for urban eradications.

A pre-requisite to any eradication effort is ensuring exposure of the kill methods to all rats (Cromarty et al. 2002). In island and rural eradications this is less of a problem as they are commonly carried out by rodenticide bait drops. However, this approach is not viable in urban pest control due to concerns of public health repercussions or non-target effects on pets. Current, standard practice in urban habitats relies heavily on the use of bait stations alongside snap traps (commonly employed by community-based "backyard" trappers). In this scenario a proportion of elusive rats becomes problematic. If just a few rats are left, the population will quickly rebound.

Taken together, a comprehensive evaluation of a range of kill and detection methods, with large sample sizes of wild rats, is needed. This will help identify the best methods or combination of methods that can effectively target an entire population. Additionally, the false impression that a more highly detectable adolescent population could give, necessitates longer monitoring periods to ensure there is no premature transition from eradication to posteradication control methods. 


\section{$4 \quad$ Chapter 4: General Conclusion}

This research aimed to provide insights into urban rat ecology, a relatively neglected habitat type in rat research, in order to help pest management conduct more effective control and eradication strategies. There were three component studies 1) A radio-telemetry study that aimed to enumerate urban rat home range and give insights into their spatial behavior 2) A capture mark re-sight study that aimed to make density estimates within an urban bush fragment 3) A detection probability study that aimed to evaluate the relative sensitivities of three devices commonly used in pest management: bait station, chew card and wax tag and to compare the detection probabilities of adolescent and adult rats.

The radio-telemetry study revealed urban ship rats had home ranges of between 0.1 and 0.45 ha. This is significantly lower than comparable studies conducted in rural areas (e.g. 0.95 ha (M), 0.79 ha (F), Dowding and Murphy, 1994; 1.52 ha (M), 0.49 ha (F), Hooker and Innes, 1995). It is possible these smaller home ranges are because rats are subsidizing their diet with human derived foods. Home range size is dependent on an animal's energy requirements and by the density of available foods (McNab, 1963). Therefore, if the urban habitat is more 'productive' it could explain the smaller home range size. Furthermore, the densities found in my capture mark re-sight study seem to corroborate this as a highly productive site. I found high densities of ship rats at 22.4 rats/ ha (12.2-88.25) within an urban bush fragment. These values are significantly higher than densities recorded at other mainland sites (6.2 - 6.7 rats/ha, Brown et al. 1996; Hooker and Innes, 1995). And are more comparable to densities found on seabird islands (6.5236.4 rats/ha, Harper and Rutherford, 2016; 6.73-36.4 rats/ha, Latham, 2006).

Seabird islands have higher primary productivity due to marine inputs, which allows greater densities of rats (Harper and Rutherford, 2016; Harper, 2007). However, throughout the radio telemetry study I found no evidence of any interaction with human food sources and no obvious sources presented during fieldwork. A study investigating what proportion of natural versus human-derived foods make up an urban rats' diet and what these human sources are would clarify this. The home ranges found here represents an important addition to a under 
researched area and have implications for pest management. Based on my findings I have recommended that control and detection devices are set at between $15 \mathrm{~m}$ and $20 \mathrm{~m}$ spacings and that areas with vegetation cover are targeted as rats were never tracked to open areas. However, due to the small sample size established and the relatively few fixes per rat these home ranges could be underestimated. The lack of sample size in both the telemetry and abundance/detection probability study was primarily due to: time constraints that came about due to delays in the initial fieldwork start date which meant trapping did not start until mid-July, five months into my thesis; time lost on other studies that ultimately did not work, such as a CMR study using camera traps at the Brooklyn site which gathered too few sightings; and the inefficiency of radio tracking rats in an urban environment where a large proportion of rats went missing before I could get significant number of fixes on them. Additional studies that address the issues of sample size here are required to confirm these findings.

Additional behavioral findings from the radio-telemetry study include a high proportion of urban ship rats exhibiting diurnal activity patterns. This has been found in rural ship rats, but not as consistently amongst subjects as found here (Whisson et al. 2007; Low et al. 2013). Diurnal activity of rats has been proposed as a foraging strategy adapted by lower status individuals to avoid competition from more dominant conspecifics (Calhoun, 1962). However, this does not seem consistent with my findings where most subjects exhibited this behavior. I suggest this could be a more commonly adopted strategy made in the absence of any significant predator within the urban ecosystem. Mustelids, the rat's main predator in New Zealand, are present in very low densities in an urban environment, if at all (Daniel, 1972; Murphy \& Bradfield, 1992; Morgan et al. 2009). Furthermore, domestic cats have been shown to have a minimal impact on rat populations, killing relatively few urban rats and selecting primarily juveniles, leaving the reproductive adult population largely alone (Marsh, 1994; Glass et al. 2009; Parsons et al. 2017). This would represent a temporal expansion in activity patterns in response to reduced predation risk: similar findings have been observed in bearded pigs in response to the absence of clouded leopards (Ross et al. 2013). However, additional sample sites that include a range of cat densities would be needed to verify these findings.

Wax tags were found to be the more effective of the two monitoring devices. Wax tags had a 
higher sensitivity at 0.45 (detections per sighting) to rat presence compared to the chew card (0.3). It remained active for longer, registering detections throughout the three-week study compared to the chew card that expired after two-weeks. This aspect is valuable for pest management where remote locations are being monitored, a longer lifetime reducing labor and costs. The higher sensitivity also makes the device more suitable for monitoring low densities of rat's post control or as an early detection method for re-invasions. The bait station - a closed structure tamper resistant station - had the highest detection probability (0.505), however its ability to 'detect' adult rats was extremely low (0.10), compared to juveniles (0.89). This is an issue for pest control operations where targeting the sexually mature rats is vital given their fecundity. For urban operations this is more problematic as their means of delivering poisoned bait are limited to bait station delivery due to public health and safety concerns. The detection study also found a considerable difference in the proportions of detections per sighting, when averaged across the three devices, between adolescent and adult rats: where adolescents were highly detectable (avg.=0.73) and adults were far less so (avg.0.22). This is likely the result of a more pronounced neophobic response in adult rats than adolescents; a result of the development of the stress system which dictates how rats react to new situations (Choi and Kelloff, 1996; Choi et al. 1997; Macri et al. 2002). Taken together I suggest that a comprehensive detection study, with larger sample sizes, is carried out comparing the efficacy of alternative kill and control methods for both age classes of rat, so that the best ones or combinations can be put forward.

In summary, urban rats appear to have small, irregular-shaped home ranges, with high population densities. Further work to understand their key food resources, the dispersal of juveniles and detection rates with traps and predators would improve efforts to manage these pests down to very low densities. In aiming for total eradication, appreciating the variations in individual behavior and the extremes in home range size, and what characteristics constitute effective barriers to dispersal will be even more important than understanding population averages. 


\section{Appendix 1: Evaluating GPS Tags as a Tool for Rat Monitoring in an Urban Environment: A Case Study in Wellington}

\section{Context}

Wellington is the first of New Zealand's cities to undergo predator eradication as part of the Predator Free 2050 effort. This eradication is being led by Predator Free Wellington (PFW): operating in association with Wellington City Council, Wellington Greater Regional Council and NEXT Foundation; and aims to eradicate all mustelids, possums and rats from an area stretching from the Miramar peninsular up and along the SH1 motorway to the Porirua city boundary. Whilst we were conducting our research PFW was well underway with phase I: the eradication of all predators from the Miramar Peninsular.

An obstacle the PFW operation faces is knowing when it can safely progress into successive phases. Manaaki Whenua - Landcare Research has been providing research support for the PFW effort and are attempting to formulate proof of freedom models for this purpose. These models will be used to confirm the success or failure of eradication phases for urban ship rats and greenlight the operations progression into the next phase. However, these models first need parametrizing with $\mathrm{G}_{0}$ - nightly detection probability of an individual with a device at the center of its home range, and Sigma values - the scale parameter of the home range size (Ball et al. 2005). To do this Landcare are proposing to carry out a large-scale operation - The $2020 \mathrm{~g} 0 /$ sigma project - using GPS technology to collect spatial data. My work, and the purpose of my Predator Free 2050 Ltd grant, was to conduct a pilot study for this project in order to assess the efficacy of GPS tags for the 2020 g0/sigma project. The grant was used to purchase:

1. $5 \times$ Pinpoint GPS and VHF 120 units (Lotek, Havelock North, New Zealand https://www.lotek.com/wp-content/uploads/2017/10/PinPoint-GPS-Spec-Sheet.pdf)

2. $1 \times$ Pinpoint commander - Allows remote download of GPS data in the field

3. $1 \times$ Connector cable - Connects to units allowing them to be programmed 


\section{Method}

Study Site: Field work was conducted in Wellington, New Zealand, at University Halls in the suburb of Kelburn (Figure 1).

Image 1: Showing the study site. Blue shaded polygon showing study area.

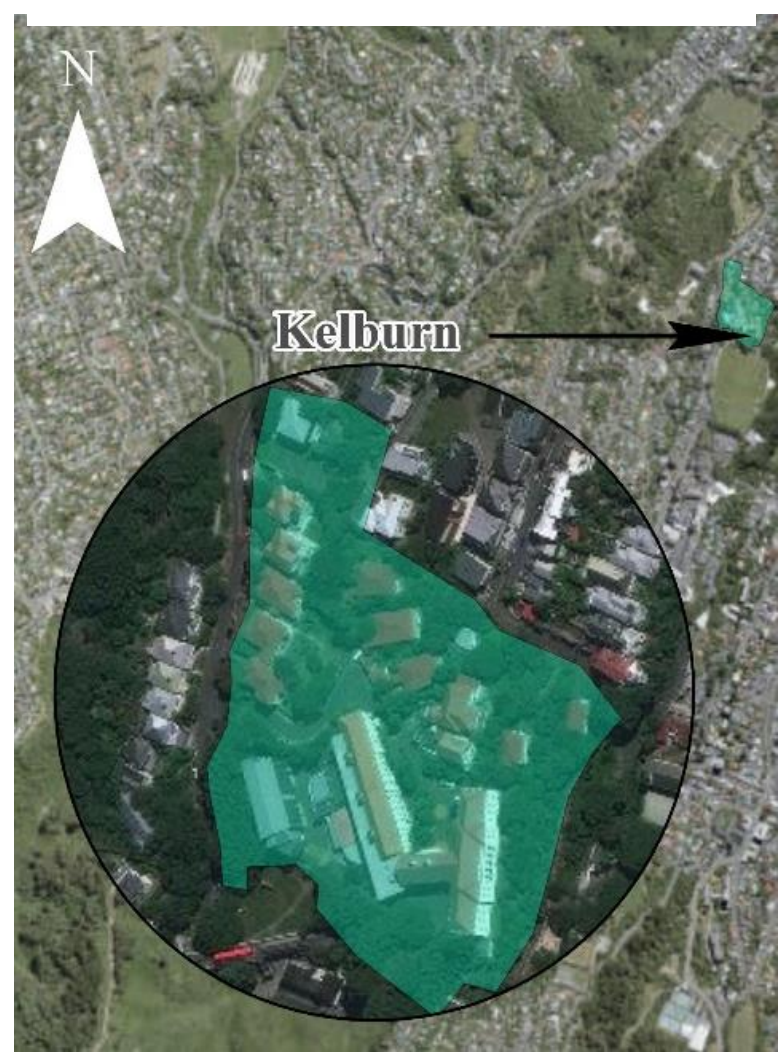

\section{Static Test of GPS Accuracy}

Two tags were tested at three areas within the study site: two of these areas were within typical and known rat habitat (Site 2 and 3; Table 1), (areas that rats were known to move in through a VHF study being conducted at the same time). Site 2 had a developed canopy layer of large pohutukawa trees (Metrosideros excelsa) with an understory present, with natives like kawakawa (Piper excelsum), taupata (Coprostnu repens) and juvenile lancewood (Pseudopanax crassifolius); with a sky availability of $5 \%$. Site 3 had no canopy layer but a thick ground layer of flax and long grasses with sky availability of $\sim 5 \%$. The other site was an open space with $100 \%$ sky availability, such that environmental factors that affect GPS accuracy were minimized. 
All tags were placed horizontally on top of a 3inch tall block to simulate a tagged rat.

Tag schedule: The tags were programmed to attempt a fix every 2 minutes for 1 hour for a total of 30 possible fixes.

Accuracy assessment: In this field test we assessed three measures of performance associated with GPS telemetry: the fix success rate (FSR) calculated as the proportion of the number of fixes made to the total number possible within the tag's activity period, proportion of "useable fixes" and location error (LE).

Useable fixes were defined as those with a horizontal dilution of precision (HDOP) of less than 4. HDOP is a measure of the relative geometry of the satellites used by the tag to determine its location. This value serves as a guide for researchers to decide which fixes to accept and which to reject. A low value of $1-5$ indicates a good relative geometry of wide angular separation between satellites above the tag. Opposed to high HDOP values which represent bunched satellites with narrow angular separation. Low values are indicative of a good fix but are not necessarily accurate due to other sources of environmental signal interference. Here we took a conservative approach and calculated LE from HDOP values of less than 4 . The LE was calculated by the mean distance between the tags true location and the fixes made that had a HDOP less than 4.

\section{$\underline{\text { Rat Tracking }}$}

Live Capturing: A total of 20 live traps were set out across the site for ten nights, taking a total of 200 trap nights to catch 5 rats.

Anesthesia: Rats were anesthetized within an airtight container using isoflurane-soaked cotton balls. The number of cotton balls used for induction varied according to the size of the rat. Once under, anesthesia was maintained by varying the distance between the subject's nose and the cotton balls.

Tagging: A piece of neoprene was fitted and then glued to the bottom of the GPS tag to provide a greater surface area to attach to the rat. A rectangular section between the rat's scapulae was shaved and the tag glued onto it. For additional security, a time-release zip tie was threaded through the tag and around the neck of the rat (Image 2).

Tag Settings: GPS tags were programmed to attempt fixes every half an hour from 21:00 to 05:00 and every 2 hours from 05:00 to 21:00 for a total of 24 possible fixes within a 24-hr 
period.

Data collection: Daily attempts were made to remotely connect and download data from the GPS tags. First the tag was located using its VHF component. Once found, we used the Pinpoint Commander to remote download any data onboard.

In the event that a tag was removed or lost by the rat a mortality signal would be emitted after 24 hours of no activity. When this happened, we were able to get within a $2 \mathrm{~m}^{2}$ area using VHF tracking and retrieve it using a metal detector.

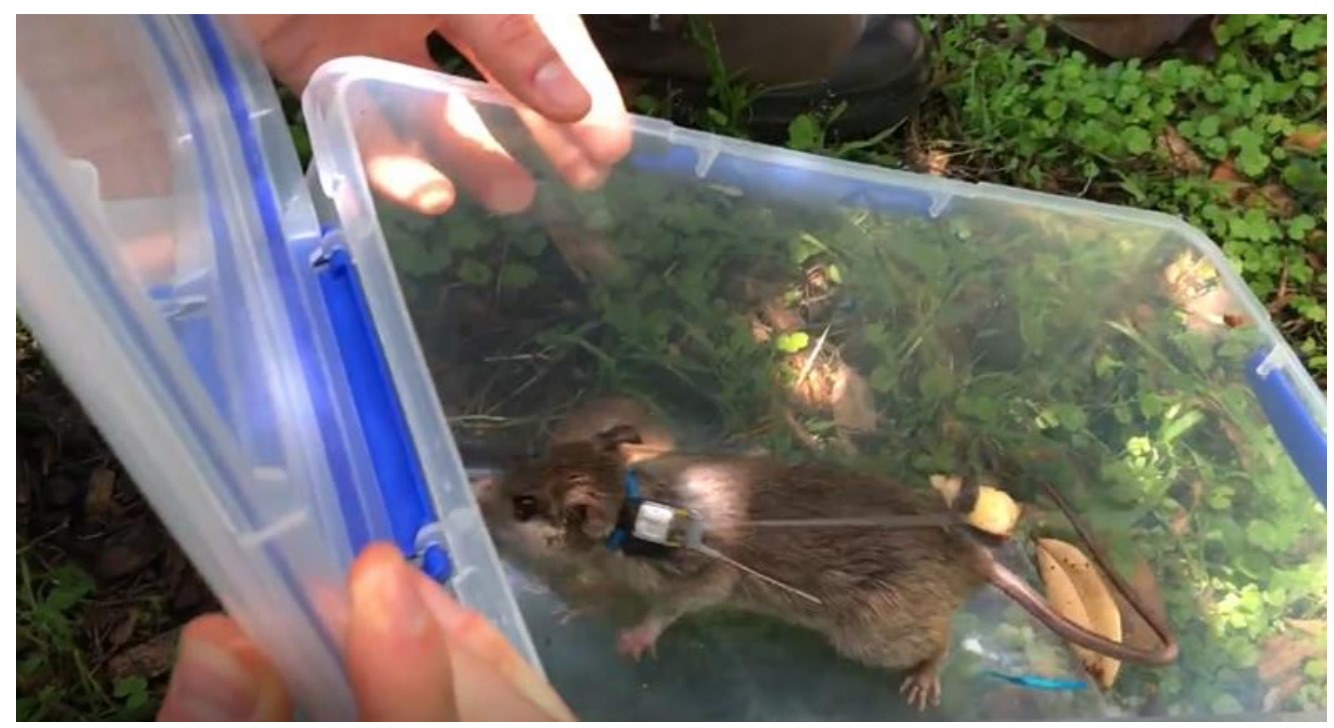

Image 2: Showing ship rat pre-release with GPS tag attached

\section{$\underline{\text { Results and Discussion }}$}

\section{$\underline{\text { Field Test }}$}

The field test revealed that there is a high degree of locational error present in fixes that are considered usable by their HDOP values: this ranged between $13 \mathrm{~m}$ and $33 \mathrm{~m}$ (Table 1 ). This error is substantial relative to the small spatial scales that urban rats operate in, where home ranges have found to be between just 0.2 - 0.6 ha, (Recht et al, 1983; Low et al, 2013). The fix success rate of the tags in rat habitat was high, ranging between 70 and $90 \%$ (Table 1). However, the proportion of usable fixes (HDOP $>4$ ) made in rat habitat was low (mean = $10(1 / 3))$ and considerably less than the control site 29 . Both a higher degree of location error and lower FSR values in rat habitat indicate that associated environmental factors substantially impacted the tags ability to obtain favorable geometries and make accurate fixes. 


\section{Rat Monitoring}

VHF contact was made with all five tagged rats on a near daily basis, however data was retrieved from only three of them (Image 3): the other two tags had no data on board when a remote download was attempted indicating insufficient connection with the satellites. The FSR values of the three tags with data were low at $4 \%, 5 \%$ and $27 \%$; this is substantially lower than those found in our field test $70 \%-90 \%$. This reduced signal acquisition is likely due to the behavior and body position of the rats during activities such as foraging or denning: these effectively alter the orientation of the tags relative to the sky reducing the strength of the tags signal (D'eon and Delparte, 2005; Augustine et al. 2011). Additionally, microhabitat use could have played a part, where rats were moving through more densely vegetated areas than was assessed in our static test.

\section{Conclusion}

GPS telemetry does not have the required accuracy to study the fine-scale spatial ecology of urban rats and likely other terrestrial urban species due to its high location error and low fix success rate in an urban environment (Table 1 and 2). Until the error of these devices is reduced through advances in technology, it is recommended that VHF telemetry be the mainstay for wildlife monitoring in urban settings. The application of GPS tags would be more applicable to animals moving in more open habitats and more mobile animals such as stoats, where an error of $10-30 \mathrm{~m}$ is not detrimental to the project aim. 


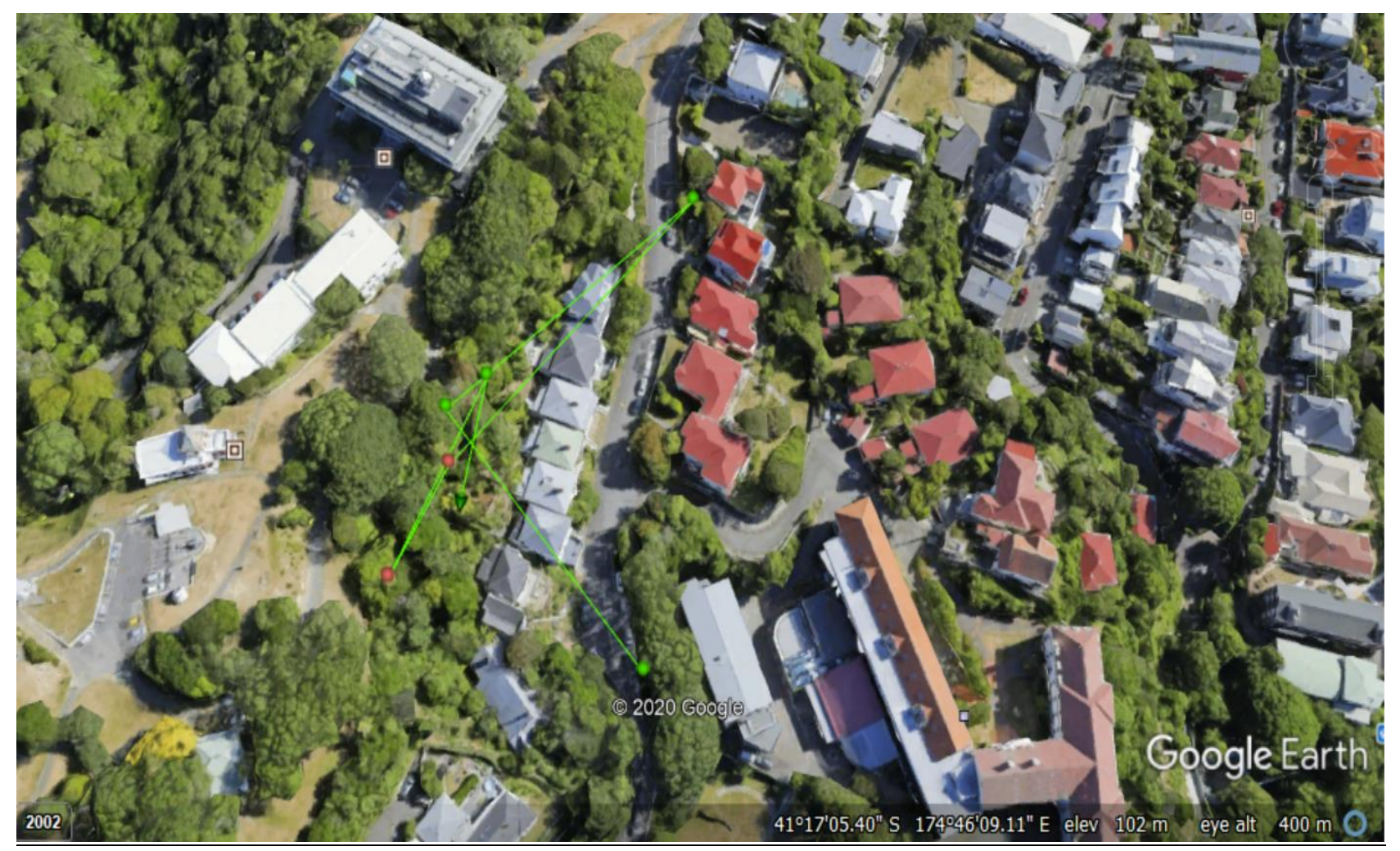

Image 4: Showing the GPS telemetry of rat no. 5. Green points: HDOP $\leq 4$; Red points: $H D O C \geq 5$; Green arrow: Last fix.

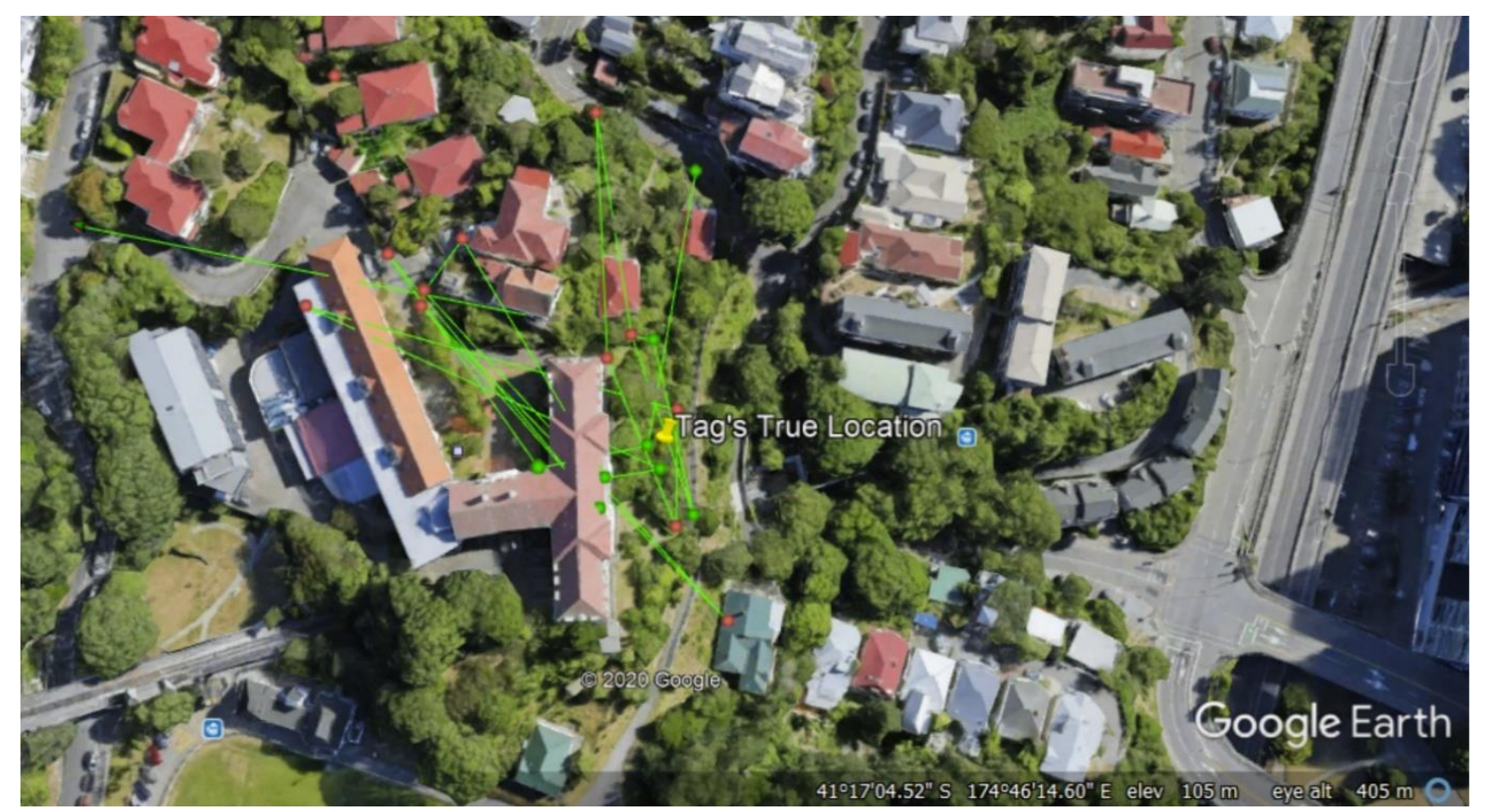

Image 3: Showing the results of tag no.82's field test at site 2. Yellow pin: tags true location; Green points: $H D O C \leq 5$; Red points: $H D O P \geq 4$ 
Table 1: Showing the results from the GPS trial across the three sites

\begin{tabular}{|c|c|c|c|c|c|c|c|c|c|c|c|c|}
\hline \multirow[t]{2}{*}{ GPS No. } & \multicolumn{4}{|c|}{ Control Site } & \multicolumn{4}{|c|}{ Site 2} & \multicolumn{4}{|c|}{ Site 3} \\
\hline & $\begin{array}{l}\text { Total no. } \\
\text { of fixes }\end{array}$ & $\begin{array}{c}\text { Fix success } \\
\text { rate }\end{array}$ & $\begin{array}{c}\text { No. of } \\
\text { usable fixes }\end{array}$ & $\begin{array}{l}\text { Mean } \\
\text { error }\end{array}$ & $\begin{array}{l}\text { Total no. } \\
\text { of fixes }\end{array}$ & $\begin{array}{c}\text { Fix } \\
\text { success } \\
\text { rate }\end{array}$ & $\begin{array}{c}\text { No. of } \\
\text { usable fixes }\end{array}$ & $\begin{array}{l}\text { Mean } \\
\text { error }\end{array}$ & $\begin{array}{l}\text { Total no. of } \\
\text { fixes }\end{array}$ & $\begin{array}{c}\text { Fix } \\
\text { success } \\
\text { rate }\end{array}$ & $\begin{array}{l}\text { No. of } \\
\text { usable } \\
\text { fixes }\end{array}$ & $\begin{array}{l}\text { Mean } \\
\text { error }\end{array}$ \\
\hline 84 & 30 & $100 \%$ & 29 & $6.4 \mathrm{~m}$ & 25 & $83 \%$ & 8 & $24 \mathrm{~m}$ & 23 & $76 \%$ & 5 & $33 \mathrm{~m}$ \\
\hline 82 & 30 & $100 \%$ & 29 & $6.9 \mathrm{~m}$ & 21 & $70 \%$ & 8 & $21 \mathrm{~m}$ & 28 & $93 \%$ & 19 & $13 \mathrm{~m}$ \\
\hline
\end{tabular}

Table 2: Summarizing the results of the GPS monitoring of 5 urban ship rats.

\begin{tabular}{|c|c|c|c|c|c|c|c|c|c|}
\hline Rat.no & Sex & Tag no. & Tag date & $\begin{array}{l}\text { Signal } \\
\text { lost }\end{array}$ & $\begin{array}{c}\text { Estimated } \\
\text { duration } \\
\text { (days) }\end{array}$ & Recovered & No. of fixes & $\begin{array}{c}\text { Fix } \\
\text { success } \\
\text { rate }\end{array}$ & $\begin{array}{c}\text { No. of fixes w/ HDOP } \\
<4\end{array}$ \\
\hline Rat 1 & Male & 81 & $21 / 12 / 19$ & $28 / 12 / 19$ & 7 & No & 0 & $0 \%$ & - \\
\hline Rat 2 & Female & 85 & $07 / 01 / 20$ & $14 / 01 / 20$ & 7 & No & 8 & $5 \%$ & 3 \\
\hline Rat 3 & Female & 83 & $07 / 01 / 20$ & $14 / 01 / 20$ & 7 & No & 0 & $0 \%$ & - \\
\hline Rat 4 & Female & 84 & $04 / 02 / 20$ & $11 / 02 / 20$ & 7 & Yes & 46 & $27 \%$ & 30 \\
\hline Rat 5 & Male & 82 & $07 / 02 / 20$ & $14 / 02 / 20$ & 7 & No & 7 & $4 \%$ & 5 \\
\hline
\end{tabular}




\section{Appendix 2}

\section{Capture Mark Re-sight 2}

A capture mark re-sight study was conducted at the Kelburn site in November 2019. A total of 16 camera traps were used. The cameras were distributed evenly across the site (Figure 17). Placement of cameras was made to maximize the number of sightings by selecting channelized areas e.g. along fences. At the time of the study there were 11 marked rats in the area. This number was known through the VHF study being conducted at the time. The results of the study are summarized in Table 14.

\section{Table 13: Capture Mark Re-sight 2 data summary}

\begin{tabular}{|c|l|l|l|l|l|l|l|}
\hline Site & $\begin{array}{l}\text { Site } \\
\text { area } \\
\text { (ha) }\end{array}$ & $\begin{array}{l}\text { No. of } \\
\text { cameras }\end{array}$ & $\begin{array}{l}\text { Study } \\
\text { duration }\end{array}$ & $\begin{array}{l}\text { Total } \\
\text { footage } \\
(\mathrm{min})\end{array}$ & $\begin{array}{l}\text { No. of } \\
\text { marked } \\
\text { rats }\end{array}$ & $\begin{array}{l}\text { No. of } \\
\text { sightings }\end{array}$ & $\begin{array}{l}\text { No. of } \\
\text { recaptures }\end{array}$ \\
\hline Kelburn & 2.5 & 16 & 3 weeks & 4 & 11 & 3 & 1 \\
\hline
\end{tabular}

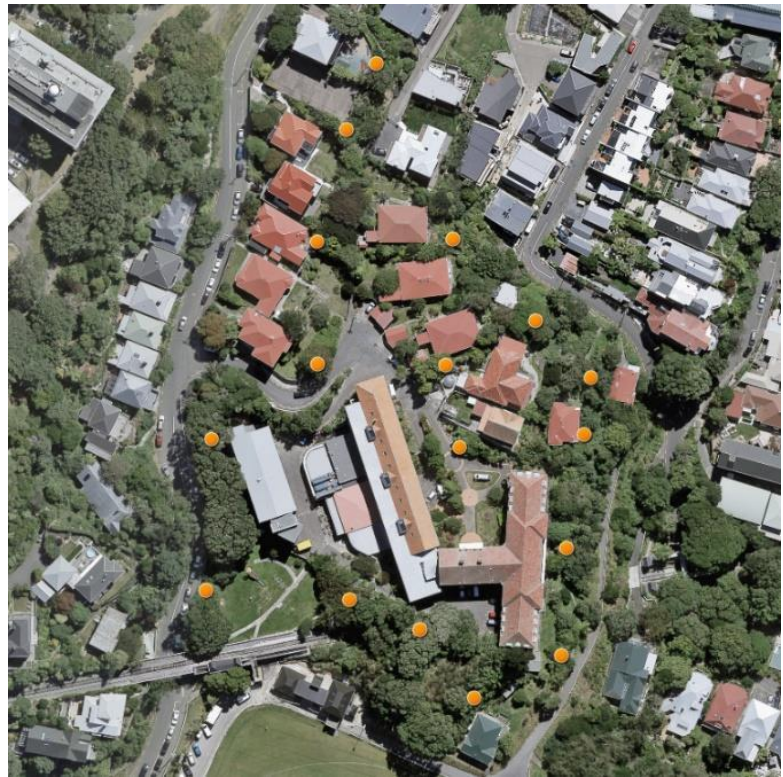

Figure 17: Camera trap locations within Kelburn site 


\section{Appendix 3}

\section{Additional Field Notes}

This section is a record of some of the natural history observations made whilst conducting fieldwork that I felt were noteworthy. They did not fit neatly within the main body of the thesis but could be helpful for similar studies or to stimulate interest in new research.

\section{Rat traversing a fence}

Whilst doing a daytime radio track in the Kelburn site I observed rat no. 25 traversing across a high wire fence surrounding the tennis courts there. The rat travelled about $5 \mathrm{~m}$ along it and from there climbed into the upper foliage of a cabbage tree, where it remained. Similar movements were observed in Recht et al. (1983) where ship rats were seen traversing electrical lines to move around the urban habitat. These observations are examples of how ship rats have adapted to the urban environment.

\section{The range of reactions to anesthesia}

The time taken for induction varied considerably between rats - from $15 \mathrm{~s}$ to $5 \mathrm{~min}$. Given the size of the range it is likely there was a physiological component. The rats that took longer to go under tended to be more agitated prior. An increased adrenal response is likely to be the reason for this. Rats had a range of physical reactions to going under anesthesia. Several of the rats, whilst under, had convulsions of varying severity. Recovery time also ranged significantly from one minute to four hours with a mean of 10 minutes.

\section{Moth predation}

On several occasions the camera trap footage captured rats predating moths. The rat would often pounce onto the moth from height, frequently from the base of a tree. 


\section{The uncaught monster Norway}

I caught one Norway rat at the Roseneath site which managed to break out of the cage as I carried it to be processed. I estimated its weight to be $>400 \mathrm{~g}$.

\section{Compost Bin Creche?}

I placed a camera trap within a compost bin at the Kelburn site. On several occasions when passing by I had noticed several juvenile rats in there. From the camera footage there were four juveniles living in the compost bin. They were very active during the day. They were observed digging into the compost and eating what appeared to be worms. They were never seen eating any human refuse, despite there being a range of edible material from fresh fruit to pizza. No adults were observed in the compost bin. It is likely these rats were recently weaned. It was interesting that they all stayed together after weaning. At some point after collecting the camera trap the rats left the compost bin and were not seen again. 


\section{References}

Anderson, D. P., Ramsey, D. S., de Lisle, G. W., Bosson, M., Cross, M. L., \& G. Nugent (2015).

Augustine BC, Crowley PH, Cox JJ (2011) A mechanistic model of GPS collar location data: Implications for analysis and bias mitigation. Ecol. Modell. 222: 3616-3625.

Development of integrated surveillance systems for the management of tuberculosis in New Zealand wildlife. New Zealand Veterinary Journal 63 Suppl 1: 89-97.

Aplin, K., Chesser, T. \& J. Have (2003a). Evolutionary biology of the genus Rattus: Profile of an archetypal rodent pest. ACIAR Monograph Series 96: 487-498.

Aplin, K.P., Brown, P.R., Jacob, J., Krebs, C.J. \& G.R. Singleton (2003b). Field methods for rodent studies in Asia and the Indo-Pacific. ACIAR Monograph No.100: 223.

Atkinson U. A. E. (1973) Spread of the ship rat (Rattus rattus L.) III New Zealand, Journal of the Royal Society of New Zealand 3(3): 457-472.

Atkinson E. \& D.R. Towns (2001) Advances in New Zealand mammalogy 1990-2000: Pacific rat. Journal of the Royal Society of New Zealand 31(1): 99-109.

Audoin-Rouzeau, F. \& J.D. Vigne (1994). La colonisation de l'Europe par le Rat Noir (Rattus rattus). Revue de Paléobiologie 13: 125-145.

Bajomi, D., \& G. Vamos (1983). A rat-free state in Budapest. Experience gained during its maintenance. Environmental Health, 263-268.

Bajomi, D. \& K. Sasvari (1986). Results of eight years' examination of the habitats of residual urban rat populations after eradication. In: Salmon, T.P., ed., Proceedings of the 12th Vertebrate Pest Conference. Davis, University of California, 66-74.

Banks, P., \& H. Smith (2015). The ecological impacts of commensal species: Ship rats, Rattus rattus, at the urban-bushland interface. Wildlife Research 42(2): 86-97.

Ball Stephen J., Ramsey David, Nugent Graham, Warburton Bruce, Efford Murray (2005) A method for estimating wildlife detection probabilities in relation to home-range use: insights from a field study on the common brushtail possum (Trichosurus vulpecula). Wildlife Research 32, 217-227.

Barnett, S. A (1967). Rats. Scientific American, 216(1), 78-85.

Best, I. W (1968). The ecology of Rattus rattus (I.) in selected areas of the South island, New 
Zealand. unpublished MSc thesis, university of canter-bury, christchurch, New Zealand

Bishop, M., \& C. Peterson (2006). When r-Selection May Not Predict Introduced-Species Proliferation: Predation of a Nonnative Oyster. Ecological Applications 16(2): 718-730.

Blackwell, Grant \& Potter, Murray \& J. Mclennan (2002). Rodent density indices from tracking tunnels, snap-traps and Fenn traps: Do they tell the same story? New Zealand Journal of Ecology 26:43- 51.

Bohonak, A. J. (1999). Dispersal, gene flow, and population structure. The Quarterly review of biology, 74(1), 21-45.

Brown, K. P., Moller, H., Innes, J., \& Alterio, N. (1996). Calibration of tunnel tracking rates to estimate relative abundance of ship rats (Rattus rattus) and mice (Mus musculus) in a New Zealand forest. New Zealand Journal of Ecology, 271-275.

Brown, K.; Elliott, G.; Innes, J., \& J. Kemp (2015). Ship rat, stoat and possum control on mainland New Zealand: an overview of techniques, successes and challenges. Department of Conservation, Wellington. 36 p.

Bull, P. C., \& A.H. Whitaker (1975). The amphibians, reptiles, birds and mammals. In Biogeography and ecology in New Zealand (pp. 231-276). Springer, Dordrecht.

Burt, W. H. (1943). Territoriality and home range concepts as applied to mammals. Journal of mammalogy 24(3): 346-352.

Byers, K.A., Lee, M.J., Patrick, D. M., \& C.G. Himsworth (2019). Rats About Town: A Systematic Review of Rat Movement in Urban Ecosystems. Frontiers in Ecology and Evolution 7: 13.

Calenge, C. (2006) The package adehabitat for the R software: a tool for the analysis of space and habitat use by animals. Ecological Modelling 197: 516-519.

Calhoun, J. B. (1948). Mortality and Movement of Brown Rats (Rattus norvegicus) in Artificially Supersaturated Populations. The Journal of Wildlife Management 12(2):167-172.

Calhoun, J. B. (1962). Population density and social pathology. Scientific American 
206(2):139-149.

Calhoun, J. B. (1963). The ecology and sociology of the Norway rat (No. 1008). US Department of Health, Education, and Welfare, Public Health Service.

Campbell, D. J., \& I.A.E. Atkinson (1999). Effects of kiore (Rattus exulans Peale) on recruitment of indigenous coastal trees on northern offshore islands of New Zealand. Journal of the Royal Society of New Zealand 29(4):265-290.

Campbell, D.J \& I.A.E. Atkinson (2002). Depression of tree recruitment by the Pacific rat (Rattus exulans Peale) on New Zealand's northern offshore islands. Biological Conservation 107:19-35.

Carleton, M.D., \& G.G. Musser (2005). Order Rodentia. In Wilson, D.E. \& Reeder, D.M. (eds.) Mammal Species of the World, Third Edition. The Johns Hopkins University Press, Baltimore: 745-752.

Carrete, M., Donázar, J.A., Margalida, A., \& J. Bertran (2006) Linking ecology, behaviour and conservation: does habitat saturation change the mating system of bearded vultures? Biol Lett. 2(4):624-627.

Caughley, G. (1977). Analysis of vertebrate populations. Analysis of vertebrate populations.

Charlesworth, P., Jacobson, I., \& C. Richards (1994). The action of pentobarbital on the excitatory amino- acid receptors of neurons dissociated from the rat olfactory brain. In journal of physiology- london 475:153.

Childs, J. E., Glass, G. E., Korch, G. W., \& LeDuc, J. W. (1989). Effects of hantaviral infection on survival, growth and fertility in wild rat (Rattus norvegicus) populations of Baltimore, Maryland. Journal of Wildlife Diseases, 25(4), 469-476.

Charnov, E. L. (1976). Optimal foraging, the marginal value theorem. Theoretical population biology, 9(2), 129-136.

Choi, J., Liu, R. M., \& Forman, H. J. (1997). Adaptation to oxidative stress: quinone-mediated protection of signaling in rat lung epithelial L2 cells. Biochemical pharmacology, 53(7), 987-993.

Choi, S., \& Kellogg, C. K. (1996). Adolescent development influences functional responsiveness of noradrenergic projections to the hypothalamus in male rats. Developmental Brain Research, 94(2), 144-151.

Christie, J. E., MacKenzie, D. I., Greene, T. C., \& Sim, J. L. (2015). Using passive detection 
devices to monitor occupancy of ship rats (Rattus rattus) in New Zealand temperate rainforest. New Zealand Journal of Ecology, 39(1), 79-86.

Clapperton, B. K., Maddigan, F., Chinn, W., \& E.C. Murphy (2019). Diet, population structure and breeding of Rattus rattus L. in South Island beech forest. New Zealand Journal of Ecology 43(2): 1-8.

Clapperton, B.K. (2006). A review of the current knowledge of rodent behaviour in relation to control devices. Science for Conservation 263: 55.

Clout, M.N., \& J.R. Hay (1989). The importance of birds as browsers, pollinators and seed dispersers in New Zealand forests. New Zealand Journal of Ecology 12 (Supplement): 27-33.

Clout, M. N., \& Russell, J. C. (2006). The eradication of mammals from New Zealand islands. Assessment and Control of Biological Invasion Risks'. 127-141.

Clutton-Brock, TH, and Harvey, PH, 1978, Mammals, resources and reproductive strategies, Nature 273:191

Combs M., Byers, K.A., Ghersi, B.M., Blum, M.J., \& A. Caccone (2018). Urban rat races: Spatial population genomics of brown rats (Rattus norvegicus) compared across multiple cities. Proc. Biol. Sci.285.

Combs, M., Byers, K., Himsworth, C., \& Munshi-South, J. (2019). Harnessing population genetics for pest management: theory and application for urban rats. Human-Wildlife Interactions, 13(2), 11.

Combs, M., Puckett, E.E., Richardson, J., Mims, D., \& J. Munshi-South (2018). Spatial population genomics of the brown rat (Rattus norvegicus) in New York City. Mol Ecol. 2018 27: 83-98.

Costa, F., Ribeiro, G. S., Felzemburgh, R. D., Santos, N., Reis, R. B., Santos, A. C., ... \& M.G. Reis (2014). Influence of household rat infestation on Leptospira transmission in the urban slum environment. PLoS neglected tropical diseases 8(12).

Cox, M.P.G. \& C.R.D.a.W.G. Cox (2000). Use of habitat by the black rat (Rattus rattus) at North Head, New South Wales: an observational and experimental study. Austral Ecology 25: 375-385. 
Cresswell WJ \& Smith GC. (1992). The effects of temporally autocorrelated data on methods of home range analysis Wildlife Telemetry Remote Monitoring and Tracking of Animals, Ellis Horwood Ltd, New York, USA

Cromarty, P., Broome, K., Cox, A., Empson, R., Hutchinson, W., \& I. McPhadden (2002). Eradication planning for invasive alien animal species on islands-the approach developed by the New Zealand Department of Conservation. Turning the Tide: The Eradication of Invasive Species: Proceedings of the International Conference on Eradication of Island Invasives. 85-91.

Cunningham, D., \& Moors, P. J. (1983). Guide to the identification and collection of New Zealand rodents (p. 20). Wellington: New Zealand Wildlife Service, Department of Internal Affairs.

Daniel, M. J. (1972). Bionomics of the ship rat (Rattus r. rattus) in a New Zealand indigenous forest. New Zealand journal of science, 15(3), 313-341.

Davis, D. E. (1953a). Analysis of home range from recapture data. Journal of Mammalogy, 34(3), 352-358.

Davis, D. E. (1953b). The characteristics of rat populations. The quarterly review of Biology, 28(4), 373-401.

Davis, D. E., Emlen, J. T., \& Stokes, A. W. (1948). Studies on home range in the brown rat. Journal of Mammalogy, 29(3), 207-225.

Davis, D., \& J. Christian (1956). Changes in Norway Rat Populations Induced by Introduction of Rats. The Journal of Wildlife Management 20(4):378-383.

D'EON, R.G. and DELPARTE, D. (2005), Effects of radio-collar position and orientation on GPS radio-collar performance, and the implications of PDOP in data screening. Journal of Applied Ecology, 42: 383-388.

Douglas, L. A., Varlinskaya, E.I., \& L.P. Spear (2003). Novel-object place conditioning in adolescent and adult male and female rats: effects of social isolation. Physiology \& Behavior 80(2-3):317-325.

Dowding J. E., \& Murphy, E. C. (1994). Ecology of ship rats (Rattus rattus) in a kauri (Agathis australis) forest in Northland, New Zealand. New Zealand Journal of Ecology, 19-27.

Dowding, J. E., Murphy, E. C., \& Veitch, C. R. (1999). Brodifacoum residues in target and non- 
target species following an aerial poisoning operation on Motuihe Island, Hauraki Gulf, New Zealand. New Zealand Journal of Ecology, 207-214.

Downs, J.A. and Horner, M.W. (2008). Effects of Point Pattern Shape on Home-Range Estimates. The Journal of Wildlife Management, 72: 1813-1818.

Duncan, R.P. \& T.M. Blackburn (2004). Extinction and endemism in the New Zealand avifauna. Global Ecology and Biogeography 13: 509-517.

Duron, Q., Shiels, A. B., \& E. Vidal (2017). Control of invasive rats on islands and priorities for future action. Conservation Biology 31(4): 761-771.

Duyck, P. F., David, P., \& S. Quilici (2007). Can more K-selected species be better invaders? A case study of fruit flies in La Réunion. Diversity and Distributions 13(5): 535-543.

Emlen, J.T., Stokes, A.W, \& C. Winsor (1948). The Rate of Recovery of Decimated Populations of Brown Rats in Nature. Ecology 29(2):133-145.

Emlen, J.T., Stokes, A.W. \& D.E. Davis (1949). Methods for Estimating Populations of Brown Rats in Urban Habitats. Ecology 30: 430-442.

Fauvelle, C., Diepstraten, R., \& T. Jessen (2017). A meta-analysis of home range studies in the context of trophic levels: Implications for policy-based conservation. PLoS ONE 12(3): e0173361.

Facon, B., Machline, E., Pointier, J. (2004). Variation in Desiccation Tolerance in Freshwater Snails and Its Consequences for Invasion Ability. Biological Invasions 6, 283-293.

Feng, A.Y.T., \& C. Himsworth (2013). The secret life of the city rat: A review of the ecology of urban Norway and black rats (Rattus norvegicus and Rattus rattus). Urban Ecosystems 17(1):149- 162.

Fernández, M. S., Cavia, R., Cueto, G. R., \& Suárez, O. V. (2007). Implementation and evaluation of an integrated program for rodent control in a shantytown of Buenos Aires City, Argentina. EcoHealth, 4(3), 271-277.

Fleming, C. H., J. M. Calabrese, T. Mueller, K. A. Olson, P.Leimgruber, and W. F. Fagan. (2014a). From fine-scale foraging to home ranges: a semi-variance approach to identifying movement modes across spatiotemporal 
scales. American Naturalist 183:E154-E167

Fleming, C. H., Fagan, W. F., Mueller, T., Olson, K. A., Leimgruber, P., \& Calabrese, J. M. (2015). Rigorous home range estimation with movement data: a new autocorrelated kernel density estimator. Ecology, 96(5), 1182-1188.

Fleming, C. H., \& Calabrese, J. M. (2017). A new kernel density estimator for accurate homerange and species-range area estimation. Methods in Ecology and Evolution, 8(5), 571-579.

Fortin, M. J., \& Dale, M. (2005). Spatial analysis: a guide for ecologists.

Garcia, H. A., Rangel, C. J., Ortíz, P. A., Calzadilla, C. O., Coronado, R. A., Silva, A. J., ... \& M.M. Teixeira (2019). Zoonotic Trypanosomes in Rats and Fleas of Venezuelan Slums. EcoHealth, 16(3), 523- 533.

Gardner-Santana, L. C., Norris, D. E., Fornadel, C. M., Hinson, E. R., Klein, S. L., \& G.E. Glass (2009). Commensal ecology, urban landscapes, and their influence on the genetic characteristics of city-dwelling Norway rats (Rattus norvegicus). Molecular ecology 18(13), 2766-2778.

German, D., \& C.A. Latkin (2016). Exposure to urban rats as a community stressor among lowincome urban residents. Journal of Community Psychology 44(2), 249262.

Glass, G., Korch, G., \& J. Childs (1988). Seasonal and Habitat Differences in Growth Rates of Wild Rattus norvegicus. Journal of Mammalogy 69(3):587-592.

Gosling, L. M., \& Baker, S. J. (1989). Demographic consequences of differences in the ranging behaviour of male and female coypus. Mammals as pests, 155, 167.

Gracceva, G., Herde, A., Groothuis, T. G., Koolhaas, J. M., Palme, R., \& J.A. Eccard (2014). Turning Shy on a Winter's Day: Effects of Season on Personality and Stress Response in Microtus arvalis. Ethology 120(8):753-767.

Guiry, E., \& M. Buckley (2018). Urban rats have less variable, higher protein diets. Proceedings. Biological sciences 285(1889):1441.

Harper, G. A., \& N. Bunbury, (2015). Invasive rats on tropical islands: their population biology and impacts on native species. Global Ecology and Conservation 3: 607627.

Harper, G. \& M. Rutherford (2016). Home range and population density of ship rats (Rattus 
rattus) on a seabird island: A case for a marine subsidised effect? New Zealand Journal of Ecology 40: 219- 228.

Harper, G. A., \& Rutherford, M. (2016). Home range and population density of black rats (Rattus rattus) on a seabird island: a case for a marine subsidised effect?. New Zealand Journal of Ecology, 40(2), 219-228.

Harper, G. A., Dickinson, K. J., \& Seddon, P. J. (2005). Habitat use by three rat species (Rattus spp.) on Stewart Island/Rakiura, New Zealand. New Zealand Journal of Ecology, 251-260.

Harper, G.A. (2007). Detecting predation of a burrow-nesting seabird by two introduced predators, using stable isotopes, dietary analysis and experimental removals. Wildlife Research 34: 443-453.

Harris, S., Cresswell, W., Forde, P., Trewhella, W., Woollard, T., \& S. Wray (1990). Home range analysis using radio-tracking data? A review of problems and techniques particularly as applied to the study of mammals. Mammal Review. 20: 97-123.

Nathan, H.W. (2016). Detection probability of invasive ship rats: biological causation and management implications [Doctoral dissertation, University of Auckland]. University of Auckland Research Respository

Himsworth, C. G., Parsons, K. L., Jardine, C., \& D.M. Patrick (2013). Rats, cities, people, and pathogens: a systematic review and narrative synthesis of literature regarding the ecology of rat-associated zoonoses in urban centers. Vector-Borne and Zoonotic Diseases, 13(6):349-359.

Himsworth, C.G., Jardine, C.M., Parsons, K.L., Feng, A.Y.T., \& D.M. Patrick (2014a). The Characteristics of Wild Rat (Rattus spp.) Populations from an Inner-City Neighborhood with a Focus on Factors Critical to the Understanding of Rat-Associated Zoonoses. PLoS ONE 9(3): e91654.

Himsworth, C.G., Parsons, K.L., Feng, A.Y.T., Kerr, T., Jardine, C.M., \& D.M. Patrick (2014b). A Mixed Methods Approach to Exploring the Relationship between Norway Rat (Rattus norvegicus) Abundance and Features of the Urban Environment in an Inner-City Neighborhood of Vancouver, Canada. PLOS ONE 9(5): e97776. 
Hogarth, A. M. (1929). The Rat: a World Menace. John Bale, Sons and Danielsson, London. Holdaway, R.N. (1989). New Zealand's pre-human avifauna and its vulnerability. New Zealand Journal of Ecology, 12 (Suppl.): 11-25.

Hooker, S., \& Innes, J. (1995). Ranging behaviour of forest-dwelling ship rats, Rattus rattus, and effects of poisoning with brodifacoum. New Zealand journal of zoology, 22(3), 291-304.

Hooker, S., \& Innes, J. (1995). Ranging behaviour of forest-dwelling ship rats, Rattus rattus, and effects of poisoning with brodifacoum. New Zealand journal of zoology, 22(3), 291-304.

Howald, G., Donlan, C. J., Galvan, J. P., Russell, J. C., Parkes, J., Samaniego, A., ... \& A. Saunders (2007). Invasive rodent eradication on islands. Conservation biology 21(5):1258-1268.

Hulme, P. E. (2006). Beyond control: wider implications for the management of biological invasions. Journal of Applied Ecology 43(5), 835-847.

Hulme, P. E., Pyšek, P., Jarošik, V., Pergl, J., Schaffner,U., \& M. Vilà (2013). Bias and error in understanding plant invasion impacts. Trends in Ecology and Evolution 28: $212-218$.

Hut, R. A., Pilorz, V., Boerema, A. S., Strijkstra, A. M., \& Daan, S. (2011). Working for food shifts nocturnal mouse activity into the day. PloS one, 6(3).

Inglis, I. R., Shepherd, D. S., Smith, P., Haynes, P. J., Bull, D. S., Cowan, D. P., \& Whitehead, D. (1996). Foraging behaviour of wild rats (Rattus norvegicus) towards new foods and bait containers. Applied Animal Behaviour Science, 47(34), $175-190$.

Innes J.G. (2001). Advances in New Zealand mammalogy 1990-2000: European rats. Journal of the Royal Society of New Zealand 31(1):111-125.

Innes, J. G. (2005). Ship rat. The handbook of New Zealand mammals 2:187-203.

Jansa, S. A., Barker, F. K., \& L.R. Heaney (2006). The pattern and timing of diversification of Philippine endemic rodents: evidence from mitochondrial and nuclear gene sequences. Systematic Biology 55(1):73-88.

Jones, P.H., Tershy, B.R., Zavaleta, E.S., Croll, D.A., Keitt, B.S., Finkelstein, M.E., \& G.R. Howald 
(2008). Severity of the effects of invasive rats on seabirds: a global review. Conservation Biology 22: 16-26

Jones, H. P. (2010). Seabird islands take mere decades to recover following rat eradication.

Ecological Applications, 20(8), 2075-2080.

Jones, E.P., Eager, H.M., Gabriel, S.I., Jóhannesdóttir, F., \&J.B. Searle (2013). Genetic tracking of mice and other bio-proxies to infer human history. Trends in Genetics 29: 298-308.

Jumeau, J., Petrod, L., \& Y. Handrich (2017). A comparison of camera trap and permanent recording video camera efficiency in wildlife underpasses. Ecology and Evolution 7(18): 7399-7407.

Kajdacsi, B., Costa, F., Hyseni, C., Porter, F., Brown, J., Rodrigues, G., Farias, H., Reis, M.G., Childs, J.E., Ko,

A.I. \& A. Caccone (2013). Urban population genetics of slum-dwelling rats (Rattus norvegicus) in Salvador, Brazil. Molecular Ecology 22: 5056-5070.

Kellner, K. F., \& R.K. Swihart (2014). Accounting for imperfect detection in ecology: a quantitative review. PloS ONE 9(10): e111436.

Kimura, M., \& Weiss, G. H. (1964). The stepping stone model of population structure and the decrease of genetic correlation with distance. Genetics, 49(4), 561.

King, C.M., Foster, S. and Miller, S. (2011), Invasive European rats in Britain and New Zealand: same species, different outcomes. Journal of Zoology, 285: 172-179.

King, C.M. (2019). Invasive Predators in New Zealand, Disaster on Four Small Paws.

Environmental Research Institute University of Waikato, Hamilton, New Zealand.

Kolar, C. S., \& D.M. Lodge. (2001). Progress in invasion biology: predicting invaders. Trends in ecology \& evolution 16(4):199-204.

Latham, J. E. (2006). The ecology of ship rats (Rattus rattus) on Ponui Island: implications for North Island brown kiwi (Apteryx mantelli) (Doctoral dissertation).Leslie, P., \& D. Davis (1939). An Attempt to Determine the Absolute Number of Rats on a Given Area. Journal of Animal Ecology 8(1):94-113.

Lippens, C., Estoup, A., Hima, M. K., Loiseau, A., Tatard, C., Dalecky, A., ... \& Brouat, C. (2017). 
Genetic structure and invasion history of the house mouse (Mus musculus domesticus) in Senegal, West Africa: a legacy of colonial and contemporary times. Heredity, 119(2), 64-75.

Low, B. W., Mills, H., Algar, D., \& N. Hamilton (2013). Home ranges of introduced rats on Christmas Island: A pilot study. Ecological Management \& Restoration 14(1): 41-46.

MacKay, J., \& Russell, J. C. (2005). Eradication of ship rats from Goat Island April-October 2005. Unpublished report to the Department of Conservation. University of Auckland.

Mackenzie, H. (2020). Evaluating GPS Tags as a Tool for Rat Monitoring in an Urban Environment: A Case Study in Wellington. Predator Free 2050. https://pf2050.co.nz/app/uploads/2020/06/PF2050-Limited-StudentGrant-Report-_-Henry-Mackenzie-May-2020.pdf

Macri, S., Adriani, W., Chiarotti, F., \& G. Laviola (2002). Risk taking during exploration of a plus-maze is greater in adolescent than in juvenile or adult mice. Animal Behaviour 64(4): 541-546.

Mangombi, J. B., Brouat, C., Loiseau, A., Banga, O., Leroy, E. M., Bourgarel, M., \& Duplantier, J. M. (2016). Urban population genetics of the invasive black rats in Franceville, Gabon. Journal of Zoology, 299(3), 183-190.

Marsh, R. E. (1994). Roof rats. The Handbook: Prevention and Control of Wildlife Damage, 6. Martin, A. R., \& M.G. Richardson, M. G. (2019). Rodent eradication scaled up: clearing rats and mice from South Georgia. Oryx, 53(1):27-35.

Martin, J.L., Thibault, J.C., \& V. Bretagnolle (2000). Ship rats, island characteristics, and colonial nesting birds in the Mediterranean: consequences of an ancient introduction. Conservation Biology 14:1452-1466.

Martin, R.E., Pine, R.H., \& A.F. Deblase (2001). Age determination. A manual of mammalogy 3. McGraw- Hill, Boston, pp 244-252.

Massawe, A. W., Mulungu, L. S., Makundi, R. H., Dlamini, N., Eiseb, S. J., Kirsten, F., ... \& P. Taylor (2011). Spatial and temporal population dynamics of rodents in three geographically different regions in Africa: implication for ecologically-based rodent management. African Zoology 46(2):393- 
405.

McClintock, B. T., White, G. C., Antolin, M. F., \& Tripp, D. W. (2009). Estimating abundance using mark- resight when sampling is with replacement or the number of marked individuals is unknown. Biometrics, 65(1), 237-246.

McNab, B. K. (1963). Bioenergetics and the determination of home range size. The American Naturalist, 97(894), 133-140.

McQueen, S., \& B. Lawrence (2008). Diet of ship rats following a mast event in beech (Nothofagus spp.) forest. New Zealand Journal of Ecology, 214-218.

Michelangeli, M., Wong, B.B.M., \& D.G. Chapple (2016). It's a trap: sampling bias due to animal personality is not always inevitable. Behavioral Ecology 27(1):62-67.

Mitchell, M. S., \& R.A. Powell (2012). Foraging optimally for home ranges. Journal of Mammalogy 93(4): 917-928.

Moors, P. J. (1985). Norway rats (Rattus norvegicus) on the Noises and Motukawao Islands, Hauraki Gulf, New Zealand. New Zealand journal of ecology, 37-54.

Morgan, D.K.J., Waas, J.R., \& J. Innes (2009) An inventory of mammalian pests in a New Zealand city. New Zealand Journal of Zoology 36(1):23-33.

Mueller, L. D. (1997). Theoretical and empirical examination of density-dependent selection. Annual Review of Ecology and Systematics 28(1): 269-288.

Mulder, C. P., Grant-Hoffman, M. N., Towns, D. R., Bellingham, P. J., Wardle, D. A., Durrett, M. S., ... \& Bonner, K. I. (2009). Direct and indirect effects of rats: does rat eradication restore ecosystem functioning of New Zealand seabird islands? Biological Invasions 11(7):671-1688.

Murphy, E., \& Bradfield, P. (1992). Change in diet of stoats following poisoning of rats in a New Zealand forest. New Zealand journal of ecology, 137-140.

Musser, G.M., Carleton, M.D., Wilson, D.E. \& D.M. Reeder (2005). Mammal Species of the World: A Taxonomic and Geographic Reference (third ed.), The Johns Hopkins University Press, Baltimore.

Neill, E., \& P. Jansen (2014). Ground-based radio tracking: a best practice protocol. Department of Conservation, Wellington, $19 \mathrm{p}$.

Nichols, J. D. (2014). The role of abundance estimates in conservation decision-making. In 
Applied Ecology and Human Dimensions in Biological Conservation (pp.

117-131). Springer, Berlin, Heidelberg.

Otero, X. L., De La Peña-Lastra, S., Pérez-Alberti, A., Ferreira, T. O., \& M.A. Huerta-Diaz (2018).

Seabird colonies as important global drivers in the nitrogen and phosphorus cycles. Nature communications 9(1):1-8.

Oyedele, D. T., Sah, S.A., Kairuddinand, L., \& W.M. Wan Ibrahim (2015). Range Measurement and a Habitat Suitability Map for the Norway Rat in a Highly Developed Urban Environment. Tropical Life Sciences Research 26(2): 27-44.

Parsons, M. H., Sarno, R. J., \& M.A. Deutsch (2015). Jump-starting urban rat research: conspecific pheromones recruit wild rats into a behavioral and pathogen-monitoring assay. Frontiers in Ecology and Evolution 3:146.

Parsons, M. H., Banks, P. B., Deutsch, M. A., Corrigan, R. F., \& J. Munshi-South (2017). Trends in urban rat ecology: a framework to define the prevailing knowledge gaps and incentives for academia, pest management professionals (PMPs) and public health agencies to participate. Journal of Urban Ecology 3(1).

Pascal, M., Lorvelec, O., Bretagnolle, V., \& J.M. Culioli (2008). Improving the breeding success of a colonial seabird: a cost-benefit comparison of the eradication and control of its rat predator. Endangered Species Research 4(3):267-276.

Petrie, G. F., \& Todd, R. E. (1923). Observations in Upper Egypt on the range of excur-sion of the house rodents, R. rattus and Acomys cahirinus. Reports and Notes of the Public Health Laboratories, Cairo, 5, 14-18.

Péron, G. (2019). Modified home range kernel density estimators that take environmental interactions into account. Mov Ecol 7, 16.

Pimentel, D., Lach, L., Zuniga, R., \& D. Morrison (2000). Environmental and economic costs of nonindigenous species in the United States. BioScience, 50(1): 53-65.

Roger A. Powell, Michael S. Mitchell. (2012). What is a home range?, Journal of Mammalogy, Volume 93, Issue 4, 14 September 2012, Pages 948-958.

Prakash, I. (1988). Bait shyness and poison aversion. Rodent pest management, 321-329.

Pryde, M., Dilks, P., \& Fraser, I. (2005). The home range of ship rats (Rattus rattus) in beech forest in the Eglinton Valley, Fiordland, New Zealand: a pilot study. New 
Zealand Journal of Zoology, 32(3), 139-142.

Puckett, E.E., Orton, D., \& J. Munshi-South (2020). Commensal Rats and Humans: Integrating Rodent Phylogeography and Zooarchaeology to Highlight Connections between Human Societies. BioEssays 42(5).

Puckett, E.E., Park, J., Combs, M., Blum, M.J., Bryant, J.E., Caccone, A., Costa, F., Deinum, E.E., Esther, A., Himsworth, C. J., Keightley, P.D., Ko, A., Åke Lundkvist, McElhinney, L. M., Morand, S., Robins, J., Russell, J., Strand, T.M., Suarez, O, Yon, L., \& J. Munshi-South (2016). Global population divergence and admixture of the Norway rat (Rattus norvegicus). Proceedings of the Royal Society (B) 283(1841):1762.

Recht, M. A. (1982). The fine structure of the home range and activity pattern of free-ranging telemetered urban Norway rats, Rattus norvegicus (Berkenhout). Bull. Soc. Vector Ecol. 7: 29- 36.

Recht, M. A., Geck, R., and Challet, G. L. (1983). The fine-structure of the home range and activity- phasing of unrestricted telemetered urban roof rats, Rattus rattus in Orange County, California. Bull. Soc. Vector Ecol. 8: 51-64.

Recht, M. A. (1988). The biology of domestic rats: telemetry yields insights for pest control. In Proceedings of the Vertebrate Pest Conference (Vol. 13, No. 13).

Richardson, D. M., Pyšek, P., Rejmánek, M., Barbour, M. G., Panetta, F. D., \& C.J. West (2000). Naturalization and invasion of alien plants: concepts and definitions. Diversity and distributions 6(2):93-107.

Richardson, J.L., Burak, M., Hernandez, C., Shirvell, J.M., Mariani, C., Carvalho-Pereira, T.S., Pertile, A.C., Panti-May, J.A., Pedra, G.G., Serrano, S., Taylor, J.A., Carvalho, M.H., Rodrigues, G., Costa, F., Childs, J.E., Ko, A.I., \& A. Caccone (2017). Using fine-scale spatial genetics of Norway rats to improve control efforts and reduce leptospirosis risk in urban slum environments. Evolutionary Applications 10:323-337.

Richerson, P., Boyd, R., \& R. Bettinger (2001). Was Agriculture Impossible during the Pleistocene but Mandatory during the Holocene? A Climate Change Hypothesis. American Antiquity 66(3):387- 411.

Robertson, B.C., \& N.J. Gemmell (2004). Defining eradication units to control invasive pests. 
Journal of Applied Ecology 41: 1042-1048.

Robins, J., Hingston, M., Matisoo-Smith, L., \& H. Ross (2007). Identifying Rattus species using mitochondrial DNA. Molecular Ecology Notes 7:717-729.

Robins, J., Mclenachan, T., Phillips, M., Craig, L., Ross, H., \& L. Matisoo-Smith (2008). Dating of divergences within the Rattus genus phylogeny using whole mitochondrial genomes. Molecular Phylogenetics and Evolution. 49: 460-6.

Ross, J., Hearn, A.J., Johnson, P.J. and D.W. Macdonald (2013). Activity of Sunda clouded leopards and their prey. Journal of Zoology 290:96-106.

Rowe, K. C., Reno, M. L., Richmond, D. M., Adkins, R. M.,\& S.J. Steppan (2008). Pliocene colonization and adaptive radiations in Australia and New Guinea (Sahul): Multilocus systematics of the old endemic rodents (Muroidea: Murinae), Molecular Phylogenetics and Evolution 47(1): 84-10

Rowe, K. C., Aplin, K. P., Baverstock, P. R. \& C. Moritz (2011). Recent and rapid speciation with limited morphological disparity in the genus Rattus. Systematic Biology 60: $188-203$.

Russell J. C. (2007). Invasion ecology and genetics of Norway rats on New Zealand islands. Ph.D. Thesis, University of Auckland.

Russell, J.C., Towns, D. \& M. Clout (2008). Review of rat invasion biology: Implications for island biosecurity. Science for Conservation 286:1-53.

Russell, J.C., Sataruddin, N. \& A. Heard (2014). Over-invasion by functionally equivalent invasive species. Ecology 95: 2268-76.

Russell, J.C., \& Holmes, N.D. (2015). Tropical island conservation: Rat eradication for species recovery, Biological Conservation 185: 1-7.

Russell, J.C., John G. Innes, Philip H. Brown, \& A.E. Byrom (2015). Predator-Free New Zealand: Conservation Country. BioScience 65(5):520-525.

Russell, J., \& K. Broome (2016). Fifty years of rodent eradications in New Zealand: Another decade of advances. New Zealand Journal of Ecology 40: 197-204.

Russell, J.C., Robins, J.H., \& R.M. Fewster (2019). Phylogeography of Invasive Rats in New Zealand. Frontiers in Ecology and Evolution 7:4 8.

Rutherford, M., Harper, G. A., \& Moller, H. (2009). Denning behaviour of ship rats (Rattus 
rattus) on Taukihepa, a seabird breeding island. New Zealand Journal of Zoology, 36(3), 343-353.

Schmid, B.V., Büntgen, U., Easterday, W. R., Ginzler, C., Walløe, L., Bramanti, B., \& N.C. Stenseth (2015). Climate-driven introduction of the Black Death and successive plague reintroductions into Europe. Proceedings of the National Academy of Sciences 112(10), 3020-3025.

Seaman, D. E., Millspaugh, J. J., Kernohan, B. J., Brundige, G. C., Raedeke, K. J., \& Gitzen, R. A. (1999). Effects of sample size on kernel home range estimates. The journal of wildlife management, 739-747.

Seber, G.A.F. (1965). A note on the multiple recapture census. Biometrika 52: 249-259 Seber, G. A. F. (1982). The estimation of animal abundance and related parameters (Vol. 8). Caldwell, New Jersey: Blackburn press.

Seton, E. T. (1909). Life-histories of Northern Animals: Flesh-eaters (Vol. 2). Scribner. Shapiro, L. (2005). Diet overlap and potential competition between North Island brown kiwi chicks (Apteryx mantelli) and ship rats (Rattus rattus) for limited resources on Ponui Island, New Zealand. MSc Thesis. Palmerston North: Massey University

Shea, K., \& P. Chesson (2002). Community ecology theory as a framework for biological invasions. Trends in Ecology and Evolution 17(4):170-176.

Simberloff, D. (2009). The role of propagule pressure in biological invasions. Annual Reviews in Ecology, Evolution, and Systematics 40: 81-102.

Simberloff, D. (2011). How common are invasion-induced ecosystem impacts? Biological Invasions 13: 1255-1268.

Simberloff, D. (2019). New Zealand as a leader in conservation practice and invasion management. Journal of the Royal Society of New Zealand 49(3): 259280.

Sinclair, A. \& C. Krebs (2002). Complex numerical response to top-down and bottom-up processes in vertebrate populations. Philosophical transactions of the Royal Society of London. Series B, 357(12)21:-31.

Singleton, G. R., Leirs, H., Hinds, L. A., \& Z. Zhang (1999). Ecologically-based management of rodent pests-re-evaluating our approach to an old 
problem. Ecologically-based Management of Rodent Pests. Australian Centre for International Agricultural Research (ACIAR), Canberra, 1729.

Singleton, G. R. (2000). Ecologically-based rodent management integrating new developments in biotechnology. In Proceedings of the Vertebrate Pest Conference 19.

Singleton, G.R., Brown, P.R., Jacob, J., \& K.P. Aplin (2007). Unwanted and unintended effects of culling: A case for ecologically-based rodent management. Integrative Zoology 2: 247-259.

Singleton, G. R. (2010). Rodent outbreaks: ecology and impacts. Int. Rice Res. Inst. Spurr, E.B., Morriss, G.A., Turner, J., O'Connor, C.E., \& P. Fisher (2007). Bait station preferences of ship rats. DOC Research \& Development Series 271. Department of Conservation, Wellington. $21 \mathrm{p}$

Stansfield, K.H., \& C.L. Kirstein (2006). Effects of novelty on behavior in the adolescent and adult rat. Developmental Psychobiology 48(1): 10-15.

Stenseth, N.C., Leirs, H., Skonhoft, A., Davis, S.A., Pech, R.P., Andreassen, H.P., Singleton, G.R., Lima, M., Machang'u, R.S., Makundi, R.H., Zhang, Z., Brown, P.R., Shi, D. and Wan, X. (2003), Mice, rats, and people: the bio-economics of agricultural rodent pests. Frontiers in Ecology and the Environment, 1: 367-375.

Sweetapple, P., \& Nugent, G. (2011). Chew-track-cards: a multiple-species small mammal detection device. New Zealand Journal of Ecology, 153-162.

Sweetapple, P.J., \& G. Nugent (2007). Ship rat demography and diet following possum control in a mixed podocarp-hardwood forest. New Zealand Journal of Ecology 31:186-201.

Swihart, R. K., \& Slade, N. A. (1985). Influence of sampling interval on estimates of homerange size. The Journal of Wildlife Management, 1019-1025.

Swihart, R. K., \& Slade, N. A. (1997). On testing for independence of animal movements. Journal of Agricultural, Biological, and Environmental Statistics, 48-63.

Taylor, K. D. (1978). Range of movement and activity of common rats (Rattus norvegicus) on agricultural land. Journal of Applied Ecology, 663-677.

Taylor, K., Hammond, L., \& R. Quy (1974). The Reactions of Common Rats to Four Types of 
Live-Capture Trap. Journal of Applied Ecology 11(2):453-459.

Taylor, R. H. \& B.W. Thomas (1989). Eradication of Norway rats (Rattus norvegicus) from Hawea Island, Fiordland, using brodifacoum. New Zealand Journal of Ecology 12: 23-32.

Taylor, R. H., \& B.W. Thomas (1993). Rats eradicated from rugged Breaksea island (170 ha), Fiordland, New Zealand. Biological conservation 65(3):191-198.

Terrell, G. R., \& Scott, D. W. (1992). Variable kernel density estimation. The Annals of Statistics, 1236-1265.

Tobin, M. E., Koehler, A. E., \& Sugihara, R. T. (1994). Seasonal patterns of fecundity and diet of roof rats in a Hawaiian macadamia orchard. Wildlife Research, 21(5), 519-525.

Tobin, P. C. (2018). Managing invasive species. F1000Research, 7. F1000 Faculty Rev-1686 Towns, D. R., \& K.G. Broome (2003). From small Maria to massive Campbell: Forty years of rat eradications from New Zealand islands. New Zealand Journal of Zoology 30(4): 377-398.

Traweger, D., Travnitzky, R., Moser, C., Walzer, C., \& G. Bernatzky (2006). Habitat preferences and distribution of the brown rat (Rattus norvegicus Berk.) in the city of Salzburg (Austria): implications for an urban rat management. Journal of Pest Science 79(3):113-125.

Vadell, M., Gómez Villafañe, I. \& C. Regino (2014). Are life-history strategies of Norway rats (Rattus norvegicus) and house mice (Mus musculus) dependent on environmental characteristics? Wildlife Research 41(2):172-184.

Villafañe, I. E. G., \& Busch, M. (2007). Spatial and temporal patterns of brown rat (Rattus norvegicus) abundance variation in poultry farms. Mammalian Biology, 72(6), 364-371.

Villafañe, I.E.G., Cavia, R., Vadell, M.V., Suárez, O.V., M. Busch (2013). Differences in population parameters of Rattus norvegicus in urban and rural habitats of central Argentina. Mammalia 77: 187-193.

Watts, C.H.S., \& P.R. Baverstock (1995). Evolution in the murinae (Rodentia) assessed by microcomplement fixation of albumin. Australian Journal of Zoology 43: 105-11. 
Whisson, D. A., Engeman, R. M., \& K. Collins (2005). Developing relative abundance techniques (RATs) for monitoring rodent populations. Wildlife Research $32(3): 239-244$.

Whisson, D. A., Quinn, J. H., \& K.C. Collins (2007). Home range and movements of roof rats (Rattus rattus) in an old-growth riparian forest, California. Journal of mammalogy 88(3): 589-594.

Williamson, M. and Fitter, A. (1996). The Varying Success of Invaders. Ecology, 77: 16611666.White, G.C. (2005). Correcting wildlife counts using detection probabilities. Wildlife Research 32, 211- 216.

Wilson, D.J., Lee, W.G., Webster, R.A., \& R.B. Allen (2003). Effects of possums and rats on seedling establishment in two forest sites in New Zealand. New Zealand Journal of Ecology 27(2): 147- 155.

Wotton, D.M. (2007). Consequences of dispersal failure: kereru and large seeds in New Zealand. Unpublished PhD thesis, University of Canterbury, Christchurch, New Zealand. 159.

Wotton, D.M. \& D. Kelly (2011). Frugivore loss limits recruitment of large-seeded trees. Proc. R. Soc. B. 278(1723):3345-3354.

Yabe, T. (1979). The Relation of Food Habits to the Ecological Distributions of the Norway Rat (Rattus norvegicus) and the Roof Rat (Rattus rattus). Japanese Journal of Ecology, 29(3), 235-244.

Zhao, Z.H., Reddy, G., Hui, C., \& B.L. Li (2016). Approaches and mechanisms for ecologically based pest management across multiple scales. Agriculture Ecosystems \& Environment 230: 199-209. 